\title{
UNITED STATES DEPARTMENT OF INTERIOR
}

GEOLOGICAL SURVEY

OCEAN BOTTOM SEISMOMETER (OBS) SOFTWARE:

MODIFICATION III

by

G. K. Miller

Open-file Report $86-269$

This report is preliminary and has not been reviewed for conformity with U.S. Geological Survey editorial standards. Use of tradenames is for purposes of identification only and does not constitute any endorsement by the USGS.

Woods Hole, Mass. 
OCEAN BOTTOM SEISMOMETER (OBS) SOFTWARE:

MODIFICATION III

This open-file publication is a listing of the modified software program for the U.S. Geological Survey's Ocean Bottom Seismometer (OBS). This listing supercedes the listing contained in Open-File Report 84 842: Ocean Bottom Instrument Package (OBIP) Sof tware: Modification II. Portions of the original program were written by John Godley (WHOI) and Ogden Hammond under contract to the U.S. Geologica 1 Survey. 
SOFTWARE LISTING: MOD III, OBS

Operating instructions ................... . 1 System equates . . . . . . . . . . . . . . . . . . 18

System macros... . . . . . . . . . . . . . . 30

Interrupt vectors. . . . . . . . . . . . . . . . 34

Main program . . . . . . . . . . . . . . . 40

Clock routines . . . . . . . . . . . . . . 52

Macro routines . . . . . . . . . . . . . . .62

Terminal routines. . . . . . . . . . . . . . 70

Tape routines. . . . . . . . . . . . . . . . . . .79

Parameter entry routines . . . . . . . . . . . . . 99 
PROGRAMMING INSTRUCTIONS FOR

THE USGS 4-CHANNEL OBS 
PROGRAM STARTUP

1. Connect the RS232 cable from a standard computer terminal to the RS232 connector on the OBS electronics rack (Figure 1). The termina1 should be setup for space parity, 7 data bits, 1200 baud, 1 stop bit, and no handshake lines.

2. Insta11 a blank data tape into the tape recorder of the OBS.

3. Apply Power by connecting the plug from the battery pack to the plug located on the power interface board (Figure 1 ).

4. Press the reset button on power interface board in the OBS (Figure 1) to start the OBS program.

5. The system will start by displaying the random access memory (RAM) test. This test will take approximately 30 seconds to perform, and any failures found will be displayed on the termina1. If you do encounter a RAM error, remove power and replace the CPU board. After the successful completion of the RAM test, the following message will be displayed at the lower left corner of your screen:

"ENTER CURRENT TIME PLUS 1 MINUTE"

"YR/Mth/Day/Hr/Min?"

6. The first information entered into the OBS is the current time, which is used by the OBS to set its calendar in sync with the satellite clock or other time reference. This time sync procedure is important as time is the only reference for data recorded by the OBS system. Connect the satellite clock to the CPU board of the OBS (Figure 1). Read the current time from the satellite clock and add at least one minute. It is critical that you enter the time correctly, as there is no way for the instrument to verify your accuracy. Time is entered into the OBS in the following format: Year ( $Y Y=$ last two digits of the year), any separator (non numerica 1), Month ( $M M=a$ number from 1 to 12 ), any separator, Day $(\mathrm{DD}=\mathrm{a}$ number from 1 to 31 ), any separator, Hour ( $\mathrm{HH}=\mathrm{a}$ number from 0 to 23), any separator, and Minute ( $\mathrm{mm}=$ a number from 0 to 59). The separator commonly used is a slash (/), although commas, periods, etc. can also be used. The time entry should appear as follows:

$\mathrm{YY} / \mathrm{MM} / \mathrm{DD} / \mathrm{HH} / \mathrm{mm}$ (RETURN)

The entry must be followed by a carriage return (RETURN) to enter the time into the OBS.

NOTE: This instrument is programmed on the basis of a 24-hour clock notation (i.e., each day extends from 00:00 to 23:59). This clock cannot correct for leap year; in leap years, the clock will be off by one day if the transition from FEB 29 to MAR 1 occurs during deployment.

7. The OBS will check the entry for any mistakes in format, and will ask again for the time entry if a error is found. If the entry made is in the correct format but is not the correct time, push the reset button on the power interface board to restart the program. If the time entry 
EARLY TERMINATION BUTTON

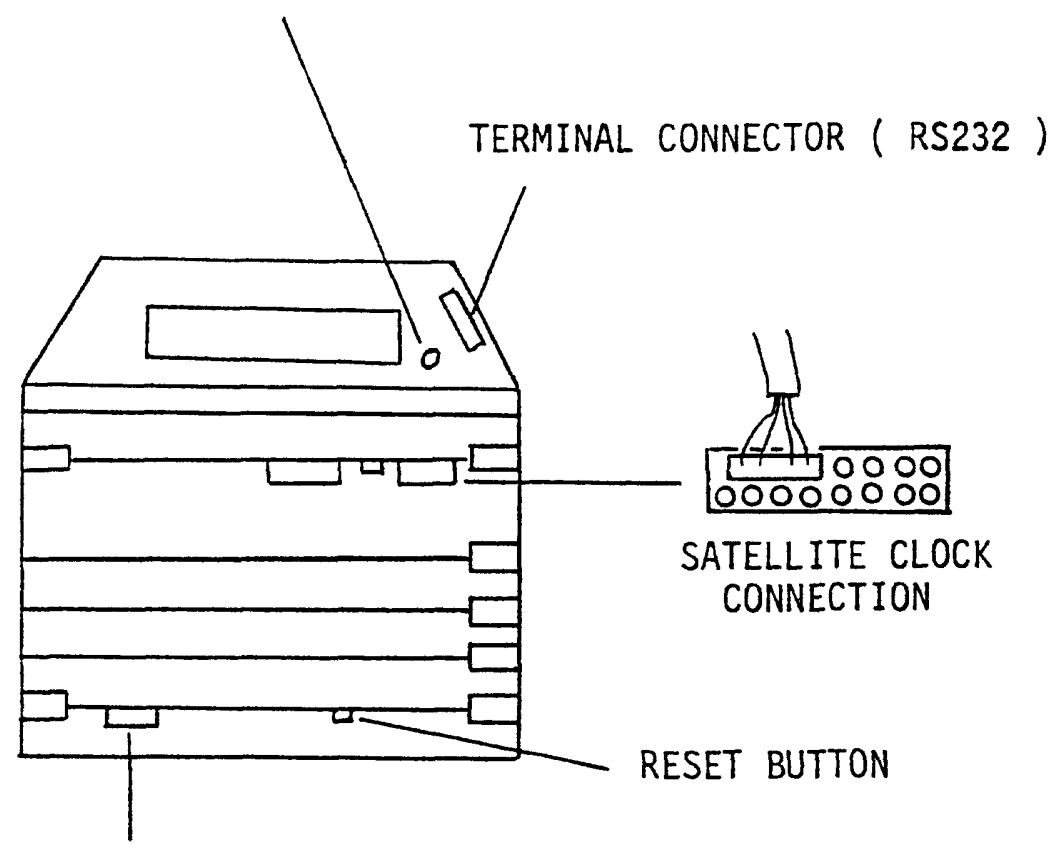

POWER CONNECTOR

Figure 1. OBS Connections 
is valid, the following message will appear on the terminal:

"HIT ANY KEY TO CONTINUE"

To continue the program, simply hit any key (using the RETURN key is suggested). The screen will then be cleared, and the following instruction will appear in the lower left corner of the screen:

"HIT RETURN WHEN LESS THAN ONE MINUTE TO GO"

Immediately below this will appear a message indicating whether or not the satellite clock is correctly connected. Just below this, the time you entered earlier will appear. Your response at this point depends on where or not the satellite clock is connected. The following descriptions provide the course of action for either condition:

A. The system displays the following message:

"SATELLITE CLOCK NOT CONNECTED"

This means that either the OBS has failed to detect that the satellite clock is connected, or that no satellite clock is available to sync the time.

If the satellite clock is connected, check to be sure the connector is correctly installed on the CPU board (Figure 1). To test whether or not the problem has been corrected, press RETURN. A successful repair will display nothing and the OBS will wait for the clock pulse to start the internal clock as described in clockconnected section (B). The following message will appear if the clock is still not properly connected:

\section{"HIT ANY KEY TO CONTINUE"}

At this point, recheck the connections and the satellite clock output to be sure of proper operation. Hitting any key, will cause the screen to clear and the satellite clock connection message to be redisplayed. If the message

\section{"SATELLITE CLOCK NOT CONNECTED"}

appears, you will almost certainly miss your synchronous start. To avoid that, push the reset button on the power board and start again. If the problem persists, change the CPU board and try again.

If you do not have access to a satellite clock or any other type of time sync, there is an alternate way to start the clock. If you type "Control B", the clock will start. Note that this method is accurate within one second and depends heavily on how accurate you are at the moment you strike the keys. 
B. Assuming a normal state of affairs, the following message will be displayed:

"HIT RETURN WHEN LESS THAN ONE MINUTE TO GO"

"SATELLITE CLOCK CONNECTED"

This indicates that the OBS has successfully detected the satellite clock connection and is ready to start the internal clock. Read the time from the satellite clock. When the clock's time is less than a minute behind the time you entered, press RETURN. The internal clock of the OBS will start when the minute pulse from the satellite clock is detected.

8. At this point, the OBS will automatically perform a tape test. The data tape, if already in the drive, will be rewound to the beginning of tape (BOT). If there is no tape in the OBS, The following message will appear on the screen and will be repeated until a tape is inserted into the drive:

\section{"INSERT TAPE CARTRIDGE"}

Once the auto-rewind sequence is completed, The OBS will check to see if the tape is write protected. If it is, the message

"CODE 1 WRITE PROTECTED"

"REMOVE TAPE CARTRIDGE"

will be repeated until the tape is removed. Once the tape has been removed, the insert tape message will be repeated until a new tape is installed. At this point, a test pattern is generated in memory, written to tape, and the message

\section{"TESTING TAPE"}

will appear. The OBS will then clear the RAM and read the test pattern from the tape for comparison to the original. If there is a failure, the messages

\section{"BAD TAPE OR DRIVE" \\ or \\ "TIME OUT ERROR"}

will appear. Install a new tape in the tape drive and restart the program by pushing the reset button. If this fails, check the power connections to be sure the proper voltages are getting to the drive. If this still doesn't work, the system needs major repair. If no errors occurred, the message

"TAPE DRIVE OK"

"HIT ANY KEY TO CONTINUE"

will appear in less than 15 seconds. Disconnect the satellite clock and hit any key to continue. 
9. The screen will clear and the prompt

\section{"DEPLOYMENT \# ?"}

will appear in the lower left corner of the screen. This is the first of the "header" prompts. The OBS provides no checking of these entries, since they have no effect on the operation of the system. The "header" prompts are provided as a convenience to record variables which identifies a particular data tape. Any entry of up to 80 characters (including hitting RETURN at the end) can be entered for each prompt. If no entry is desired, then hit RETURN. If you notice your mistake in an entry before pressing RETURN, the normal CPM editing keys (Back Space, Delete, or Control $\mathrm{X}$ ) can be used. The following prompts will appear after the previous one has been entered:

\begin{tabular}{|c|c|c|}
\hline \multicolumn{3}{|c|}{$\begin{array}{l}\text { "INSTRUMENT 非?" } \\
\text { "CHIEF SCIENTIST?" }\end{array}$} \\
\hline "CRUISE \# & & ?" \\
\hline "SPHERE 非 & & ?" \\
\hline "LATITUDE & & ?" \\
\hline "LONGITUDE & & ?" \\
\hline "FRONT END & GAIN & \\
\hline "CHANNEL 1 & ?" & \\
\hline "CHANNEL 2 & ?" & \\
\hline "CHANNEL 3 & ?" & \\
\hline "CHANNEL 4 & ?" & \\
\hline "FRONT END & DAMP & ING' \\
\hline "CHANNEL 1 & ?" & \\
\hline "CHANNEL 2 & ?" & \\
\hline "CHANNEL 3 & ?" & \\
\hline "CHANNEL 4 & ?" & \\
\hline
\end{tabular}

After the last prompt has been entered, the message

"IS THIS CORRECT ( $\mathrm{Y} / \mathrm{N})$ ?"

will appear. If there is an error in your entries, answering no (N) will restart the "header" prompts at the beginning. All prompts will have to be reentered. If there are no errors, answering yes ( $Y$ ) will store the entries, and the program will move on to the experiment parameters. No RETURN is necessary in answering this question, as the OBS will respond immediately to the first key entered.

Remember that your response, or lack of it,has no effect on the performance of the instrument.

10. At this point, the experimental parameters which affect the operation of the OBS are entered. There are two basic modes of operation for the OBS: the Timer (or window) mode and the Event mode. The OBS can operate in either mode but not simultaneous $1 y$.

The screen will clear and the following message will be displayed in the lower left corner: 


\section{"SERIES 非" \\ "非 OF CHANNELS (1-4)"}

"SERIES \#1" indicates that the parameters that are about to be entered are for the first series. There can be up to eight series per deployment, and each series represents a group of data recordings which are defined by the parameters entered for that series.

There are four parameters which are common to both modes of operation, so they are entered before determining which mode is desired. These four parameters are combined to determine the length of time for each data recording and include the number of channels, the base channe1, the record size, and the sample rate. If the length of the data recording is important, some calculations should be done prior to parameter entry. The OBS calculates the length of recording after these parameters are entered, but at that point, all of the rest of the parameters must be entered before there is an chance of reentering the first four entries again. The length of recording can be determined using the number of channels( 1 to 4$)$, record size ( 1,2 , or $48-\mathrm{K}$ by te blocks), and sample rate $(1,2,4$, or $8 \mathrm{milliseconds)}$ in the following equation:

[(record size)x( 8192 bytes/block)-256 by tes]x(sample rate)

(no. channels) $\times(2$ by tes/channe1) $\times(1000 \mathrm{msec} / \mathrm{sec}$.)

The 8192 bytes/block converts the record size value to the total number of bytes of data recorded. The 256 by tes is subtracted from this value to account for the loss of memory space due to the 256-byte trailer written on the data tape at the end of each data recording. The 2 bytes/channel converts the number of channels to the total number of bytes recorded for all channels. The $1000 \mathrm{msec} / \mathrm{sec}$. converts the sampling rate from milliseconds to seconds between data. The options for entering these parameters are as follows:

The first prompt is shown above and requests an entry for the number of channels that are recorded at each data recording. The OBS can record from as $f e w$ as one or as many as four channels simultaneously. The number $1,2,3$, or 4 is entered and followed by a carriage return (RETURN). The OBS will check to see if the entry was valid, and if not, reprompt for the number of channels. If the entry is valid, the following prompt will appear:

"BASE CHANNEL (1-4)"

The base channel is the first active channel used to record data, and the other active channels must lie above it. In other words, if four channels are active (i.e, the total number of channels is 4), then channe 11 must be the base channel. If three channels are active, then either channel 1 or channel 2 can be the base channel. A base channel of one would make channels 1,2 , and 3 active. A base channel of 2 would make channels 2,3 , and 4 active. The number $1,2,3$, or 4 is entered (followed by a RETURN). The OBS will check to see if this entry is valid when compared with the total number of channels entered earlier. If the 
entry is not valid, the OBS will go back and reprompt for both the total number of channels and the base channel. If the entry is valid then the following prompt will appear:

\section{"ENTER 1, 2, or 4 BLOCKS OF 8K" \\ "RECORD SIZE = "}

The series record size can be one of three lengths -- either 8-K (an entry of 1), 16-K (an entry of 2), or 32-K (an entry of 4) bytes long. This entry represents the total amount of memory used to store the data. The number 1,2 , or 4 is entered (followed by a RETURN). If the entry is not valid, the OBS will go back and reprompt for the record size. If the entry is valid then the following prompt will appear:

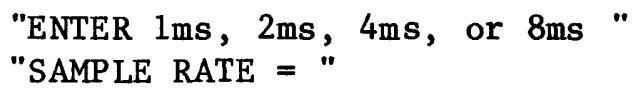

The sample rate determines how fast the data is acquired. The sample rate can be either $8 \mathrm{~ms}$ ( 128 hertz), $4 \mathrm{~ms}$ ( 256 hertz), $2 \mathrm{~ms}$ ( 512 hertz), or $1 \mathrm{~ms}$ (1024 hertz). Data are gathered simultaneous ly from a 11 active channels at the selected rate until the memory space, determined by the record size entry, is full. The number $1,2,4$, or 8 is entered (followed by a RETURN). The OBS will check this entry, and reprompt for the sample rate if the entry is not valid. If the entry is valid, the OBS will display a warning message to make sure that the proper resistor headers have been installed in the analog board of the system. The data are filtered at different frequencies for each sampling rate, and four resistor headers located on the analog board set these frequencies. The warning message will indicate which resistor headers should be installed. If the wrong headers are installed, the power must be removed, the analog board removed, the correct headers installed, and the program restarted from the beginning. The warning message is followed by the record time as calculated by the OBS and by a prompt requesting the mode of operation. As an example, 4 is entered for the number of channels, 1 is entered for the base channel, 4 is entered for the record size, and 8 is entered for the sampling rate. This would result in the following message:

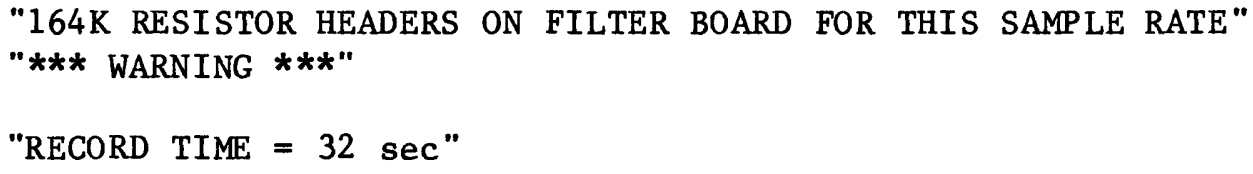

11. At this point, you must decide which mode of operation (i.e. timer or event) this series will use. If event mode is desired, skip this step and proceed to step 12 .

Timer mode in the OBS records data at fixed intervals during a predetermined "window" of time. This mode of operation is commonly used for refraction lines where a acoustic source is triggered at well defined intervals of time. The OBS, which at this point is on the ocean floor, will record data at times in sync with the time that the sound source is triggered. The series start and stop times usually correspond to the beginning and end of the refraction line. When the start time for the 
series is reached, the OBS will record data in fixed, minute intervals of time until the stop time or a maximum number of data recordings is reached. The specific parameters controlling when, how often, and how many times the OBS records data are described in the following paragraphs.

To program the OBS for timer mode, simply enter the letter " $\mathrm{T}$ " followed by a RETURN. The following message will then appear:

$$
\text { "\# OF RECORDS = " }
$$

The number of records is the total number of data recordings to be done during this series. The maximum number of records that the OBS software can handle is 9999, which is a larger value than the current data tape can record. The maximum number of records that can be recorded onto the data tape is determined by knowing the total number of series that will be programed for this deployment, the total number of records for each series, and the record size for each series. The data tape records up to $2000,8-\mathrm{K}$ byte blocks of data. The record size, entered earlier, equals the number of $8-\mathrm{K}$ by te blocks written to tape $\mathrm{for}$ each data recording, so the maximum number of records for one series is determined by dividing the record size into 2000. For example, the data tape can record up to 500 records (data recordings) with a record size of 4. If you desire more than one series per deployment, some juggling of numbers will be necessary to determine how many records per series can fit onto the data tape. A number from 1 to 9999 is entered (followed by a RETURN). The OBS will check this entry, and reprompt for the number of records if the entry is not valid. If the entry is valid, the following messages (using series 1 and 2 as examples) will appear:

"TIME NOW: 3/28/86 12:34"
"START TIME SERIES 1 (YR/MTH/DAY/HR/MIN)"

or

"TIME NOW: $3 / 28 / 86 \quad 12: 34 "$

"STOP TIME OF LAST SERIES 3/29/86 17:05"

"START TIME SERIES 2 (YR/MTH/DAY/HR/MIN)"

This prompt requests the start time for this series of records. The OBS uses this time to determine when to begin acquiring data at regular intervals, and the time usually corresponds the time of the first sound source trigger for a refraction line. The time entry is done in the same format as described in step 6 , and the same checking is done by the OBS. The system will also check to be sure that you have not entered a start time that is earlier than the current time, for obvious reasons, and reprompt if an error is made. The current time is displayed in the first line to help prevent this error. The display of current time is also be used to check the operation of the clock in the OBS. Check this time against your time reference. If they do not agree, push the reset button and start over. If this does not work, change the CPU board and begin again. After series 1 , the OBS will check the start time against the stop time of the last series to be sure that there is no overlap between 
the two series. The stop time for the last series is displayed to help prevent any errors. If the system finds that the start time is before the stop time of the last series the following message (using series 1 and 2 as examples) will appear:

\author{
"IMPROPER START TIME " \\ "TIME NOW: $3 / 28 / 86$ 12:34" \\ "STOP TIME OF LAST SERIES 3/29/86 17:05" \\ "START TIME SERIES 2 (YR/MTH/DAY/HR/MIN)"
}

This checking will repeat until a valid time is entered. If the start time is still in error, in spite of all the checking done by the OBS, you have another opportunity to correct the mistake at the end of the parameter entry for the series. This requires, however, that all of the parameters for the series be reentered. After successful entry of the start time, the following message (using series 1 as an example) will appear:

\title{
"STOP TIME SERIES 1 (YR/MTH/DAY/HR/MIN)"
}

When the stop time is reached, the OBS will stop collecting data and automatically setup for the next series (or terminate data collection completely if there is no other series). This stop time has precedence over any other parameter (i.e., number of records) and will unconditionally terminate the series. The time is entered in the same manner as described for the start time. The OBS will check to see that the stop time is later than the start time and reprompt, if an error is found, as follows:

\section{"IMPROPER STOP TIME" \\ "START TIME SERIES 1 (YR/MTH/DAY/HR/MIN)"}

Notice that the system is asking for the start time again rather than the stop time. You must reenter the start time and the stop time, as the OBS has no way of determining which time is in error. If the stop time is still in error, in spite of all the checking done by the OBS, you have another opportunity to correct the mistake at the end of the parameter entry for the series. This requires, however, that all of the parameters for the series be reentered. After successful entry of the stop time, the following message will appear:

$$
\begin{aligned}
& \text { "ENTER ( } 0 \text { - } 59 \text { sec.)" } \\
& \text { "WINDOW OFFSET =" }
\end{aligned}
$$

There are situations where it is desirable to start acquiring data at a time "offset" from the time of sound source trigger used in a refraction lines. In other words, to start data-acquisition several seconds after the sound source has been triggered. This is particularly useful if something (such as explosives) are detonated on the even minute and the time that soundwaves must travel is known. The offset will save wasting valuable data space if no useful data can be acquired for the several seconds after the detonation. The offset entry can be any number 
of seconds from 0 to 59 (followed by hitting RETURN), and represent the number of seconds after the even minute that the OBS will begin acquiring data. Remember that this offset will be applied to every record in this series. The OBS will check this entry, and reprompt for the offset if the entry is not valid. If the entry is valid, the following message will appear:

The period of records is the time from the beginning of one record to the beginning of the next record. This entry determines how of ten the data will be acquired between the start and stop times. The minimum period of records is calculated by the OBS. If the time required to fill the data buffer and write the data to tape exceeds one minute, the prompt will appear as follows:

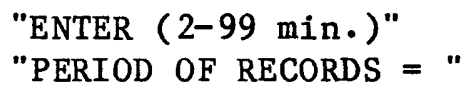

The period number is entered and followed with a RETURN. The OBS will check the entry to be sure you are within the minimum and maximum values and reprompt if in error. If the entry is valid, the following message will appear:

\section{"HIT ANY KEY TO CONTINUE"}

You have reached the end of the parameter entry for this series. Hitting any key (RETURN is suggested), will cause the screen to clear and all of the entered parameters to be displayed. At the end of this list, you will be asked if these entries are correct. As an example, you entered, for series 1 , a value of 4 for the number of channe1s, 1 for the base channel, 4 for the record size, 8 for the sampling rate, " $T$ " for the mode of operation, 100 for the number of records, 86/3/28/17/05 for the start time, $86 / 3 / 28 / 21 / 00$ for the stop time, 4 for the offset, and 2 for the period. The following information will be displayed after the last parameter has been entered:

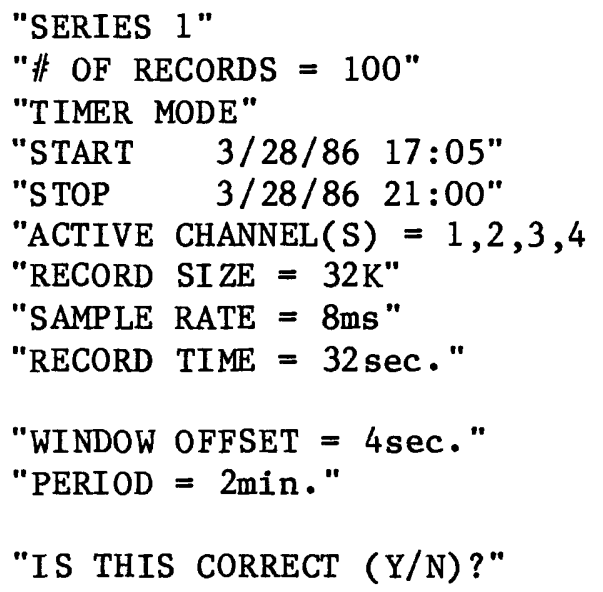


If you answer $N$ (no) to this question, you must reenter all of the parameters for this series. If you answer $Y$ (yes) to this question go to step 13. No RETURN is necessary in answering this question, as the OBS will respond immediately to the first key entered.

12. Event mode in the OBS records data triggered by an external seismic event. This mode is used when the acoustic source does not occur at defined intervals of time, as is the case in earthquake detection studies. The OBS has an event-detector as part of its circuitry, which monitors the data continuously and initiates data recording when a seismic event (i.e., earthquake) has been detected. The system continuously puts data into a circular buffer which has been defined by the parameters entered in step 10. When an event occurrs, the OBS will continue to record this data until the buffer is filled and then write the data to the data tape. The time of the event is recorded as the time the data buffer is full. The time is recorded at the end of data collection to prevent the loss of data that would occur if the system read the clock at the moment of the event (the OBS cannot do two things at once). The exact time of the event can only be calculated when the data is processed. Note that because of the filter design (and the very low frequencies that are of interest to geologists), there exists a significant phase $1 \mathrm{ag}$ in the data. Arrival times computed from data gathered by this mode or the Timer mode could easily be off by $50 \%$ of the period of the waveform of interest. The following parameters are entered to setup the event-detector, and establish when and how much data is recorded. To enter event mode for this series type an " $E$ " followed by a RETURN, and the following prompt will appear:

"ENTER $87(.5), 75,50$, or $25 \% "$

"POST-EVENT SAMPLE (\%) "

The post-event sample represents the percentage of the data buffer that is recorded after an event is detected and determines when the OBS will stop collecting data for this event. The " $87(.5)$ " option is entered by typing 87 even though the actual value is 87.5 . This was done to simplify the software in the OBS required to check the entry for errors. The number $87,75,50$, or 25 is entered (followed by a RETURN). The OBS will check the entry and reprompt if an error is found. If the entry is valid, the following message will appear:

$$
\begin{aligned}
& \text { "ENTER .05, .10, .25, or .50 SEC." } \\
& \text { "STA TIME CONSTANT }="
\end{aligned}
$$

The short-term averager (STA) time constant represents the time base, used in the event-detector, for averaging the short-term data signals. The smaller the time constant, the faster the event-detector will react. The STA entry must be exactly as shown in the prompt, or the OBS will not accept it. The entry must be .05, .10, .25, or .50 (followed by a RETURN). The OBS will check the entry and reprompt if an error is found. If the entry is valid, the following message will appear:

\footnotetext{
"ENTER 6, 12, 18, or $24 \mathrm{db} "$ 
The threshold value for the hardware event-detector represents a fixed signal level above the long-term average level that is used to determine if an event has occurred. Although the entry is an exact number, the actual value is highly dependent on the hardware and the stability of the background noise. This entry does give some measure of control in determining how far above the background noise the event will occur. The number $6,12,18$, or 24 is entered (followed by a RETURN). The OBS will check the entry and reprompt if an error is found. If the entry is valid, the following message will appear:

$$
\text { " \# OF RECORDS = (Enter } 0 \text { for maximum number)" }
$$

In most event-detection deployments, the number of records (data recordings) will be unimportant. Event detection will occur until the data tape is filled, or the OBS is retrieved. If this is the case, simply enter the number 0 followed by a RETURN. If, however, you desire to end this series after a certain number of events, enter a number from 1 to 9999 followed by a RETURN. The number of records, in this case, is the total number of events to be done during this series. The maximum number of records that the OBS software can handle is 9999 , which is a larger value than the current data tape can record. The maximum number of records that can be recorded onto the data tape is determined by knowing the total number of series that will be programed for this deployment, the total number of records for each series, and the record size for each series. The data tape records up to $2000,8-\mathrm{K}$ by te blocks of data. The record size, entered earlier, equals the number of $8-\mathrm{K}$ by te blocks written to tape for each data recording, so the maximum number of records for one series is determined by dividing the record size into 2000. For example, the data tape can record up to 500 records (data recordings) with a record size of 4. If you desire more than one series per deployment, some juggling of numbers will be necessary to determine how many records per series can fit onto the data tape. The OBS will check this entry, and reprompt for the number of records if the entry is not valid. If the entry is valid, the following messages (using series 1 and 2 as examples) will appear:

"TIME NOW: $3 / 28 / 86 \quad 12: 34 "$

"START TIME SERIES 1 (YR/MTH/DAY/HR/MIN)"

or

"TIME NOW: $3 / 28 / 86$ 12:34"

"STOP TIME OF LAST SERIES 3/29/86 17:05"

"START TIME SERIES 2 (YR/MTH/DAY/HR/MIN)"

This prompt requests the start time for this series of records. The OBS uses this time to determine when to begin acquiring data in the event mode. Allow 8 hours after the start time for the event-detector to stabilize before valid events will be recorded. This is due to the slow response of the long-term averager, in the event-detector, to background noise. The time entry is done in the same format as described in step 6 , and the same checking is done by the OBS. The system will also check 
to be sure that you have not entered a start time that is earlier than the current time, for obvious reasons, and reprompt if an error is made. The current time is displayed in the first line to help prevent this error. The display of current time is also be used to check the operation of the clock in the OBS. Check this time against your time reference. If they do not agree, push the reset button and start over. If this does not work, change the CPU board and begin again. After series 1 , the OBS will check the start time against the stop time of the last series to be sure that there is no overlap between the two series. The stop time for the last series is displayed to help prevent any errors. If the system finds that the start time is before the stop time of the last series the following message (using series 1 and 2 as examples) will appear:

\author{
"IMPROPER START TIME " \\ "TIME NOW: $3 / 28 / 86$ 12:34" \\ "STOP TIME OF LAST SERIES 3/29/86 17:05" \\ "START TIME SERIES 2 (YR/MTH/DAY/HR/MIN)"
}

This checking will repeat until a valid time is entered. If the start time is still in error, in spite of all the checking done by the OBS, you have another opportunity to correct the mistake at the end of the parameter entry for the series. This requires, however, that all of the parameters for the series be reentered. After successful entry of the start time, the following message (using series 1 as an example) will appear:

\title{
"STOP TIME SERIES 1 (YR/MTH/DAY/HR/MIN)"
}

When the stop time is reached, the OBS will stop collecting data and automatically setup for the next series (or terminate data collection completely if there is no other series). This stop time has precedence over any other parameter (i.e., number of records) and will unconditionally terminate the series. In event mode, however, the stop time is not checked until the end of an event, so one event must occur after the stop time before this series will end. The time is entered in the same manner as described for the start time. The OBS will check to see that the stop time is later than the start time and reprompt, if an error is found, as follows:

"IMPROPER STOP TIME"

"START TIME SERIES 1 (YR/MTH/DAY/HR/MIN)"

Notice that the system is asking for the start time again rather than the stop time. You must reenter the start time and the stop time, as the OBS has no way of determining which time is in error. If the stop time is still in error, in spite of all the checking done by the OBS, you have another opportunity to correct the mistake at the end of the parameter 
entry for the series. This requires, however, that all of the parameters for the series be reentered. After successful entry of the stop time, the following message will appear:

\section{"HIT ANY KEY TO CONTINUE"}

You have reached the end of the parameter entry for this series. Hitting any key (RETURN is suggested), will cause the screen to clear and a11 of the entered parameters to be displayed. At the end of this list, you will be asked if these entries are correct. As an example, you entered, for series 1 , a value of 4 for the number of channels, 1 for the base channe1, 4 for the record size, 8 for the sampling rate, "E" for the mode of operation, 75 for the post-event samples, .10 for the STA time constant, 12 for the threshold, 0 (maximum) for the number of records, $86 / 3 / 28 / 12 / 00$ for the start time, and $86 / 4 / 10 / 8 / 00$ for the stop time. The following information will be displayed after the last parameter has been entered:

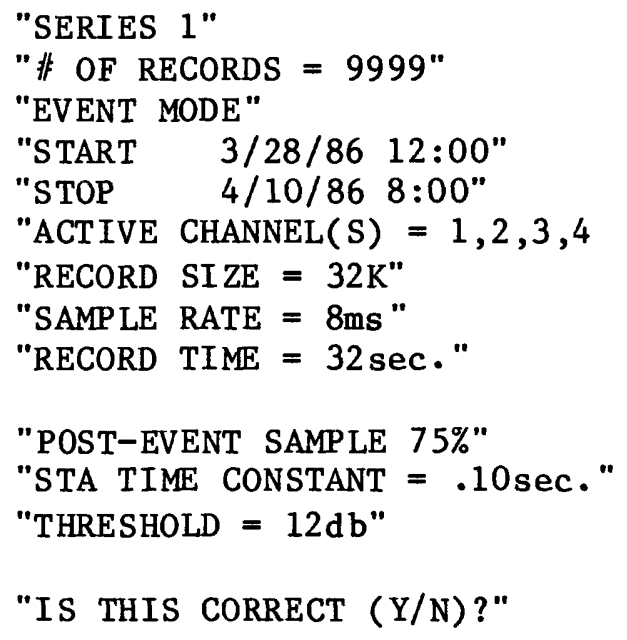

If you answer $N$ (no) to this question, you must reenter all of the parameters for this series. If you answer $Y$ (yes) to this question go to step 13. No RETURN is necessary in answering this question, as the OBS will respond immediately to the first key entered.

13. If you answer $Y$ (yes) to this question, the following question will appear:

"DO YOU WISH ANOTHER SERIES?"

If you answer $Y$ (yes) to this question, the parameter entry routines for the next series will begin. No RETURN is necessary in answering this question, as the OBS will respond immediately to the first key entered. If you answer $N$ (no) to this question, you will be asked the following question:

"IS THIS A TEST? (N/Y)"

Answering $Y$ (yes) to this question is strictly for testing purposes and should not be used in field work. In testing mode, the header is written to tape immediately, and series information is displayed on the terminal. 
The terminal is usually left connected to monitor progress of each series. This mode has none of the checking procedures used to ensure that the system is working before deployment.

If you answer $N$ (no) to this question, you will be instructed to disconnect the terminal. After the terminal is unplugged, you should be able to hear the tape drive turn on to write the header information to tape. If this happens, you have successfully programmed the OBS and are ready for deployment.

If this does not happen, something went wrong. It is strongly suggested that you start over. 
1. Push the Early Termination button (Figure 1) to end data gathering.

2. Connect the terminal as described in step 2 of the program startup section and hit RETURN. The OBS should write two end of file marks on the data tape and display the time once a second on the terminal. If this does not happen, try entering a Control U. This is a keyboard interrupt that goes directly to the clock read routines. If the time still does not appear on the terminal, press the reset button on the Power Interface Board (Figure 1). After the RAM test is completed and when the OBS asks you to enter the time, enter a Control U instead. If the clock is still working, you will see the current time displayed on the terminal. The year, in this case, will be zeros.

3. Connect the satellite clock (Figure 1) and check the time sync.

4. Remove the data tape and set the write protect.

5. Disconnect the power. 


\section{PROGRAM LISTING}

FOR THE USGS 4 CHANNEL OBS 
SYSTEM EQUATES

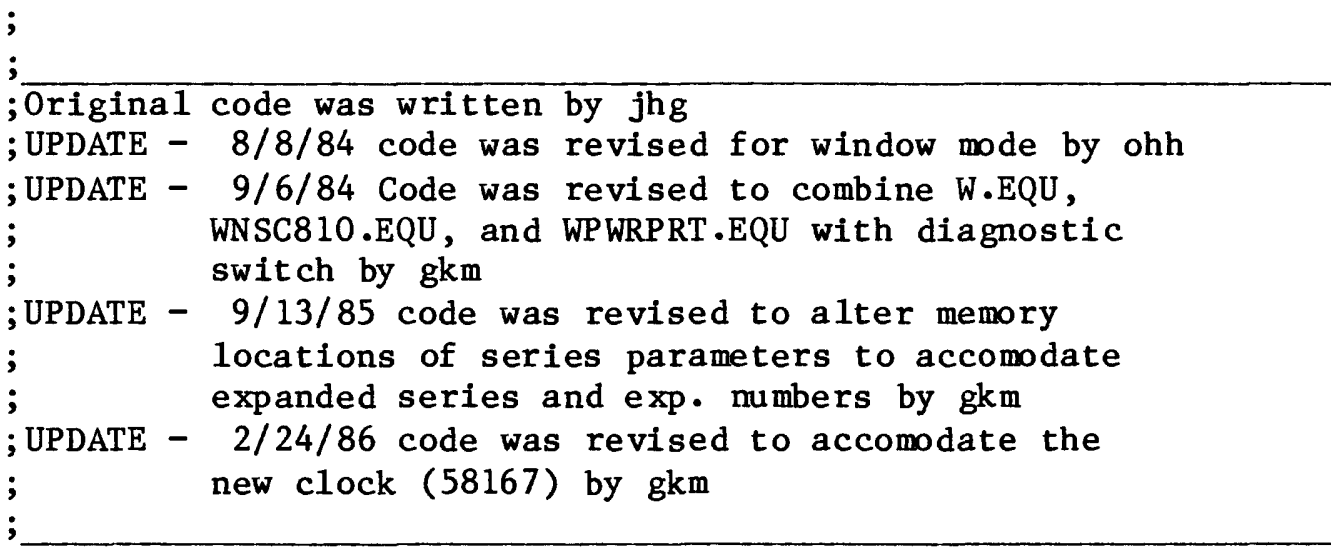




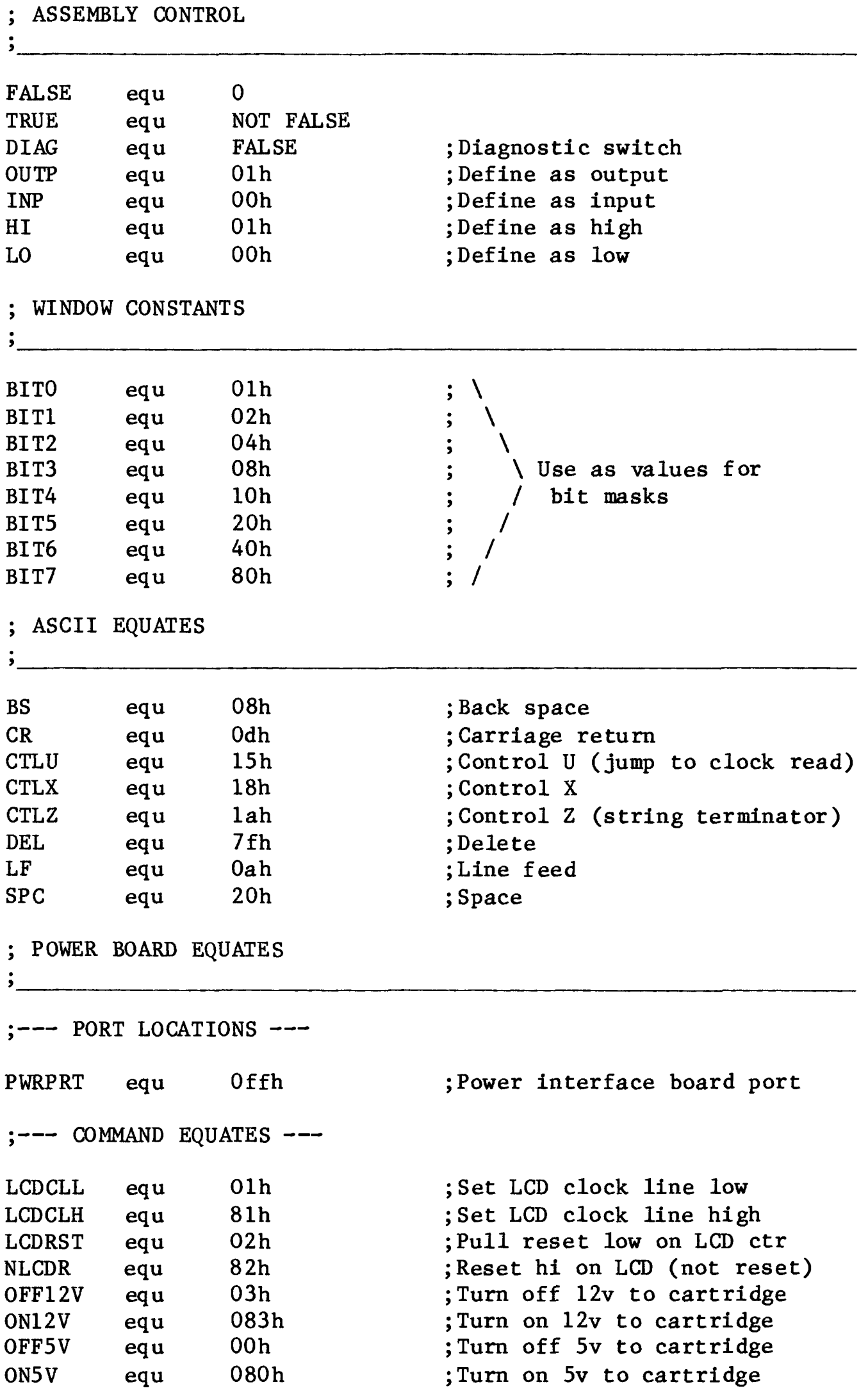


; ANALOG BOARD EQUATES

;

;-- PORT LOCATIONS ---

ANAPRT equ $\quad 010 \mathrm{~h} \quad$; Analog board STA \& threshold

AVGPRT equ ANAPRT+01h ;Analog board average enable

; A-D BOARD EQUATES

;--- PORT LOCATIONS ---

ADPORT equ $\quad 018 \mathrm{~h} \quad$; A-D board base address

; CONTROL BOARD EQUATES

;

; $\mathrm{CPU}$

; -

;--- PORT LOCATIONS ---

INTPRT equ Obbh ; NSC-800 interupt mask port

;--- COMMAND EQUATES ---

AD_INT_EN equ $08 \mathrm{~h} \quad$; RSTA from A-D enable

$\mathrm{Tl}^{-}$INTEN equ $04 \mathrm{~h}$

RST̄C EN $\bar{N}$ equ $02 \mathrm{~h}$

; Timer 1 interrupt enable

EARL $\bar{Y}$ TERM

equ $\quad 01 \mathrm{~h}$

; RSTC enable

; Early terminator enable 


\begin{tabular}{|c|c|c|c|}
\hline NSCIOT & equ & $3080 \mathrm{~h}$ & ; NSC810 I/0-timer base \\
\hline PBDATA & eq $\mathrm{u}$ & NSCIOT+01h & ; NSC810 port B- data reg. \\
\hline PCDATA & equ & NSCIOT+02h & ; Port C data reg \\
\hline PBDDIR & equ & NSCIOT+05h & ; Port $\mathrm{B}$ data direction reg \\
\hline PCDDIR & eq $\mathbf{u}$ & NSCIOT+06h & ; Port $\mathrm{C}$ data direction reg \\
\hline NSCMDR & equ & NSCIOT+07h & ; Mode definition reg \\
\hline PBCLRB & equ & NSCIOT+09h & ; NSC810 port B- bit clear reg. \\
\hline PCCLRB & equ & NSCIOT+Oah & ; Port C bit clear reg \\
\hline PBSET B & equ & NSCIOT+Odh & ; NSC810 prot B- bit set reg. \\
\hline PCSETB & equ & NSCIOT+0eh & ;Port C bit set reg \\
\hline TMR0 & equ & NSCIOT+010h & ;Timer 0 reg \\
\hline TMROLS & equ & NSCIOT+010h & ; Timer $01 \mathrm{sb}$ \\
\hline TMROMS & equ & NSCIOT+011h & ; Timer $0 \mathrm{msb}$ \\
\hline TMR1 & equ & NSCIOT+012h & ; Timer 1 reg \\
\hline TMR1LS & equ & NSCIOT+012h & ; Timer $11 \mathrm{sb}$ \\
\hline TMR1 MS & equ & NSCIOT+013h & ; Timer $1 \mathrm{msb}$ \\
\hline STOPTO & equ & NSCIOT+014h & ; Timer 0 stop \\
\hline STRT0 & equ & NSCIOT+015h & ; Timer 0 start \\
\hline STOPT1 & equ & NSCI0T+016h & ; Timer 1 stop \\
\hline STRT1 & equ & NSCIOT+017h & ; Timer 1 start \\
\hline CMDT0 & equ & NSCIOT+018h & ; Timer 0 command reg \\
\hline CMDT1 & equ & NSCIOT+019h & ; Timer 1 command reg \\
\hline ; & & $-\mathrm{AI}$ & SSES RELATIVE TO NSCIOT(IN IX REG.) \\
\hline PADADD & equ & $\mathrm{Oh}$ & ;Port A data reg \\
\hline PBDADD & equ & $01 \mathrm{~h}$ & ; Port B data reg \\
\hline PCDADD & equ & $02 \mathrm{~h}$ & ; Port C data reg \\
\hline PADIR & equ & $04 \mathrm{~h}$ & ; Port A data direction reg \\
\hline PBDIR & equ & $05 \mathrm{~h}$ & ; Port $B$ data direction reg \\
\hline PCDIR & equ & $06 \mathrm{~h}$ & ; Port $C$ data direction reg \\
\hline CMDRAD & equ & $07 \mathrm{~h}$ & ; Mode definition reg \\
\hline PACADD & equ & $08 \mathrm{~h}$ & ;Port A bit clear reg \\
\hline PBCADD & equ & $09 \mathrm{~h}$ & ; Port B bit clear reg \\
\hline PCCADD & equ & Oah & ; Port C bit clear reg \\
\hline PASADD & eq $\mathbf{u}$ & $0 \mathrm{ch}$ & ; Port A bit set reg \\
\hline PBSADD & equ & $0 \mathrm{dh}$ & ; Port B bit set reg \\
\hline PCSADD & equ & Oeh & ; Port C bit set reg \\
\hline TOLSB & equ & $10 \mathrm{~h}$ & ; Timer $01 \mathrm{sb}$ \\
\hline TOMS B & equ & $11 \mathrm{~h}$ & ; Timer $0 \mathrm{msb}$ \\
\hline TILSB & equ & $12 \mathrm{~h}$ & ; Timer $11 \mathrm{sb}$ \\
\hline $\mathrm{T} 1 \mathrm{MSB}$ & equ & $13 \mathrm{~h}$ & ; Timer $1 \mathrm{msb}$ \\
\hline TOSTOP & equ & $14 \mathrm{~h}$ & ; Timer 0 stop \\
\hline TOSTRT & equ & $15 \mathrm{~h}$ & ; Timer 0 start \\
\hline T1 STOP & equ & $16 \mathrm{~h}$ & ; Timer 1 stop \\
\hline T1 STRT & equ & $17 \mathrm{~h}$ & ; Timer 1 start \\
\hline T0 CMD & equ & $18 \mathrm{~h}$ & ; Timer 0 command reg \\
\hline T1CMD & equ & $19 \mathrm{~h}$ & ; Timer 1 command reg \\
\hline
\end{tabular}




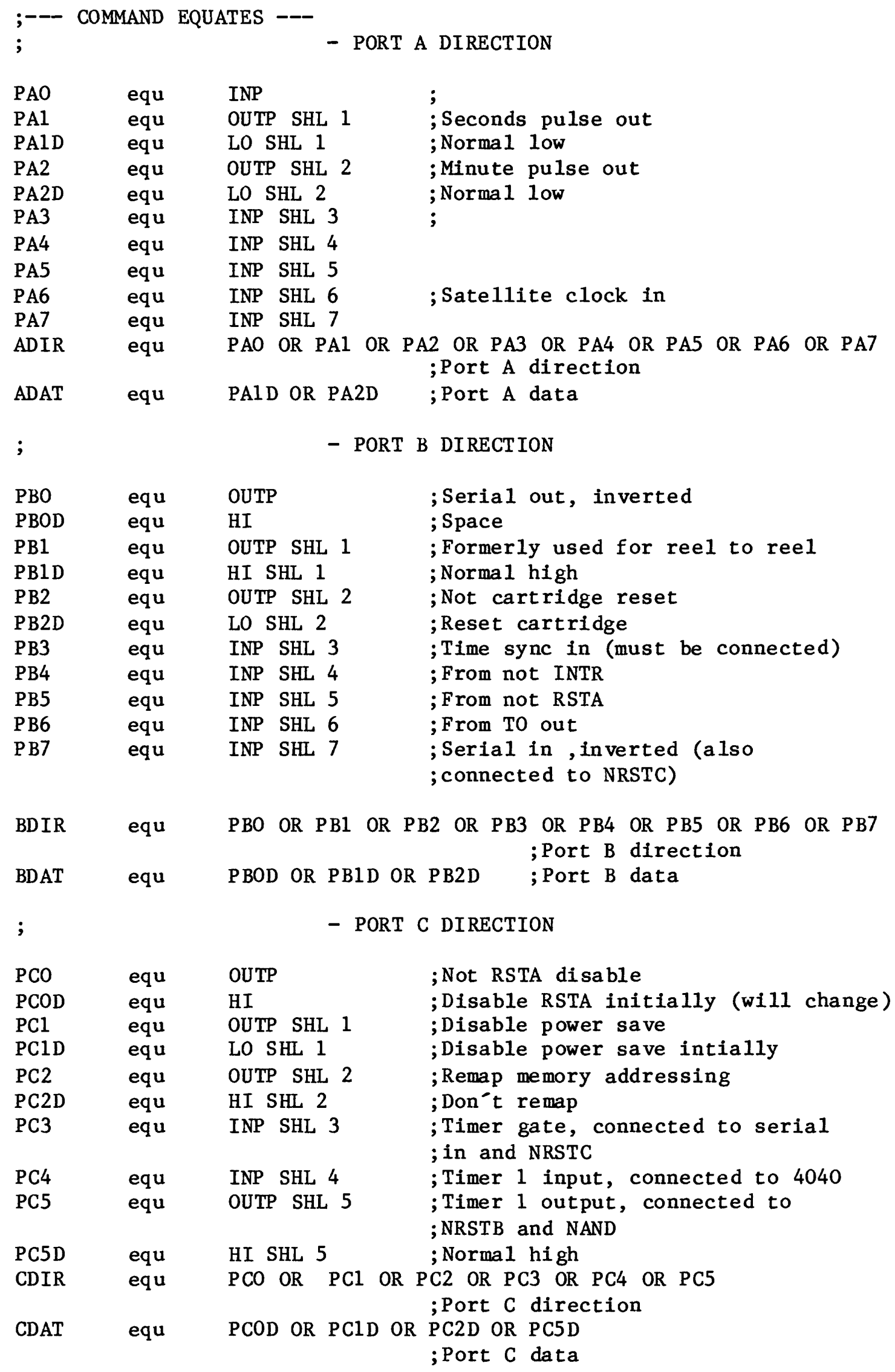




\begin{tabular}{|c|c|c|c|c|}
\hline MODEO & equ & $\mathrm{OOh}$ & & ; Port A basic IO \\
\hline MODE1 & equ & $01 \mathrm{~h}$ & & ; Strobed input mode (affects $A$ and $C$ ) \\
\hline MODE2 & equ & $03 \mathrm{~h}$ & & ; Strobed output mode \\
\hline MODE3 & equ & $07 \mathrm{~h}$ & & ; Tristate strobed output \\
\hline ; & & & - TIMER & MODES \\
\hline TMODEO & equ & $\mathrm{OOh}$ & & ; Kil1 timer \\
\hline TMODE1 & equ & $01 \mathrm{~h}$ & & ; Event counter mode \\
\hline TMODE2 & equ & $02 \mathrm{~h}$ & & ; Stopwatch event timer \\
\hline TMODE3 & equ & $03 h$ & & ; Event timer with reset \\
\hline TMODE4 & equ & $04 \mathrm{~h}$ & & ; One shot \\
\hline TMODE5 & equ & $05 \mathrm{~h}$ & & ; Square wave \\
\hline TMODE6 & equ & $06 \mathrm{~h}$ & & ; Pulse generator \\
\hline ; & & & - TIMER & PRESCALER \\
\hline PRE1 & equ & OOh & & ; No prescale \\
\hline PRE2 & equ & $08 \mathrm{~h}$ & & ;Divide by 2 \\
\hline PRE64 & equ & $018 \mathrm{~h}$ & & $\begin{array}{l}\text {; Divide by } 64 \text {, timer } 0 \text { only } \\
\text {; (SEE NSC810 SPECS) }\end{array}$ \\
\hline ; & & & - TIMER & READ/WRITE MODE \\
\hline BIT8T & equ & O20h & & ; Single byte read/write mode ( $\mathrm{Hi}$ or LO) \\
\hline BIT16T & equ & $00 \mathrm{~h}$ & & $\begin{array}{l}\text {; } 16 \text { bit timer. Read or write low } \\
\text {; byte first }\end{array}$ \\
\hline ; & & & - TIMER & GATE CONTROL \\
\hline GPOLH & equ & $\mathrm{OOH}$ & & ; Gate input active high(PC3). \\
\hline GPOLL & equ & $040 \mathrm{~h}$ & & $\begin{array}{l}\text {; This is the common gate for both timers } \\
\text {; Gate input active low }\end{array}$ \\
\hline ; & & & - TIMER & OUTPUT CONTROL \\
\hline OUTPOLH & equ & $080 \mathrm{~h}$ & & $\begin{array}{l}\text {; Timer output active high. } \\
\text {; } 1=\mathrm{PC} 5, \mathrm{~T} 0=\mathrm{PIN} 6\end{array}$ \\
\hline OUTPOLL & equ & OOh & & ; Timer output active low \\
\hline
\end{tabular}




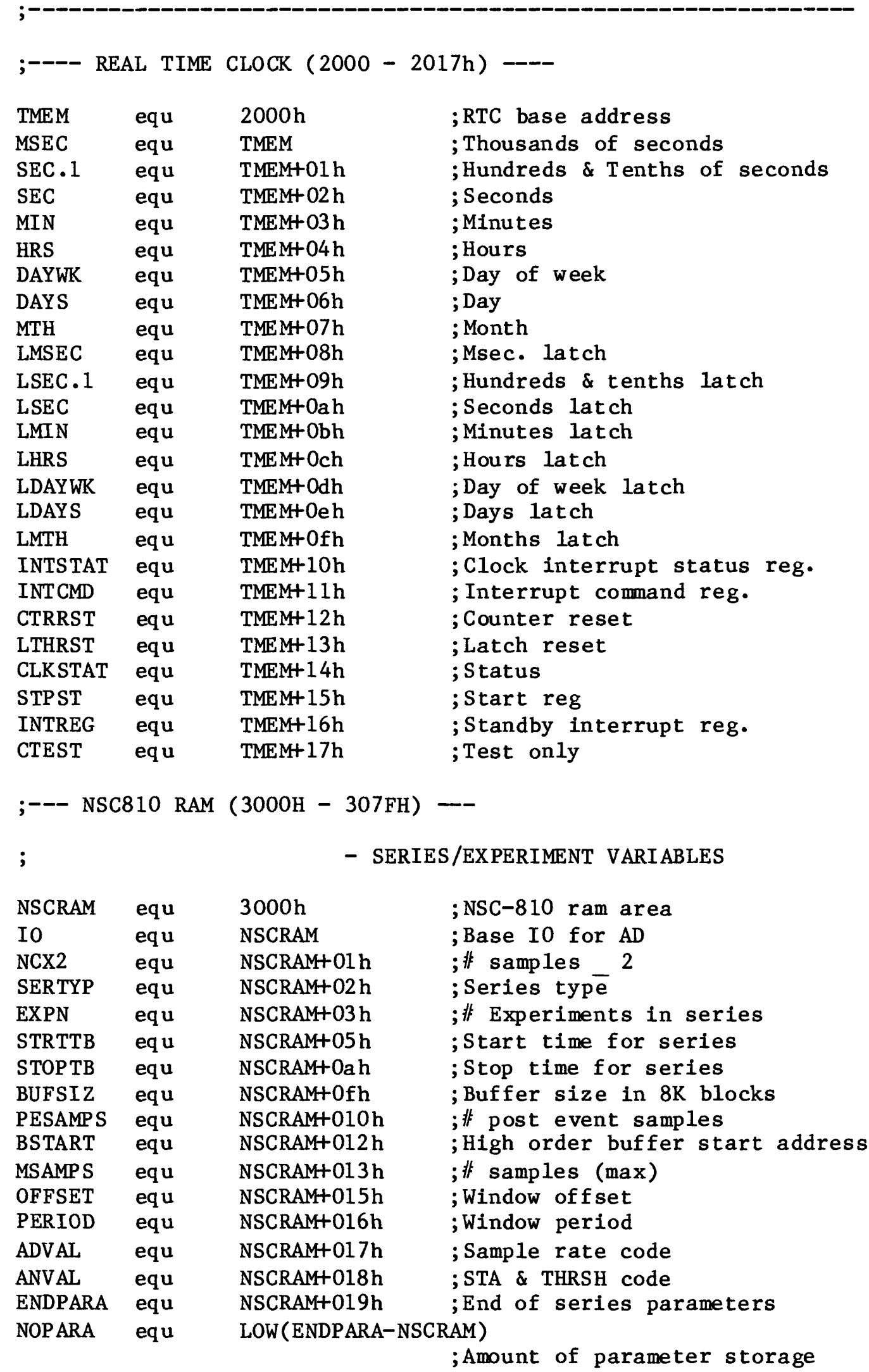




\begin{tabular}{|c|c|c|}
\hline PESAMS & equ & NSCRAM+019h \\
\hline THRSHSV & equ & NSCRAM+01 ah \\
\hline STASAV & eq $\mathbf{u}$ & NSCRAM+01bh \\
\hline SRATE & equ & NSCRAM+01 ch \\
\hline BSZSAV & equ & NSCRAM+01dh \\
\hline PARBUF & eq $\mathbf{u}$ & NSCRAMHOl eh \\
\hline LSTCP & equ & NSCRAM+020h \\
\hline HDRBUF & equ & NSCRAM+022h \\
\hline GPCTRL & equ & NSCRAM+024h \\
\hline GPCTRH & eq $\mathbf{u}$ & NSCRAM+025h \\
\hline NSAMP S & equ & NSCRAM+026h \\
\hline BUFPTR & equ & $\mathrm{NSCRAM}+028 \mathrm{~h}$ \\
\hline WBUFSAV & equ & NSCRAM+02 ah \\
\hline WBSTART & equ & NSCRAM+02 ch \\
\hline RDBUF & equ & NSCRAM+02dh \\
\hline TIMSAVE & equ & NSCRAM+02 fh \\
\hline STACK & equ & NSCRAM+050h \\
\hline RAMST & equ & NSCRAM+05ah \\
\hline ENDRAM & equ $\mathbf{u}$ & NSCRAM+05ch \\
\hline ADDRESS & equ & NSCRAM+05eh \\
\hline PATRN & equ & NSCRAM+05fh \\
\hline RECN & equ & NSCRAM+062 h \\
\hline RWN & equ & NSCRAM+065h \\
\hline ABRTV & equ $u$ & NSCRAM+067H \\
\hline LSN & equ & NSCRAM+069h \\
\hline EQFY & equ & NSCRAM+06bh \\
\hline BEND & equ $\mathbf{u}$ & NSCRAM+06ch \\
\hline
\end{tabular}

\section{WORKING PARAMETERS}

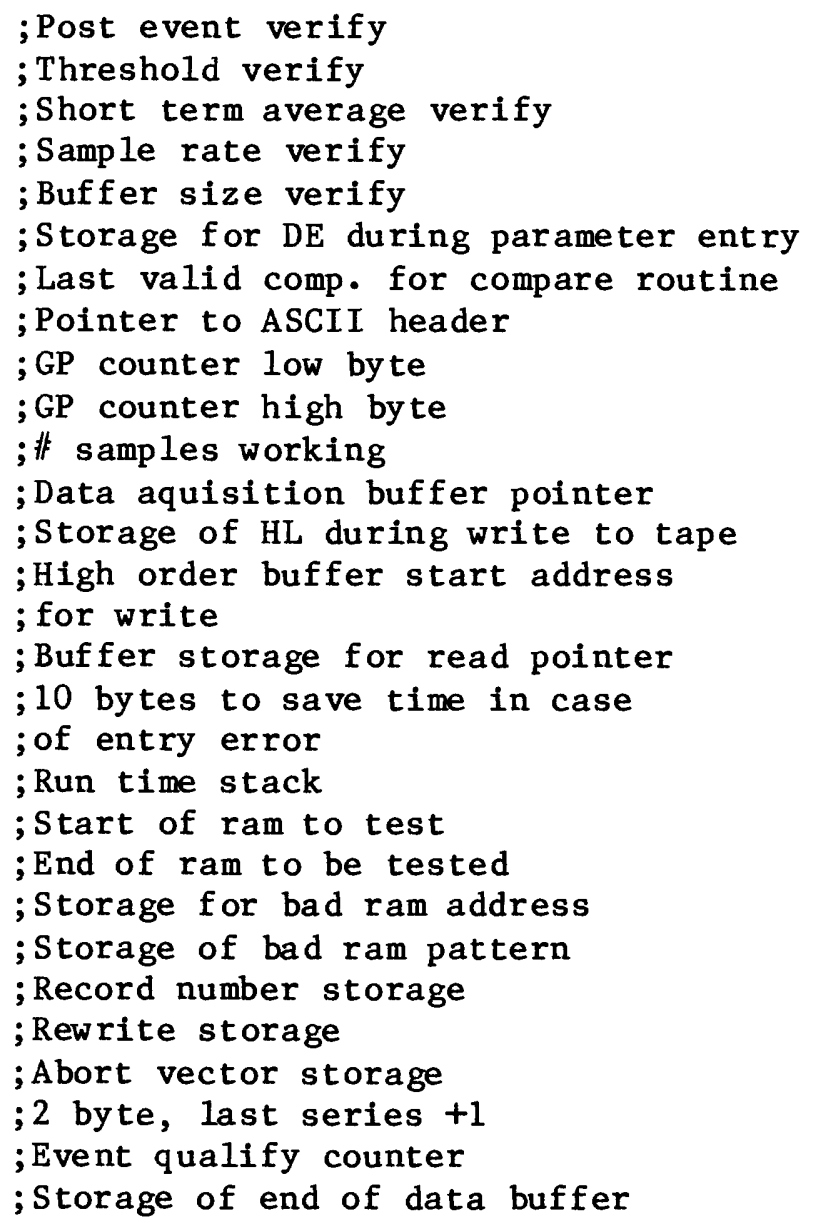

;--- SCRATCH

\section{PAD}

\section{RAM (4000 - 5FFFh) --}

4000h ; Scratch pad ram

SCRATCH+200h

NSTACK $+02 \mathrm{~h}$

NSTACK $+04 \mathrm{~h}$

NSTACK+06h

NSTACK+08h

NSTACK+Oah

NSTACK+Obh

NSTACK+Odh

NSTACK +0 fh

NSTACK+010h

NSTACK+011 h

NSTACK+012h

NSTACK+013h

NSTACK $+014 \mathrm{~h}$

NSTACK+015h

SCRATCH+300h

SCRATCH+350h

SCRATCH+400h

; Operating stack after ramtest

; Temporary storage

; Flag for ram test

; Length of recording (mins, secs)

; Used to divideto get above value

; Save sector count for write error

; Save buffer ptr for write error

; T1 interupt vector

; Stored drive status

; Stored interface status

; Mode argument copy

; Pos. arg copy

; Command argument copy

; Analog board gain code

; Sample rate value for A-D board

; Elapsed minute count

; Base address

; ASCII input buffer

; No. characters in buffer 


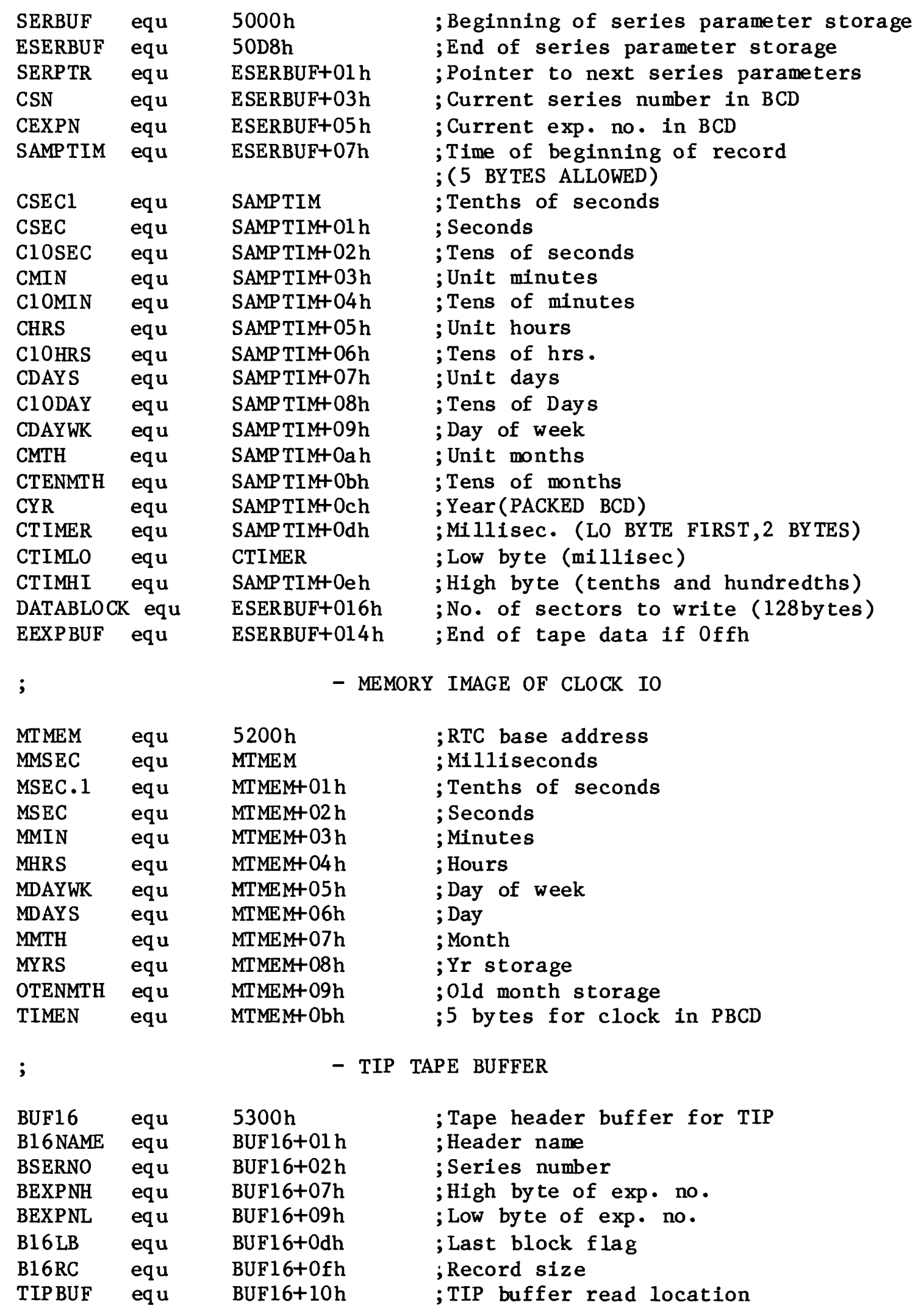


;--- AQUISITION RAM (8000 - FFFFh)---

BUFMEM equ $\quad 08000 \mathrm{~h} \quad$; Aquistion ram

;

- HEADER RAM

HDRRAM equ $0 \mathrm{e} 000 \mathrm{~h}$; Start of header ram 
;--- PORT LOCATIONS ---

$\begin{array}{lll}\text { CPORT } & \text { equ } & \text { OfOh } \\ \text { MA } & \text { equ } & \text { CPORT } \\ \text { PA } & \text { equ } & \text { CPORT+1 } \\ \text { CA } & \text { equ } & \text { CPORT }+2 \\ \text { DA } & \text { equ } & \text { CPORT }+3 \\ \text { PS } & \text { equ } & \text { CPORT }+1\end{array}$

;--- COMMAND EQUATES ---

\begin{tabular}{|c|c|c|}
\hline \multirow{3}{*}{$\begin{array}{l}\text { READC } \\
\text { WRITEC } \\
\text { WRITEFMC }\end{array}$} & equ & $01 \mathrm{~h}$ \\
\hline & equ & $02 \mathrm{~h}$ \\
\hline & equ & $03 h$ \\
\hline \multicolumn{3}{|c|}{ FWDSPRECC } \\
\hline & equ & $04 \mathrm{~h}$ \\
\hline \multicolumn{3}{|c|}{ FWDSPFILC } \\
\hline REVSPCREC & equ & $05 \mathrm{~h}$ \\
\hline & equ & $06 \mathrm{~h}$ \\
\hline \multicolumn{3}{|c|}{ REV SP CF ILC } \\
\hline & equ & $07 \mathrm{~h}$ \\
\hline \multicolumn{3}{|l|}{ CURSTATC } \\
\hline & equ & $08 \mathrm{~h}$ \\
\hline \multicolumn{3}{|c|}{ SETRECLENC } \\
\hline & equ & $09 \mathrm{~h}$ \\
\hline \multicolumn{3}{|c|}{ WRITEWCHC } \\
\hline & equ & $\mathrm{Oah}$ \\
\hline \multicolumn{3}{|c|}{ RECSERMASC } \\
\hline & equ & $\mathrm{Obh}$ \\
\hline REWINDC & equ & $40 \mathrm{~h}$ \\
\hline BREADC & equ & $41 \mathrm{~h}$ \\
\hline BWRITEC & equ & $42 h$ \\
\hline \multicolumn{3}{|c|}{ BWRITEFMC } \\
\hline & equ & $43 h$ \\
\hline RWREADC & equ & $81 \mathrm{~h}$ \\
\hline RSTCC & equ & $04 \mathrm{~h}$ \\
\hline
\end{tabular}

;--- MASKS --

$\begin{array}{lll}\text { BOTM } & \text { equ } & 08 \mathrm{~h} \\ \text { COMSTATM } & & \\ & \text { equ } & 030 \mathrm{~h} \\ \text { EOTM } & \text { equ } & 04 \mathrm{~h} \\ \text { MAN } & \text { equ } & 060 \mathrm{~h} \\ \text { TRACKMA } & \text { equ } & 03 \mathrm{~h} \\ \text { MSMA } & \text { equ } & 0 \mathrm{e} 0 \mathrm{~h}\end{array}$

; Cartridge controller base

; Mode argument

;Position argument

; Command argument

; Data argument(write data only)

; Port status

; Read a record

; Write a record

; Write a file mark

; Foward space a record

; Forward space a file

; Reverse space a record

; Reverse space a file

; send current status command to ; tape

; Set record length

; Write a record with check

; Mask search

; Rewind

; Buffer read

; Buffer write

; Buffer file mark

; Ram read

; Cartridge controller reset line ; on port $B$

; clear to reset, set to allow operation

;BOT mask for DS

; Command status mask for IS check

;End of track mask

; Status mask

; Track mask

; Mask search MA exc1. track bits 


\section{SYSTEM MACROS}

;Original code written by jhg ;UPDATE - 5/ 6/84 PRINT macro was added by ohh ; UPDATE - 10/18/84 code compiled into a seperate module by $\mathrm{gkm}$ ; UPDATE - 7/30/85 QPRINT macro was added by $\mathrm{gkm}$

; 


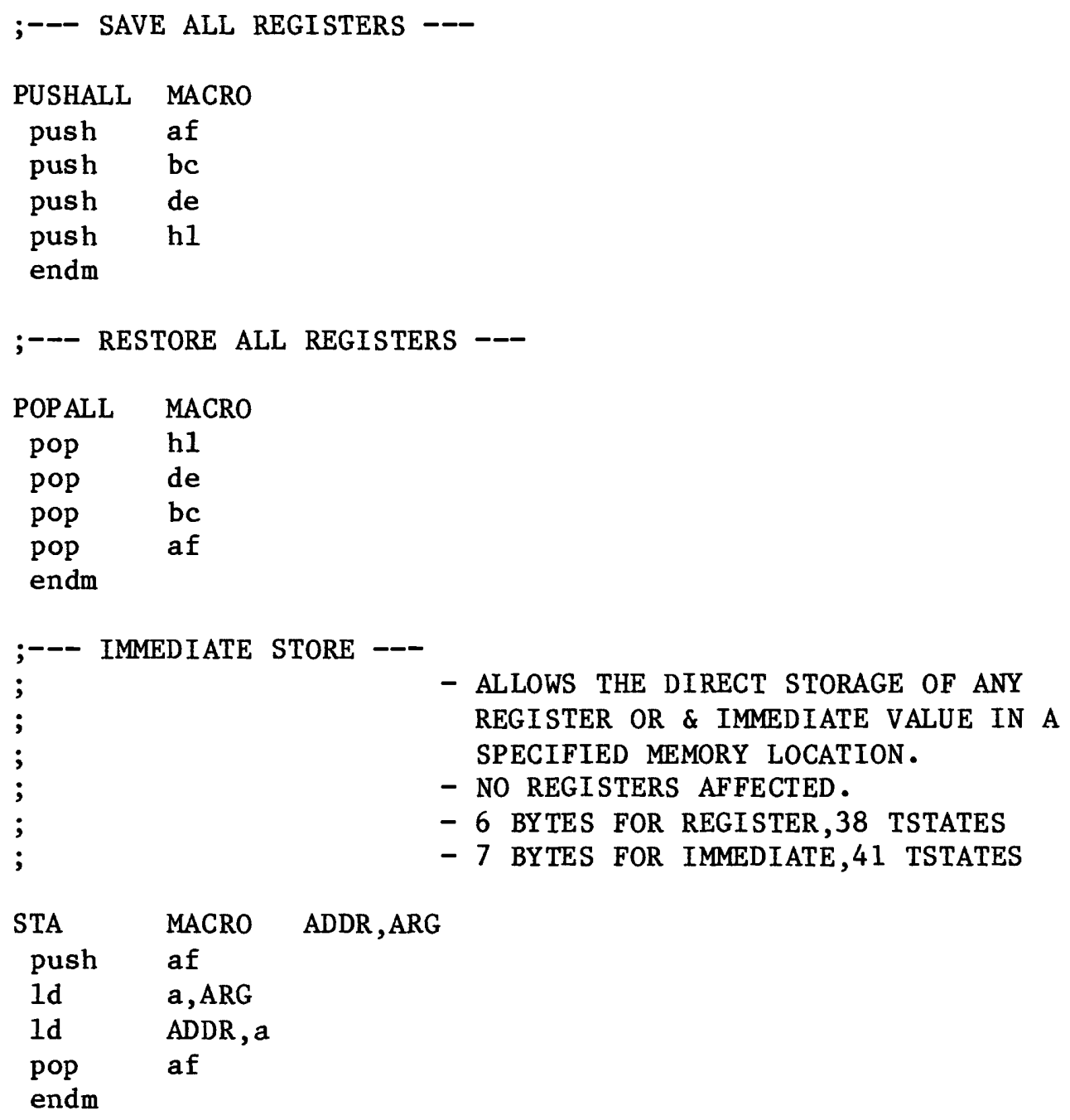




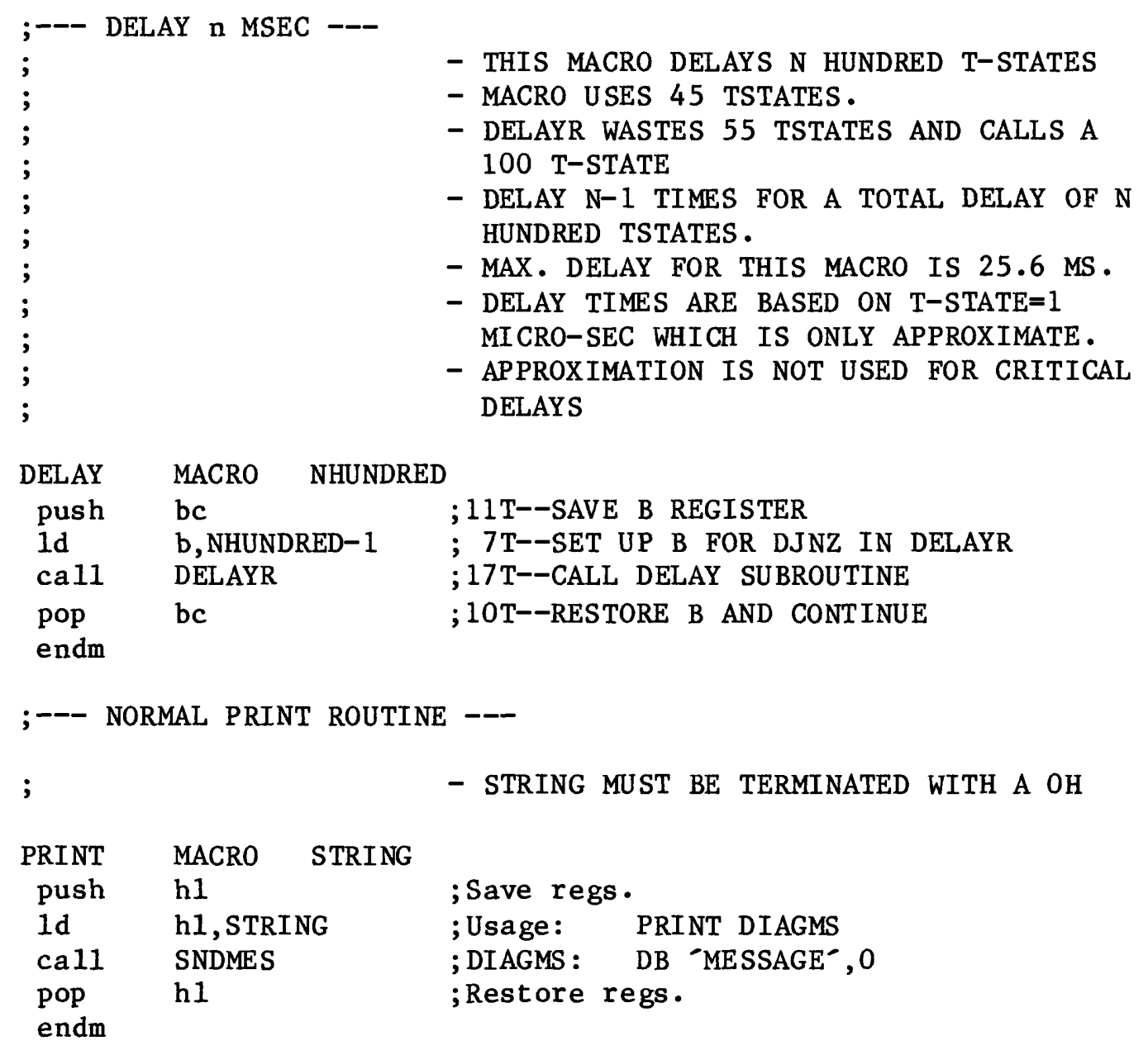




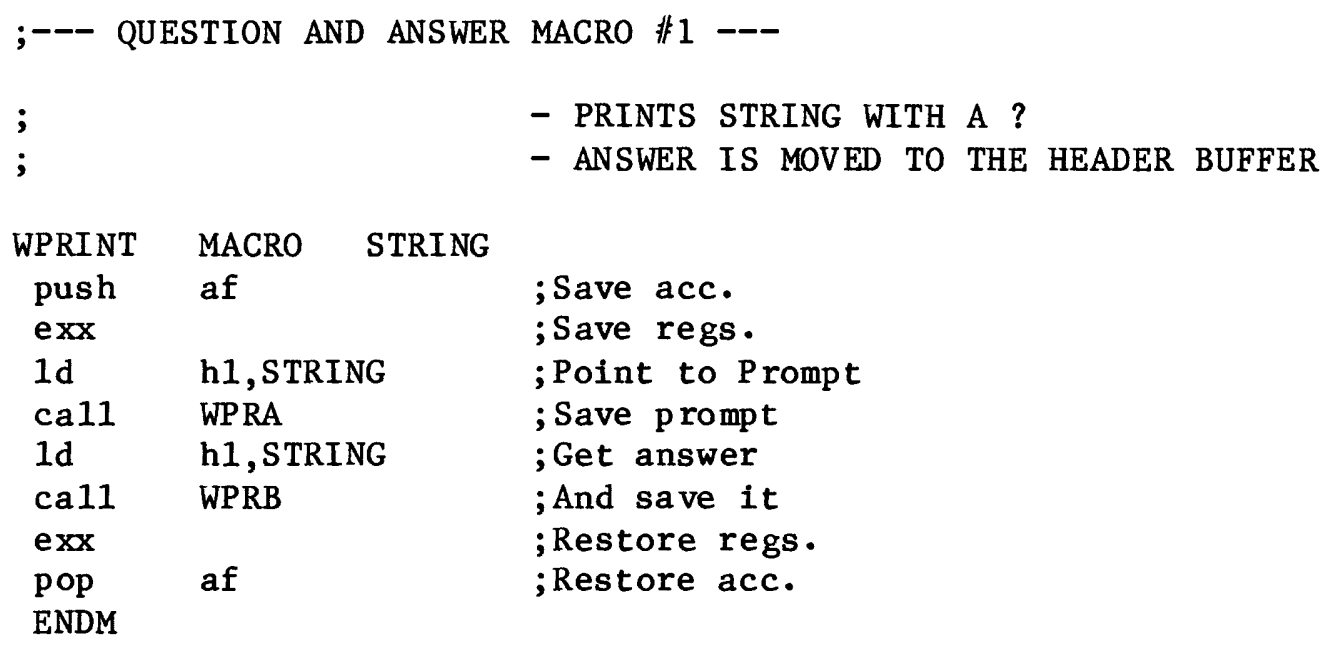


PAGE ZERO, INTERRUPT, AND RST VECTORS

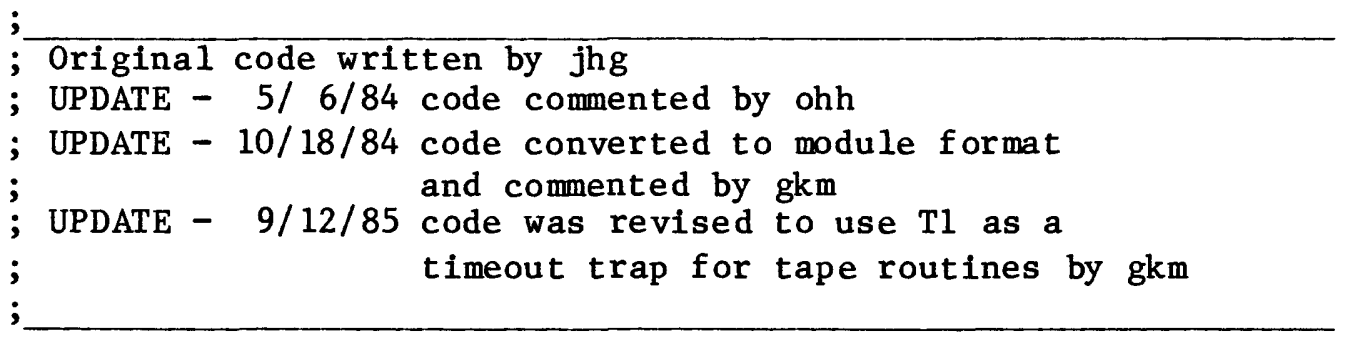


ASEG

org $0000 \mathrm{~h}$

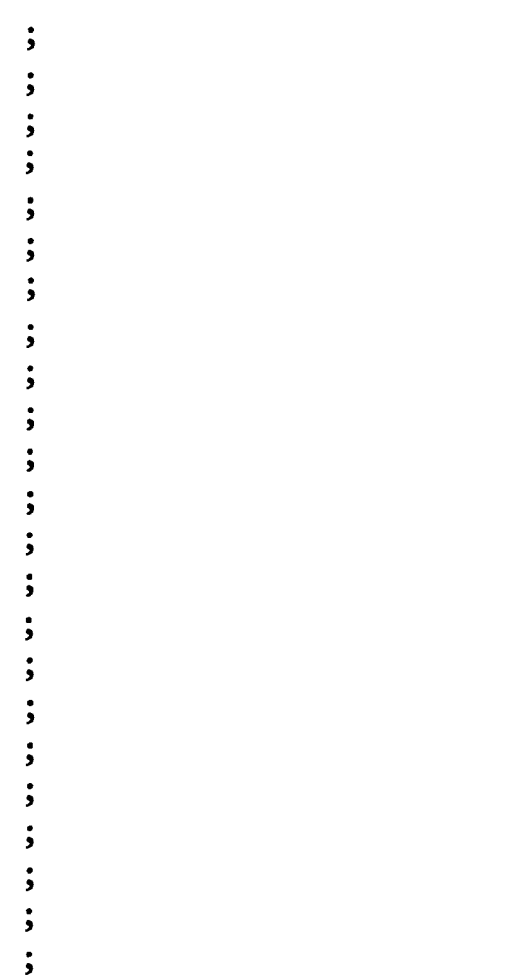

- PROCESSOR STARTS HERE ON RESET.

- INTERRUPT AND REFRESH REGS ARE CLEARED.

- ALL INTERRUPTS ARE DISABLED(HARDWARE DI INSTRUCTION).

- INTERRUPT CONTROL REGISTER IS SET TO 01, WHICH ENABLES "NOT INTR" AND MASKS OFF "NOT" RSTA,RSTB, RSTC.

- NO INTERRUPT CAN WORK UNLESS BOTH AN EI INSTRUCTION HAS BEEN ISSUED AND THERE IS A ONE IN THE APPROPRIATE SPOT IN THE INTERRUPT MASK REGISTER, WHICH IS A WRITE ONLY REGISTER ADDRESSED AS AN OUTPUT PORT (LOWER 4 BITS ONLY) BY AN OUT BBH OR EQUIV. INSTRUCTION.

- THE FOLLOWING VALUES ENABLE THE CORRESPONDING INT. LINES:

$\begin{array}{lll}08 \mathrm{H} & \text { ENABLES RSTA } \\ 04 \mathrm{H} & \text { ENABLES RSTB } \\ 02 \mathrm{H} & \text { ENABLES RSTC } \\ 01 \mathrm{H} & \text { ENABLES INTR }\end{array}$

- NOTE THAT OFH ENABLES ALL INT. LINES

- 8080 INTERRUPT MODE IS AUTOMATICALLY SELECTED ON RESET

;---RESTART O (11000111)---

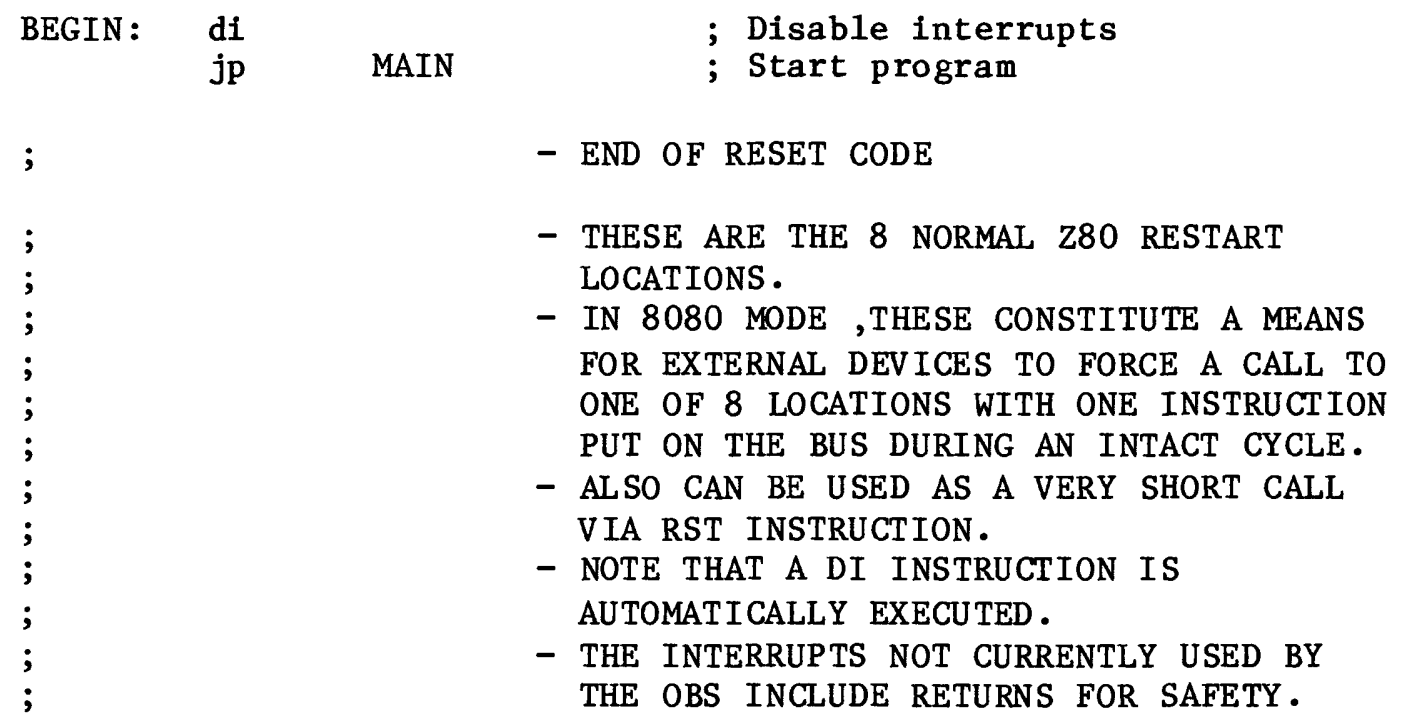




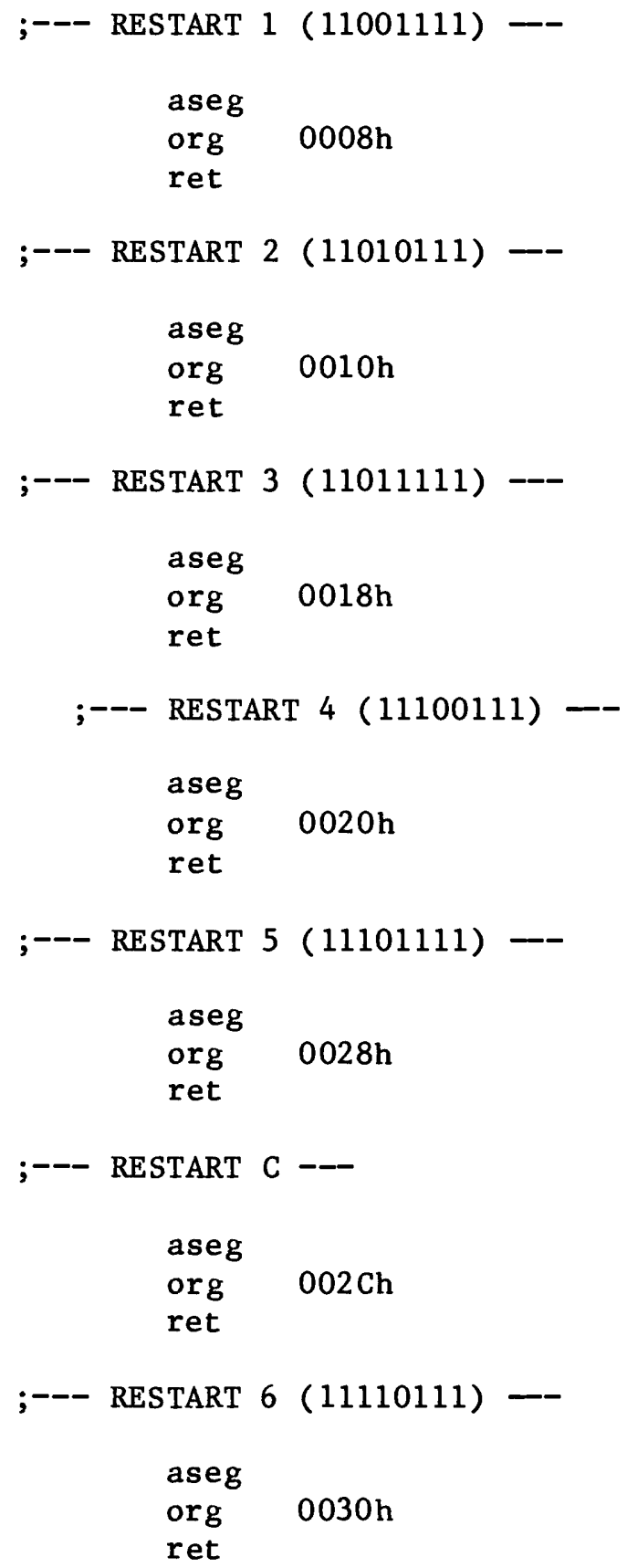


;---RESTART B ---

- THIS INTERRUPT IS FROM TIMER 1. IT IS USED AS A TIME OUT ERROR TRAP.

aseg

org $0034 \mathrm{~h}$

jp TFAIL

; Tape fail routine

;--- RESTART 7 (11111111) --

;

- IN MODE 1,WILL COME HERE ON NOT INTR GOING LOW

- PUSHING THE EARLY TERMINATION BUTTON BRINGS YOU HERE.

$\begin{array}{ll}\text { aseg } & \\ \text { org } & \text { 0038h } \\ \text { jp } & \text { ETERM }\end{array}$

; Early termination routine

- NOTE THAT THIS REQUIRES HARDWARE OR MODEI INTERRUPTS! 


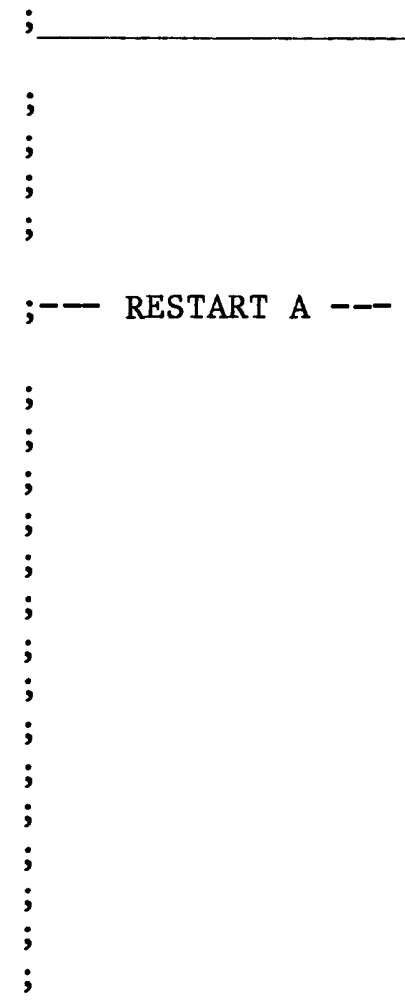

- IF INT. ENABLED AND MASK OK WILL COME HERE AS SHOWN.

- NO INSTRUCTION NEEDED ON BUS-- JUST PULL THE APPROPRIATE PIN LOW.

- INTERRUPT IS GENERATED ON THE A/D BOARD.

- IT IS CONTROLLED BY A NUMBER OF CPU BOARD OUTPUTS.

- THE NSC 810 PORT C PIN 0 CONTROLS AN OR GATE WHICH DISABLES THE INTERRUPT COMING FROM THE A/D BOARD ON S-100 PIN 4 IF $\mathrm{C}-0$ IS $\mathrm{HIGH}$.

- THE A/D BOARD WILL NOT GENERATE AN INTERRUPT IF ITS FIRST INTERRUPT WAS NOT ACKNOWLEDGED.

- THE A/D INTERRUPT OCCURS IMMEDIATELY AFTER CONVERSION COMPLETE FOLLOWING A TIME-OUT OF THE SOFTWARE SETTABLE COUNTER WHICH GIVES THE APPROXIMATE SAMPLE(WILL HAVE ABOUT 200 MICROSECONDS OF SLOP) TIME

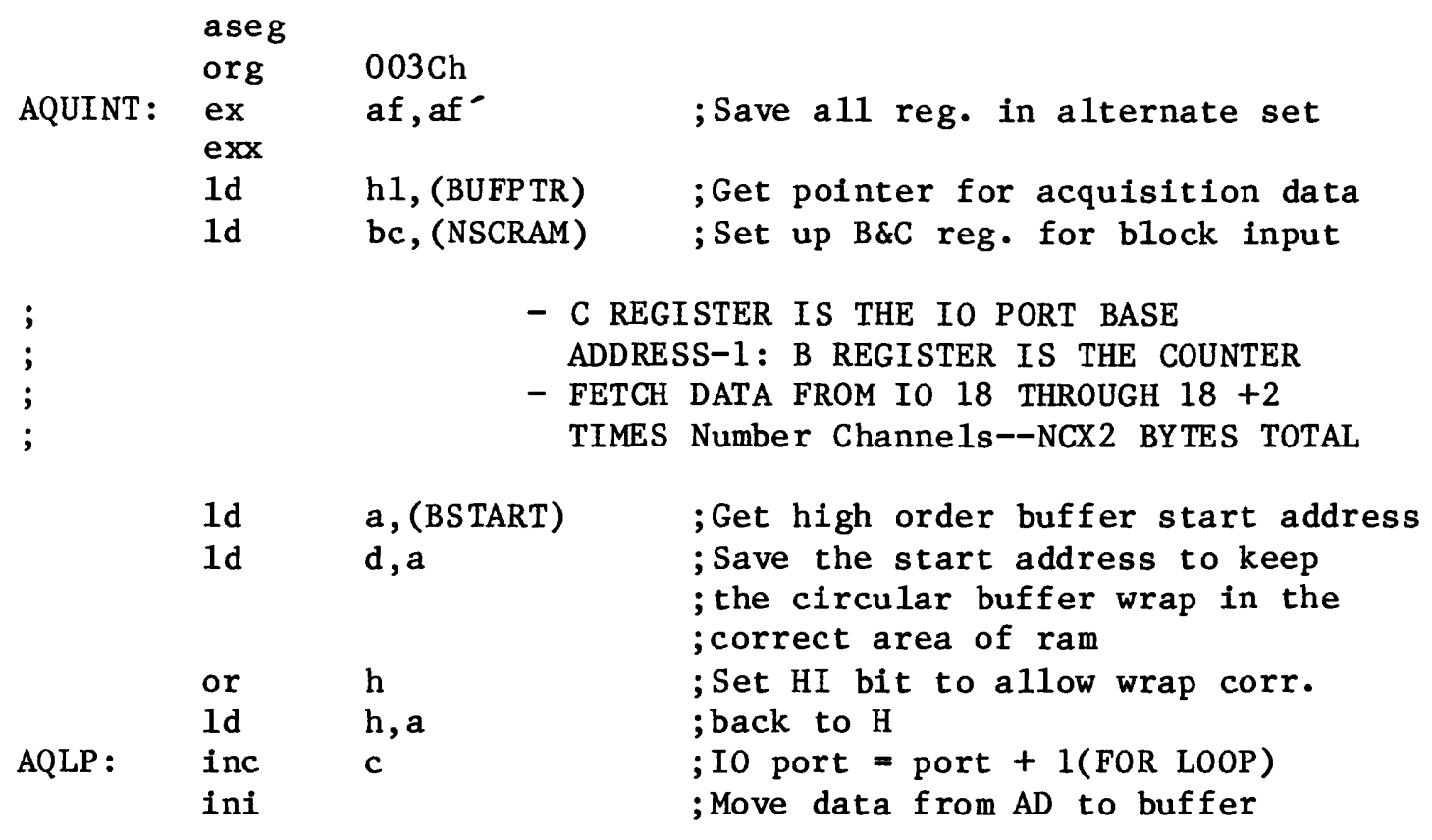


- FETCH FROM IO PORT (C), STORE AT HL, DECR . B, INCR . HL .

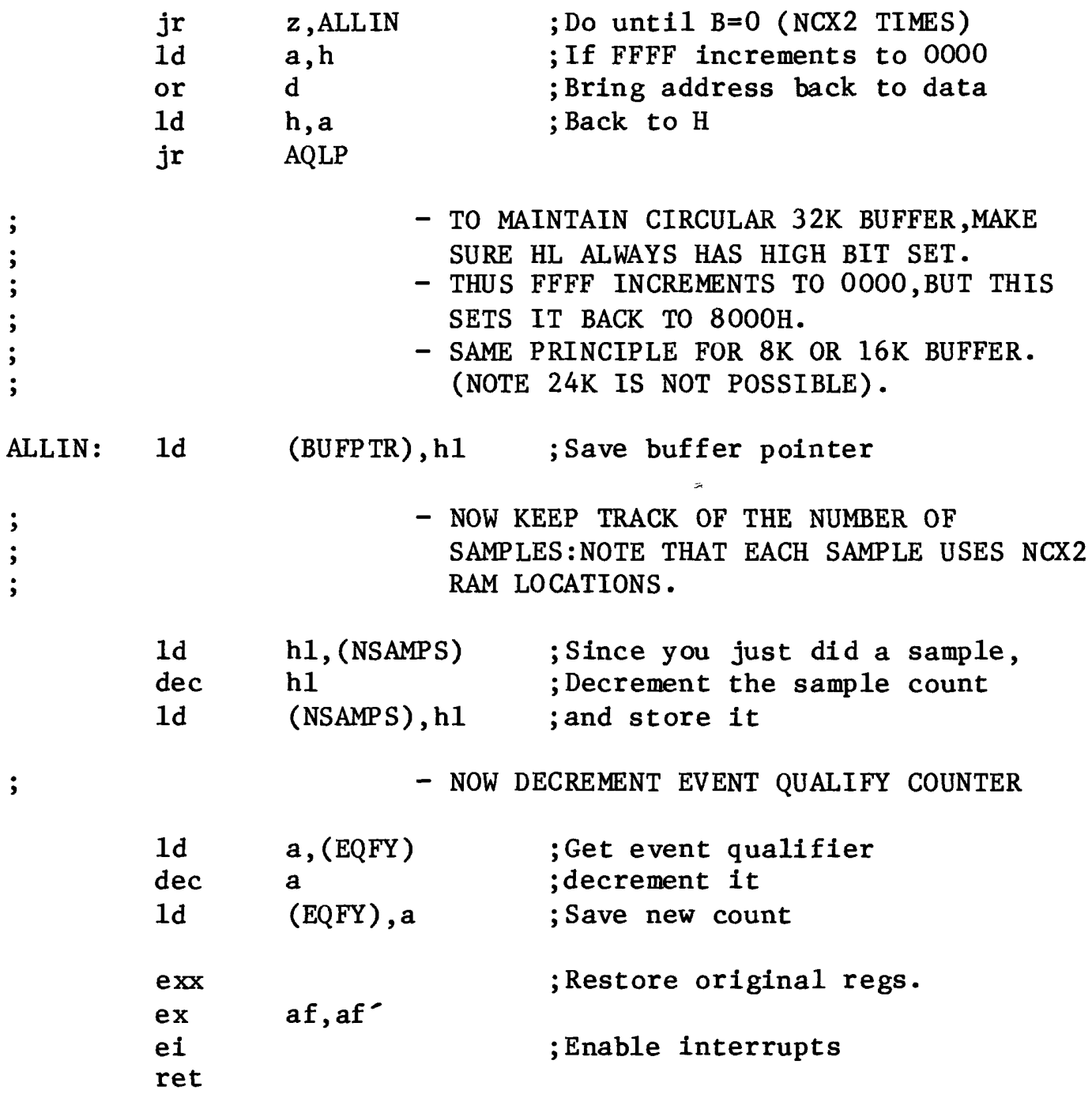


MAIN PROGRAM

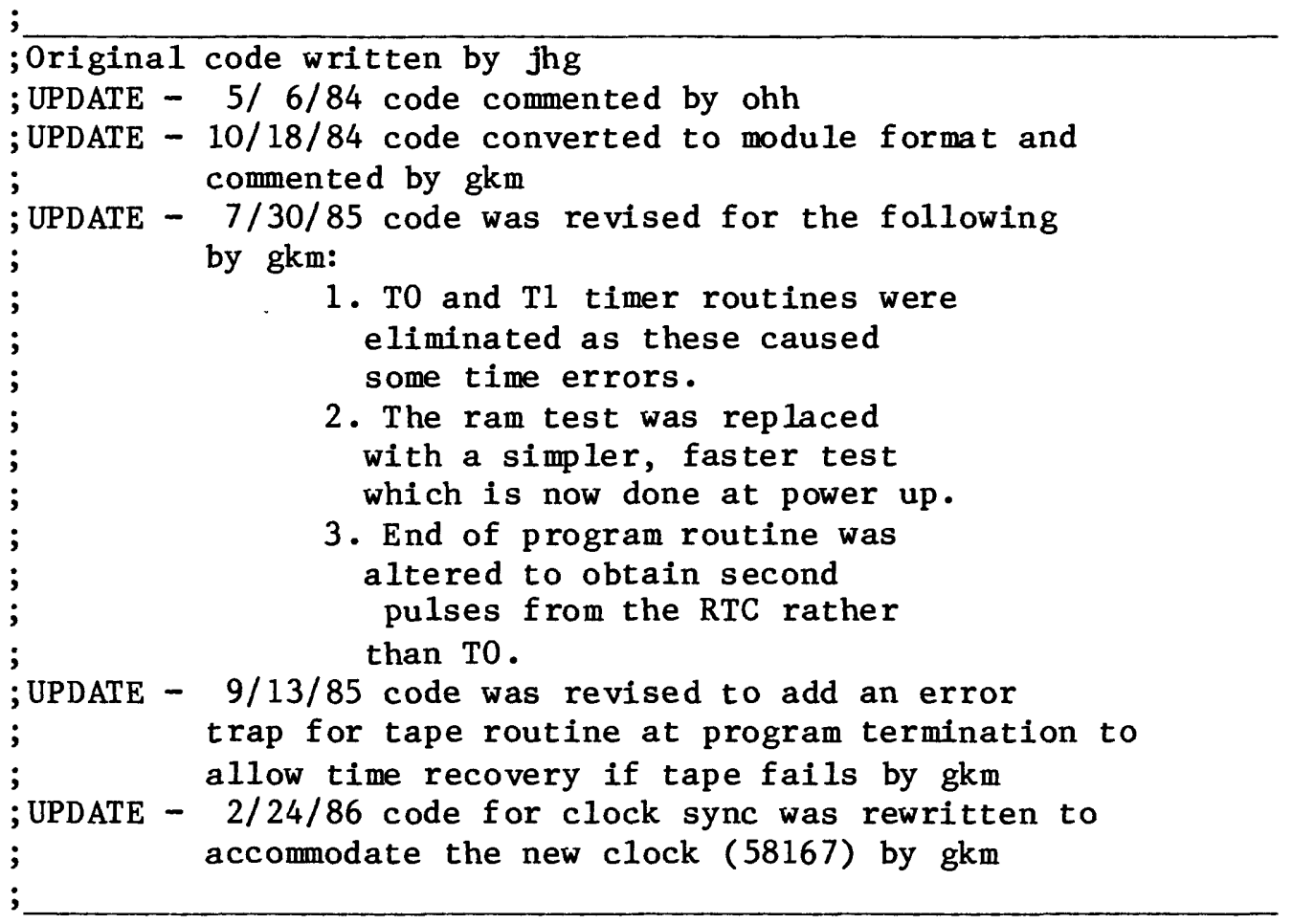




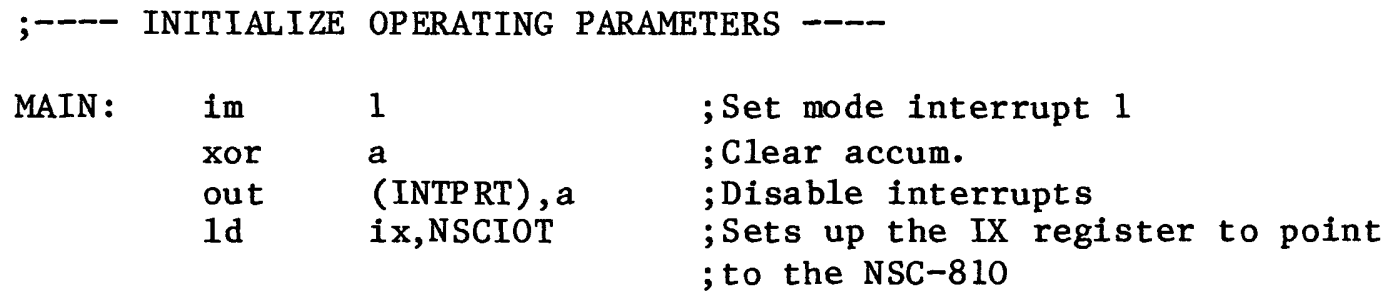

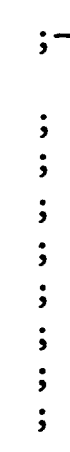

\begin{tabular}{|c|c|c|}
\hline INI810: & $1 d$ & $(\mathrm{IX}+\mathrm{PADADD}), \mathrm{ADAT}$ \\
\hline & $1 d$ & $(\mathrm{IX}+\mathrm{PBDADD}), \mathrm{BDAT}$ \\
\hline & $1 d$ & (IX+PCDADD), CDAT \\
\hline & $1 \mathrm{~d}$ & (IX+PADIR), ADIR \\
\hline & $1 d$ & $(I X+P B D I R)$, BDIR \\
\hline & $1 d$ & $(\mathrm{IX}+\mathrm{PCDIR}), \mathrm{CDIR}$ \\
\hline & $1 d$ & (IX+CMDRAD), MODEO \\
\hline
\end{tabular}

; Intialize port A data ; Init. port B data ; Init. port $C$ data ; Init. port A direction ; Init. port B direction ; Init. port $C$ direction ; Init. NSC-810 mode

T1DAT equ TMODE1 or PRE1 or BIT16T or GPOLH or OUTPOLL 1d (IX+T1CMD), T1DAT ; Init. timer 1

;-- LOAD TIMER ---
$1 d$
(STOPT1), a
; Stop timer 1
1d (IX+TILSB), offh
; Load low byte
$1 d$
$(\mathrm{IX}+\mathrm{TI} M S \mathrm{~B}), 06 \mathrm{~h}$
; Load high byte $=6 \mathrm{sec}$.

;--- INITIALIZE EVENT DETECTOR ---

1d $\quad a, 1$

out (AVGPRT), a
; Set average high and ; Clear pending interrupts 


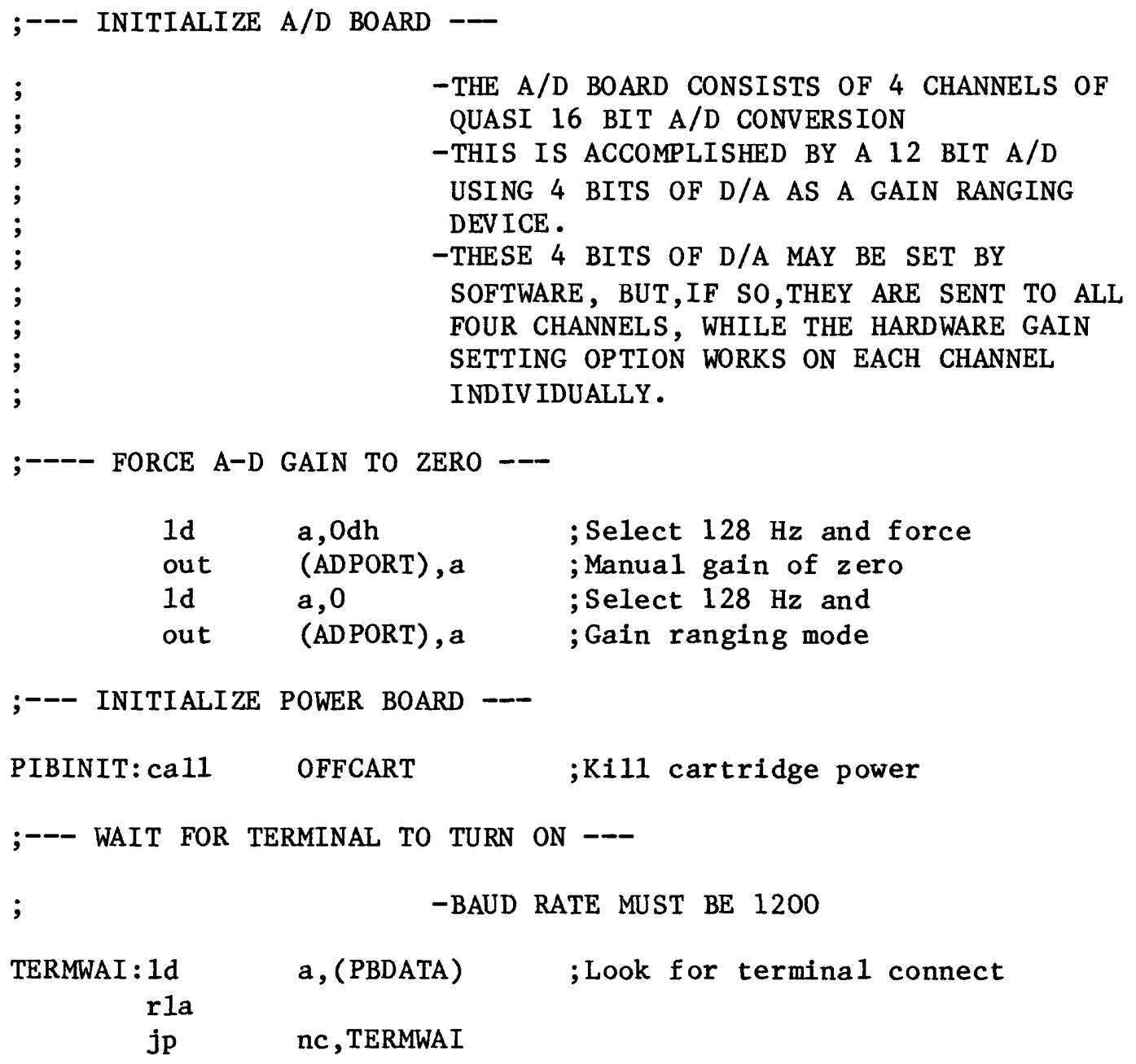


;

;--- TEST NSCRAM ---

- THIS CHECKS THE RAM LOCATIONS FROM $3000 \mathrm{H}$ TO $3080 \mathrm{H}$.

- THE TEST FILLS THE AREA OF RAM AND THEN RECREATES THE TEST PATTERN TO CHECK THE VALUE LOADED IN EACH LOCATION.

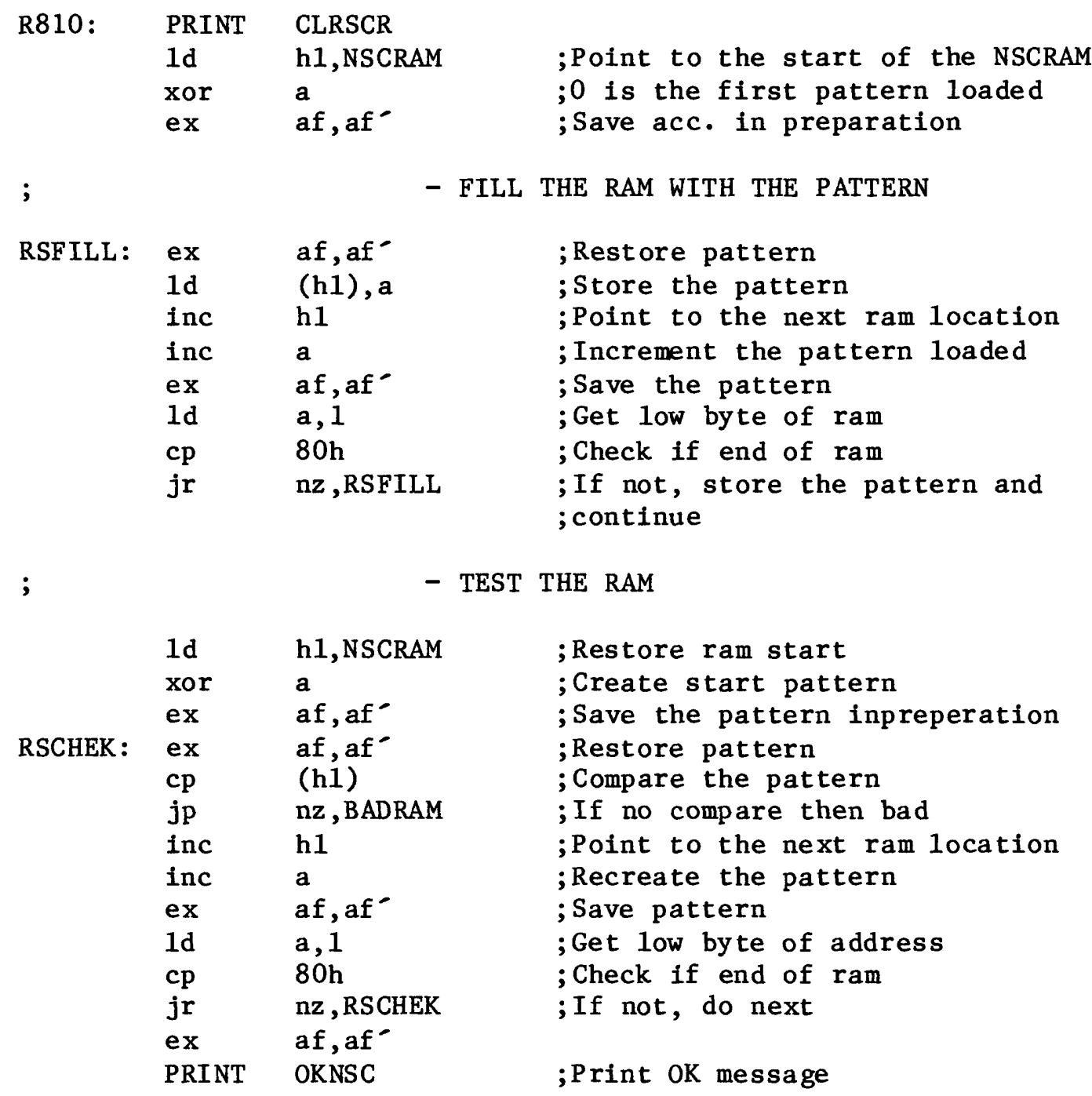




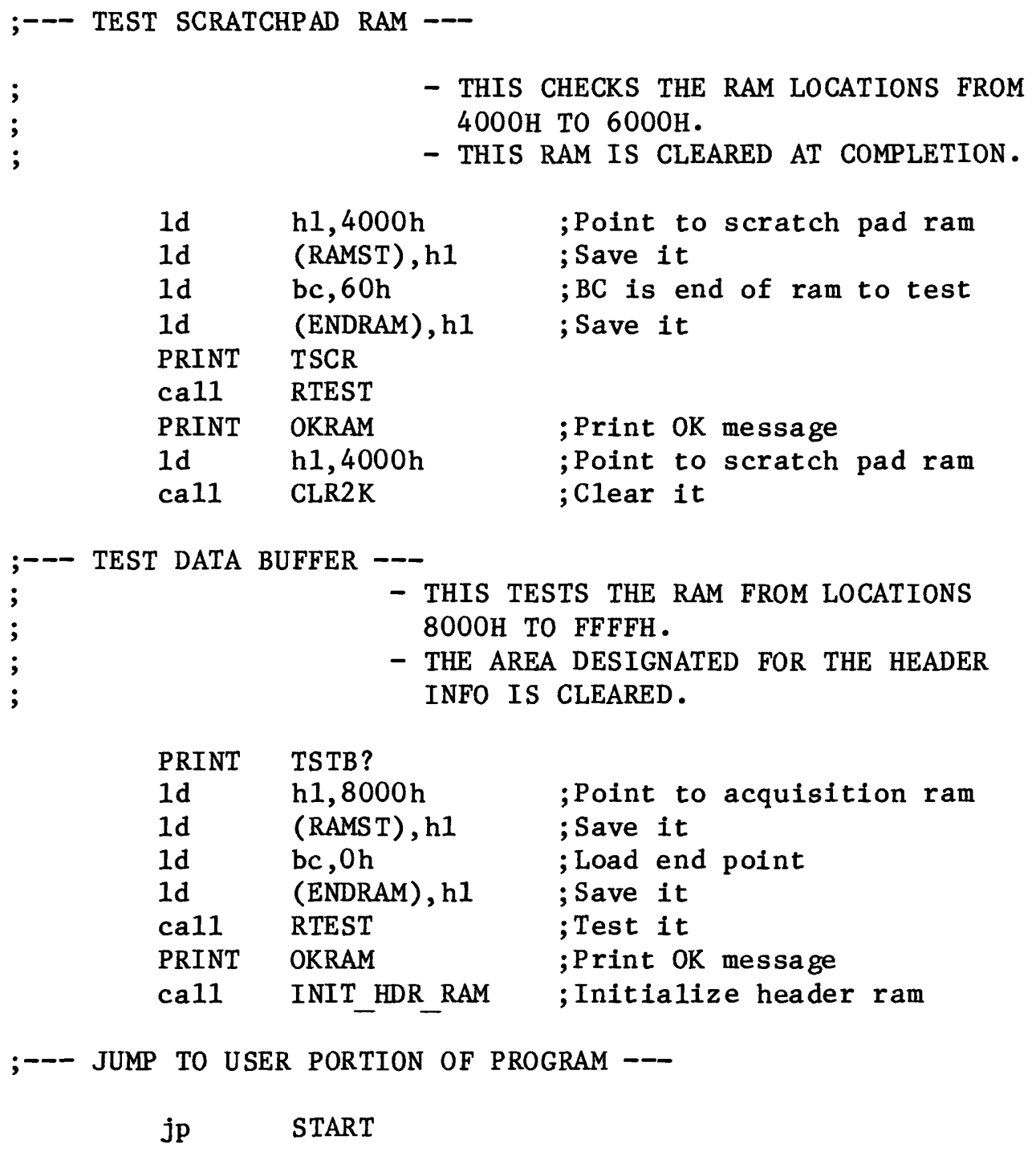


;--- TEST THE AREA OF RAM --

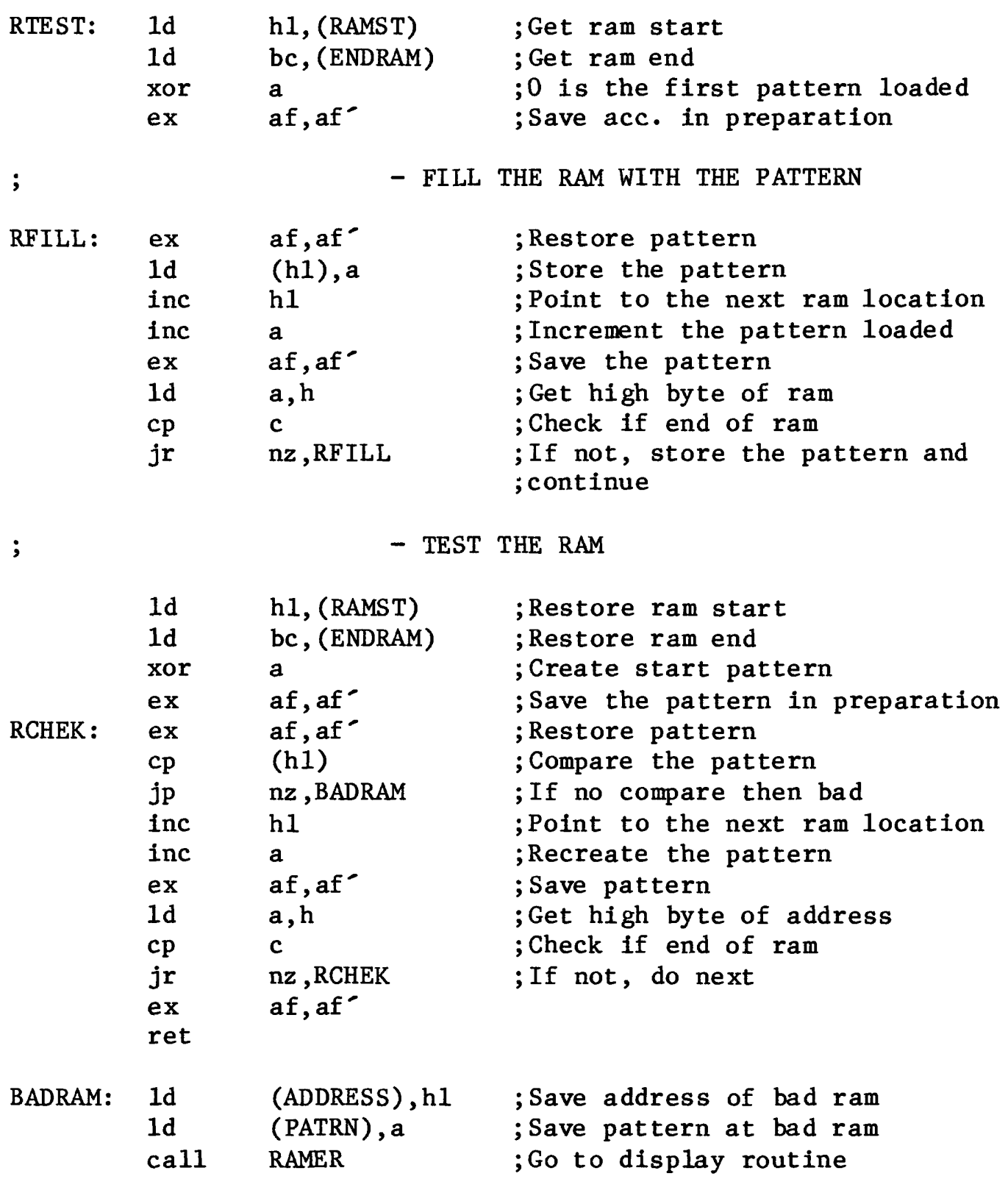

;--- CLEAR HEADER RAM ---

INIT_HDR_RAM:

1d h1,HDRRAM ; Point to start of header ram

1d (HDRBUF), hl ; Save it

cal1 CLR2K ; Clear it

ret 


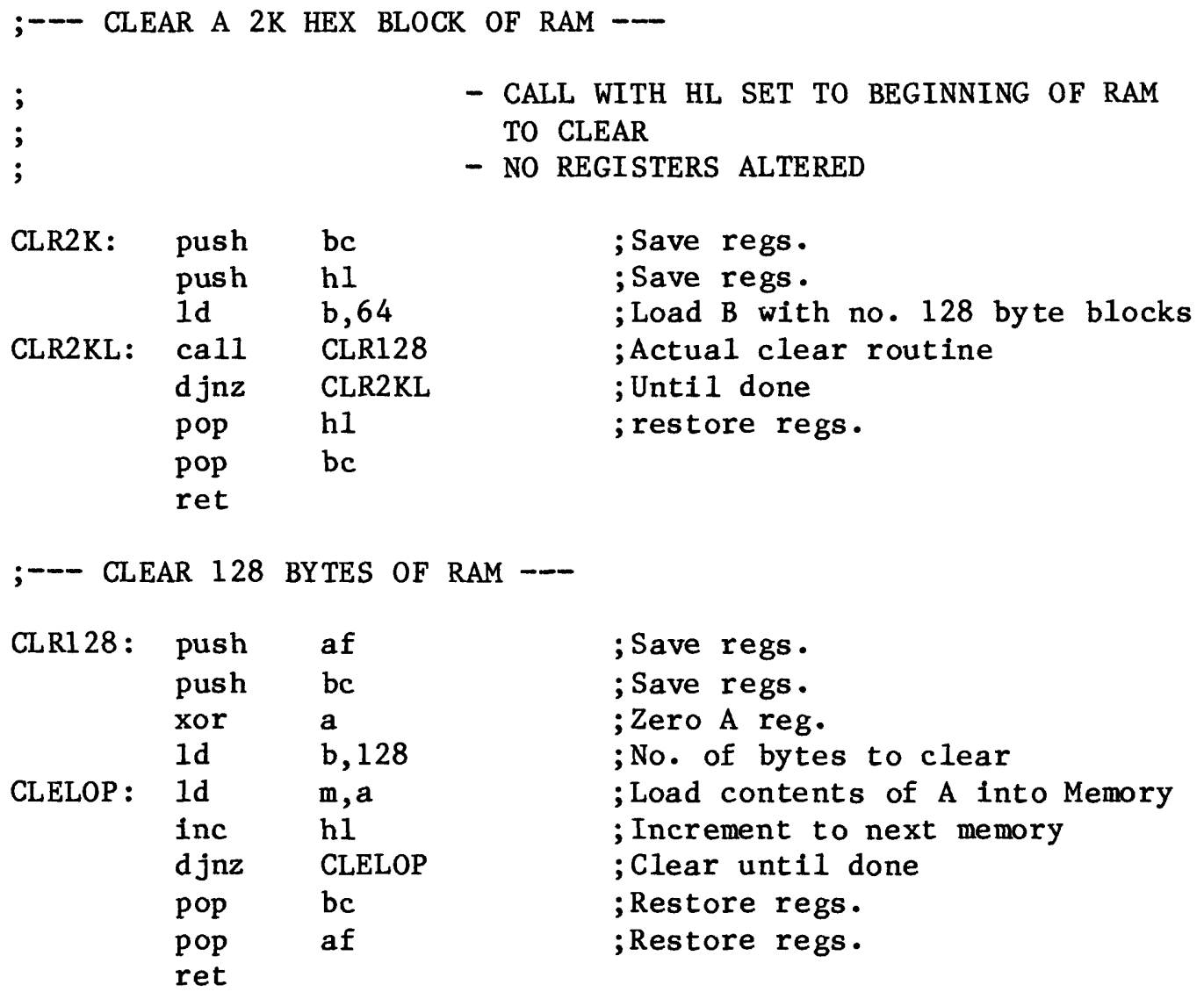

;--- RAM TEST ERROR ROUTINE ---

\begin{tabular}{|c|c|c|c|}
\hline RAMER : & $\begin{array}{l}\text { PRINT } \\
1 d \\
\text { cal1 } \\
\text { call } \\
\text { PRINT } \\
\text { 1d } \\
\text { cal1 } \\
\text { call } \\
\text { PRINT } \\
\text { cal1 } \\
\text { cp } \\
\text { ret } \\
\text { HALT }\end{array}$ & $\begin{array}{l}\text { RAMER1 } \\
\text { h1, (ADDRESS) } \\
\text { PHREG } \\
\text { CRLF } \\
\text { RAMER2 } \\
\text { a, (PATRN) } \\
\text { HEXOUT } \\
\text { CRLF } \\
\text { RAMER3 } \\
\text { GBYT } \\
\text { CR } \\
z\end{array}$ & $\begin{array}{l}\text {; Print message } \\
\text {; Get bad address } \\
\text {; Print address } \\
\text {; Print next message } \\
\text {; Get bad pattern } \\
\text {; Print it } \\
\text {; Print next message } \\
\text {; Wait for character } \\
\text {; Is it a carriage return? } \\
\text {; If so normal exit } \\
\text {; Else, stop }\end{array}$ \\
\hline
\end{tabular}


;--- PRINT RAM ADDRESS ---

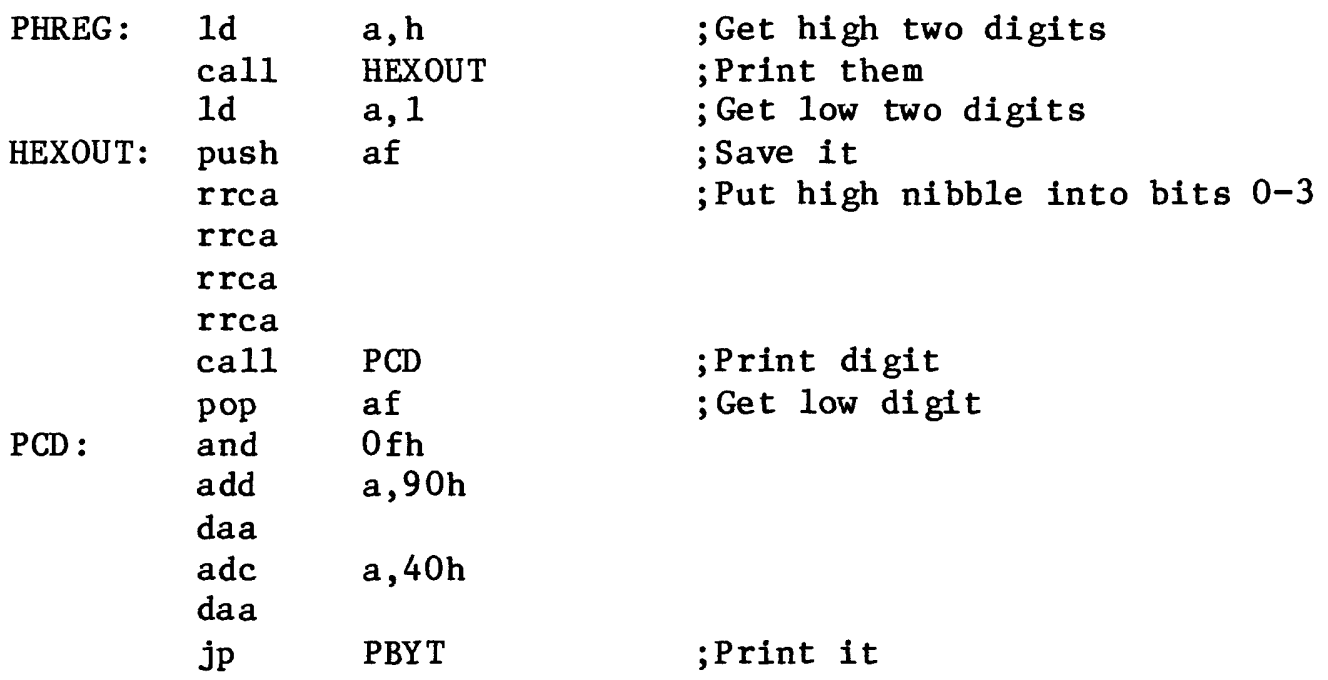


RECORD HEADER AFTER TERMINAL UNPLUGGED ---

$$
\begin{aligned}
& ; \\
& ; \\
& ; \\
& ; \\
& ; \\
& ; \\
& ; \\
& ;
\end{aligned}
$$

- IN EXECUTION YOU HAVE THE OPTION OF A DATA ACQUISITION MODE OR A TEST MODE.

- THE DATA ACQUISITION MODE WILL ASK YOU TO DISCONNECT THE TERMINAL. AFTER THE TERMINAL IS DISCONNECTED, THE HEADER WILL BE WRITTEN AND THE SYSTEM WILL GO TO WORK. DOING THIS IS THE ONLY WAY TO DETERMINE IF THE SYSTEM IS WORKING AFTER EVERYTHING IS DISCONNECTED AND READY FOR DEPLOYMENT .

- THE TEST MODE WILL WRITE THE HEADER IMMEDIATELY AND DISPLAY EXPERIMENT PARAMETERS AND CURRENT EXPERIMENT NUMBER.

\section{EXECU : QPRINT TSTM}

cp $\quad \mathrm{Y}$ '

jp $\quad z, Y T E S T$

cp $\quad y^{\prime}$

jp $\quad z, Y$ TEST

PRINT UNPLUGM

DISCON: 1d a, (PBDATA)

rla

jr c,DISCON

Id $b, 20$
;Operator must indicate if this

; is a test

; Is it yes

; If so go to test

;Print instruction

; Look for terminal disconnect

; Load count 
;

SLOWPOKE:

$\begin{array}{ll}\text { PRINT } & \text { BEEP } \\ \text { DELAY } & 256\end{array}$

Id

rla

jr

d jnz

YTEST: $\quad$ xor

$1 d$

STA

$1 d$

Id

call

1d

ca11

ca11

ca 11

call

ca 11

1d

ca11

1d

ca11

LTMR1 : jp

a
- IF SLOW IN DISCONNECT, THE TERMINAL WILL BEEP AT YOU UNTIL YOU DO.

; every $25.6 \mathrm{~ms}$

; Check terminal for disconnect

; Continue until disconnect

; Do 20 times to be sure

; Start of write buffer is 00

; Save it (noncircular)

(WBSTART), a (DATABLOCK), $40 \mathrm{~h}-2$

; Store number of write sectors

h1, HDRRAM

; Point to header ram

; Save it in case of trouble

; Clear the TIP header

; Point to the header ram

; Loader the TIP header name

; Turn on the cartridge

;Write the GPheader

; Turn off the cartridge

; Clear the TIP header

; Point to series header TIP name

; Create it

; Point to header ram

; Clear it

; User now unnecessary 


$\begin{array}{llll}\text {;--- PROGRAM TERMINATION --- } & \\ \text { ETERM: } & \text { ca11 } & \text { OFFCART } & \\ & \text { PRINT } & \text { TERMIN } & \text {; Print message } \\ & \text { cal1 } & \text { CONT } & \text {; Wait } \\ & \text { jp } & \text { ENDPRO } & \text {; Go to clock sync routine }\end{array}$

;--- CHECK CLOCK SYNC ---$$
\text { ; }
$$

$\begin{array}{lll}\text { ENDPRO: } & \text { ca11 } & \text { CRLF } \\ \text { PRINT } & \text { OVR } \\ 1 \mathrm{~d} & \text { h1,CLKRD } \\ \text { ca11 } & \text { ONCART } \\ \text { ca11 } & \text { FMK } \\ \text { ca11 } & \text { FMK } \\ \text { ca11 } & \text { OFFCART }\end{array}$

CLKRD : di

CLKRD1 : 1d

daa

cp

jr

xor

CLKRD2 : $1 d$

EDPR1 : $1 d$

$\mathrm{cp}$

jr

;

e, a

e

$\mathrm{nz}, \mathrm{EDPR} 1$ inc

- THIS ROUTINE DISPLAYS THE TIME UPDATING EVERY SECOND AND SENDS OUT THE SECOND PULSE TO ALLOW COMPARISON WITH THE SATELLITE CLOCK.

; Print CRLF

;Print message

; Save abort vector

; Write first file mark

; Write second file mark

; Disable interrupts

; Look for second transition

; Increment second

; Decima 1 adjust

; Check if minute

; If not, continue

; Set sec. to 0

; Move it to $\mathrm{E}$

a, (TMEM+2)

; Loop until valid second

; transition

- OUTPUT SECONDS TO PORT A

1d (IX+PASADD), 2

ca11 GCLOCK

1d h1,TIMEN

ca11 TIMOUT

ca11 SECOUT

ca11 CRLF

1d (IX+PACADD), OFFH

jp CLKRD1
; Set port A of NSC 810 ; Read the clock ;Point to clock ;Print the time ;Print seconds ;Print CRLF

; Clear port A of NSC810 
;

\begin{tabular}{|c|c|c|}
\hline OKNSC: & $\mathrm{db}$ & ${ }^{-} \mathrm{NSC}$ RAM IS $\mathrm{OK}^{-}, \mathrm{CR}, \mathrm{LF}, 0$ \\
\hline OKRAM: & $\mathrm{db}$ & ${ }^{-T H I S ~ R A M ~} \mathrm{OK}^{\prime}, \mathrm{CR}, \mathrm{LF}, 0$ \\
\hline OVR: & $\mathrm{db}$ & ${ }^{-} \mathrm{PROG} O \mathrm{OVR}^{\prime}, \mathrm{CR}, \mathrm{LF}, \mathrm{O}$ \\
\hline RAMER1 : & $\mathrm{db}$ & ${ }^{-B A D}$ RAM @ HEX ADDRESS $`, 0$ \\
\hline $\begin{array}{l}\text { RAMER2 : } \\
\text { RAMER3 : }\end{array}$ & $\begin{array}{l}\mathrm{db} \\
\mathrm{db}\end{array}$ & $\begin{array}{l}\text { 'HEX PATTERN LOADED }=-{ }^{-}, 0 \\
\text {-HIT RETURN TO TEST NEXT RAM }{ }^{-}, \mathrm{CR}, \mathrm{LF}, 0\end{array}$ \\
\hline TERMIN : & $\mathrm{db}$ & 'TERMINATED',CR, LF, 0 \\
\hline TSCR: & $\mathrm{db}$ & 'TESTING SCRATCH PAD RAM',CR,LF, 0 \\
\hline TSTB?: & $\mathrm{db}$ & 'TESTING DATA BUFFER', CR,LF,0 \\
\hline TSTM: & $\mathrm{db}$ & CR,LF, ${ }^{-}$IS THIS A TEST? $(\mathrm{Y} / \mathrm{N})^{-}, 0$ \\
\hline UNPLUGM: & $\begin{array}{l}d b \\
d b \\
d b\end{array}$ & $\begin{array}{l}\text { CR,LF, 'UNPLUG TERMINAL FROM OBS', CR,LF } \\
\text { "HEADER WILL BE WRITTEN ABOUT } 5 \text { SEC. LATER' } \\
0\end{array}$ \\
\hline BEEP : & $\mathrm{db}$ & 7,0 \\
\hline
\end{tabular}


CLOCK SUBROUTINES

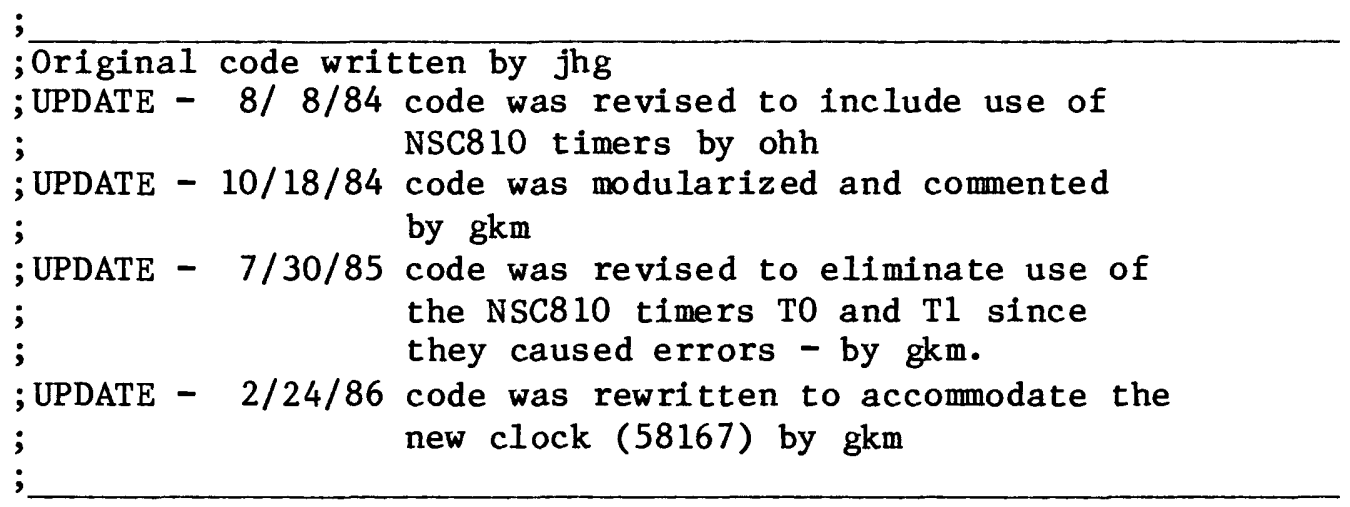




$\begin{array}{lll}\text { SETCLK } & \text { PUSHALL } & \text {; Save reg. } \\ \text { PRINT } & \text { SETM } & \text {; Print set clock message } \\ \text { 1d } & \text { hl,TIMEN } & \text {; Point to memory storage of time } \\ \text { cal1 } & \text { TIMINP } & \text {; Get time } \\ \text { 1d } & \text { a,(TIMEN) } & \text {; Get year } \\ \text { 1d } & \text { (MYRS),a } & \text {; Save it } \\ \text { 1d } & \text { a, (TIMEN+1) } & \text {; Get Month } \\ \text { ld } & \text { (OTENMTH), a } & \text {; Save it for year check } \\ \text { cal1 } & \text { LCM } & \text {; Load the clock }\end{array}$

;--- SYNCH WITH SATELLITE CLOCK ---

\begin{tabular}{|c|c|c|c|}
\hline \multirow{9}{*}{ SETCLK2: } & $1 d$ & ix,NSCIOT & ; Set up for IO \\
\hline & cal1 & CONT & ; Pause \\
\hline & PRINT & CLRSCR & ; Clear screen \\
\hline & PRINT & CLKPRM & ;Print message \\
\hline & $1 d$ & $a,(I X+0)$ & ; Read port "A" BIT 6 \\
\hline & bit & $6, a$ & ; Test bit 6 \\
\hline & jr & $z, S C C O N$ & ; Is sat. clock connected? \\
\hline & PRINT & SATNC & ; NO! Not connected \\
\hline & & CLK2 & ; Skip connected message \\
\hline \multirow{10}{*}{$\begin{array}{l}\text { SCCON : } \\
\text { CLK2: }\end{array}$} & PRINT & SATC & ; Print sat clk. conn. \\
\hline & $\begin{array}{l}\text { cal1 } \\
1 d \\
\text { cal1 }\end{array}$ & $\begin{array}{l}\text { GCLOCK } \\
\text { h1,TIMEN } \\
\text { TIMOUT }\end{array}$ & ;Print time of projected start \\
\hline & ca 11 & GBYT & ; Test for control B from \\
\hline & cp & 02 & ; console \\
\hline & jr & $z$, SKIP & ; Start clock if cntl "b" \\
\hline & cp & & ; Look for carriage return \\
\hline & $\begin{array}{l}\text { jr } \\
\text { cal1 }\end{array}$ & $\begin{array}{l}\mathrm{nz}, \text { SE TCLK2 } \\
\mathrm{LCM}\end{array}$ & $\begin{array}{l}\text {; Repeat procedure is screw-up } \\
\text {; Load clock }\end{array}$ \\
\hline & $1 \mathrm{~d}$ & $a,(I X+0)$ & ; Read port "a" \\
\hline & bit & $6, a$ & ; Test bit 6 \\
\hline & jr & $\mathrm{nz}$, SETCLK2 & ; Must have sat clk. connected \\
\hline \multirow[t]{3}{*}{ CLKLOO: } & Id & $a,(I X+0)$ & ;Read port "a" \\
\hline & bit & $6, a$ & ; stay in 1oop until bit 6 \\
\hline & jr & z, CLKLOO & ;goes high \\
\hline \multirow[t]{4}{*}{ SKIP : } & ca11 & LCM & ; Load clock \\
\hline & DELAY & 10 & ;Delay lms \\
\hline & $1 d$ & $a, 0$ & ; Load acc. with 0 to start \\
\hline & $1 d$ & $(\mathrm{STPST}), \mathrm{a}$ & ; real time clock \\
\hline \multirow[t]{5}{*}{; } & \multicolumn{3}{|c|}{ - Satellite start sequence complete. } \\
\hline & PRINT & SYNTM & ; Print message \\
\hline & & $a,(T M E M+2 h)$ & ; Get second \\
\hline & inc & a & ; increment it \\
\hline & $1 d$ & $e, a$ & ; Move it to $\mathrm{E}$ \\
\hline \multirow[t]{3}{*}{ SECLP : } & $1 d$ & $a,($ TMEM+2h) & ; Get second again \\
\hline & & & ; Has second incremented? \\
\hline & $\begin{array}{l}\text { jr } \\
\text { POPALL } \\
\text { ret }\end{array}$ & $\mathrm{nz}, \mathrm{SECLP}$ & $\begin{array}{l}\text {; Repeat until they do } \\
\text {; Restore reg. }\end{array}$ \\
\hline
\end{tabular}




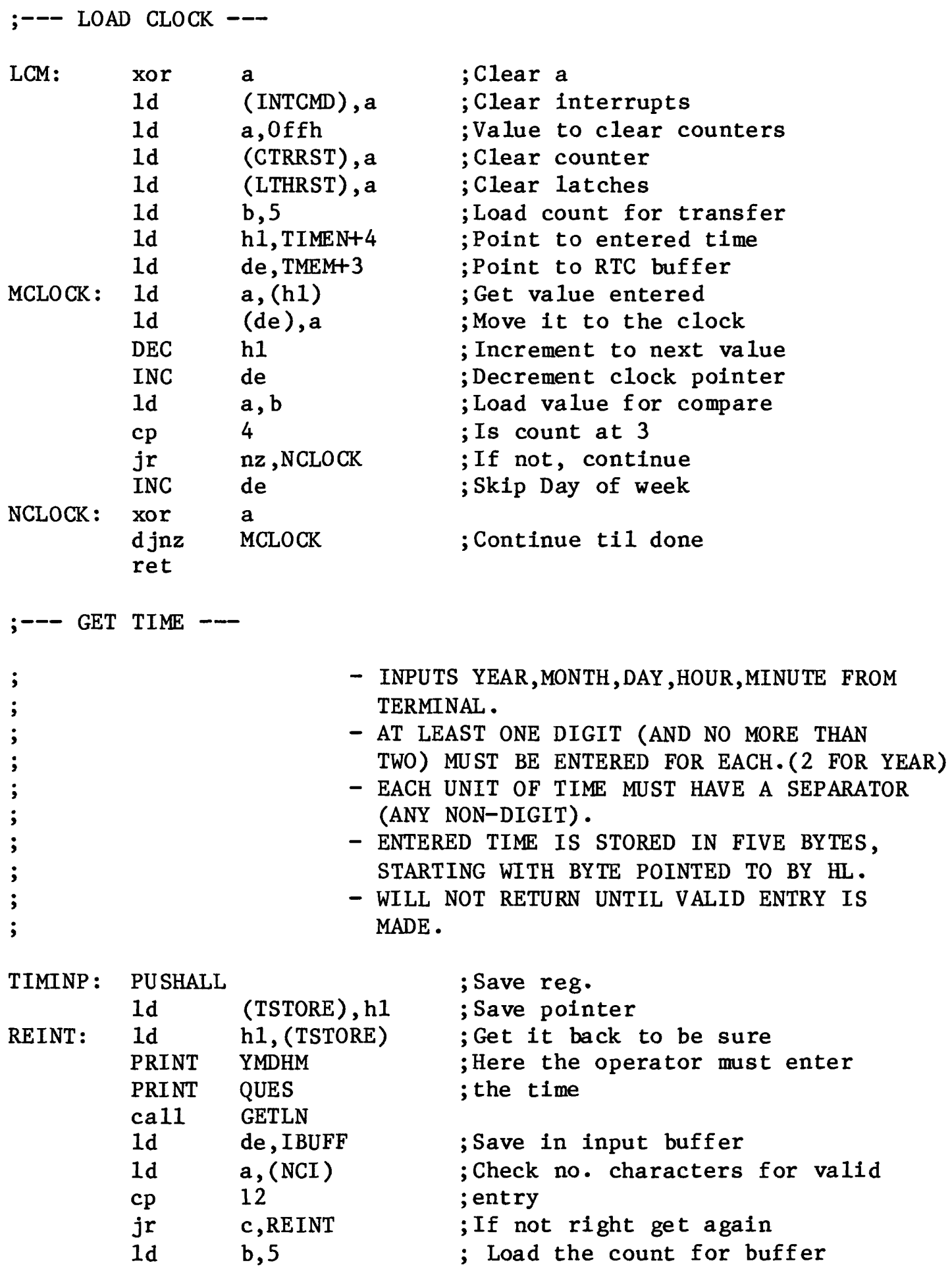


- CHECKING IS DONE TO INSURE VALID ENTRY FOR VALUE

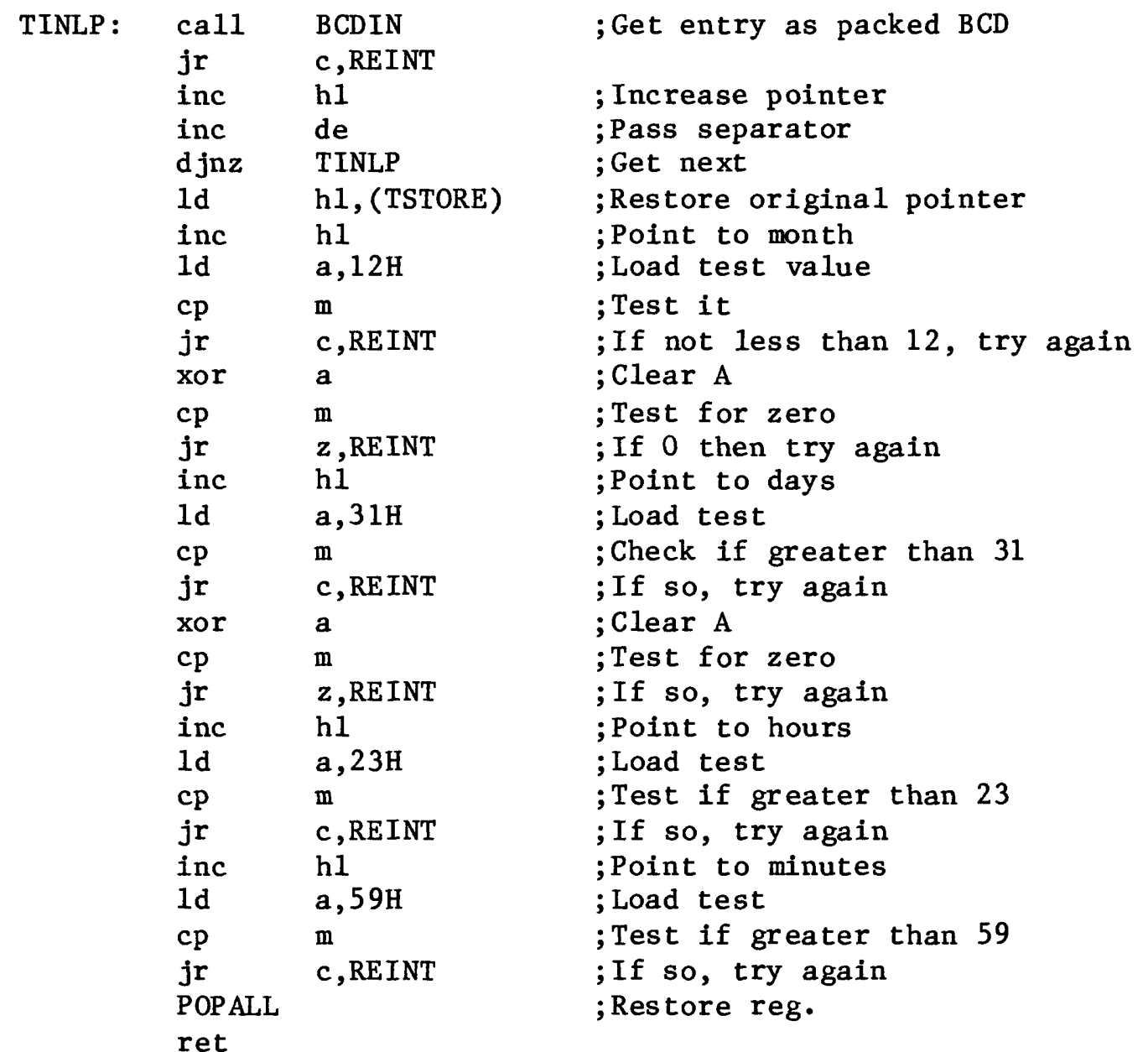




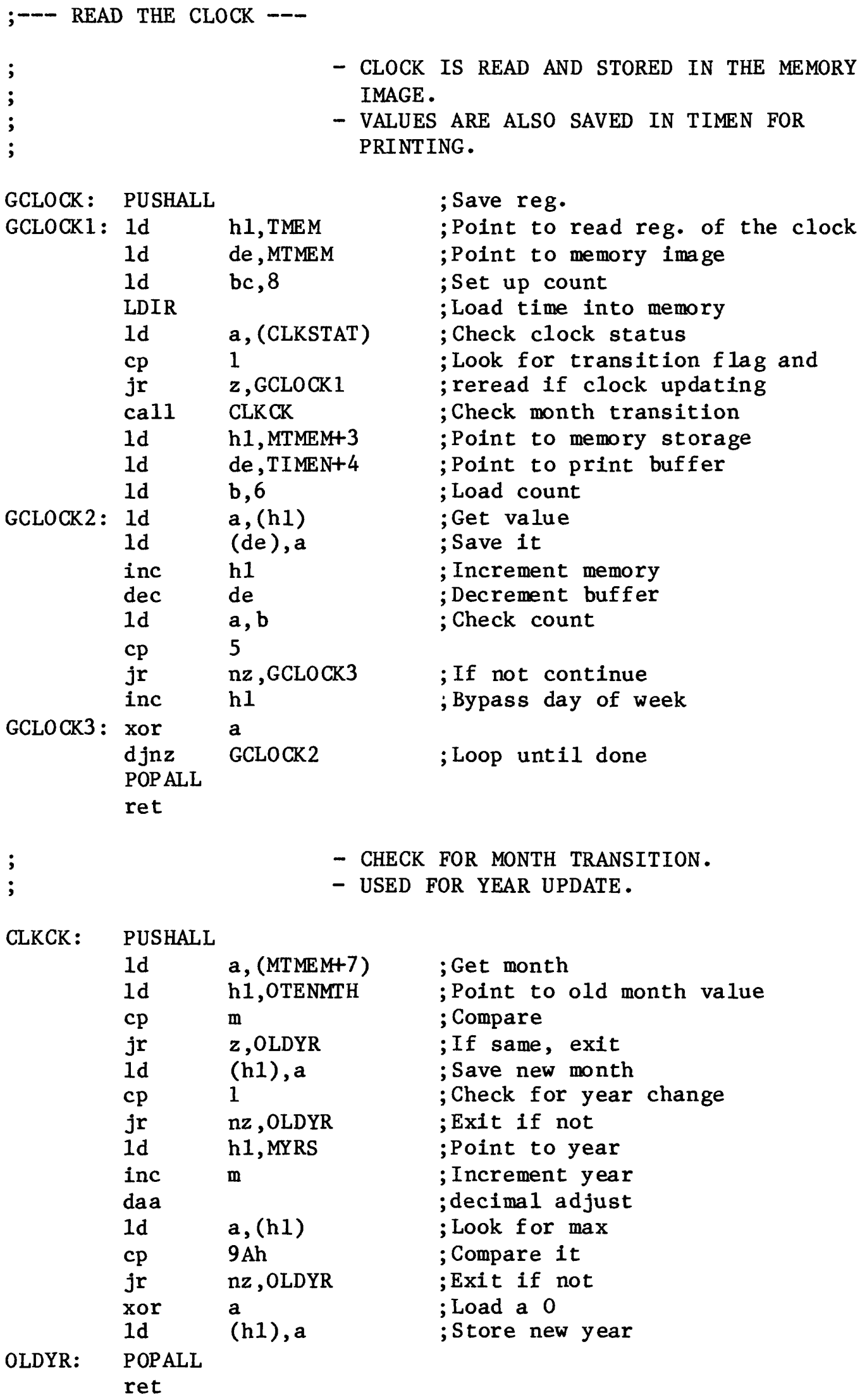




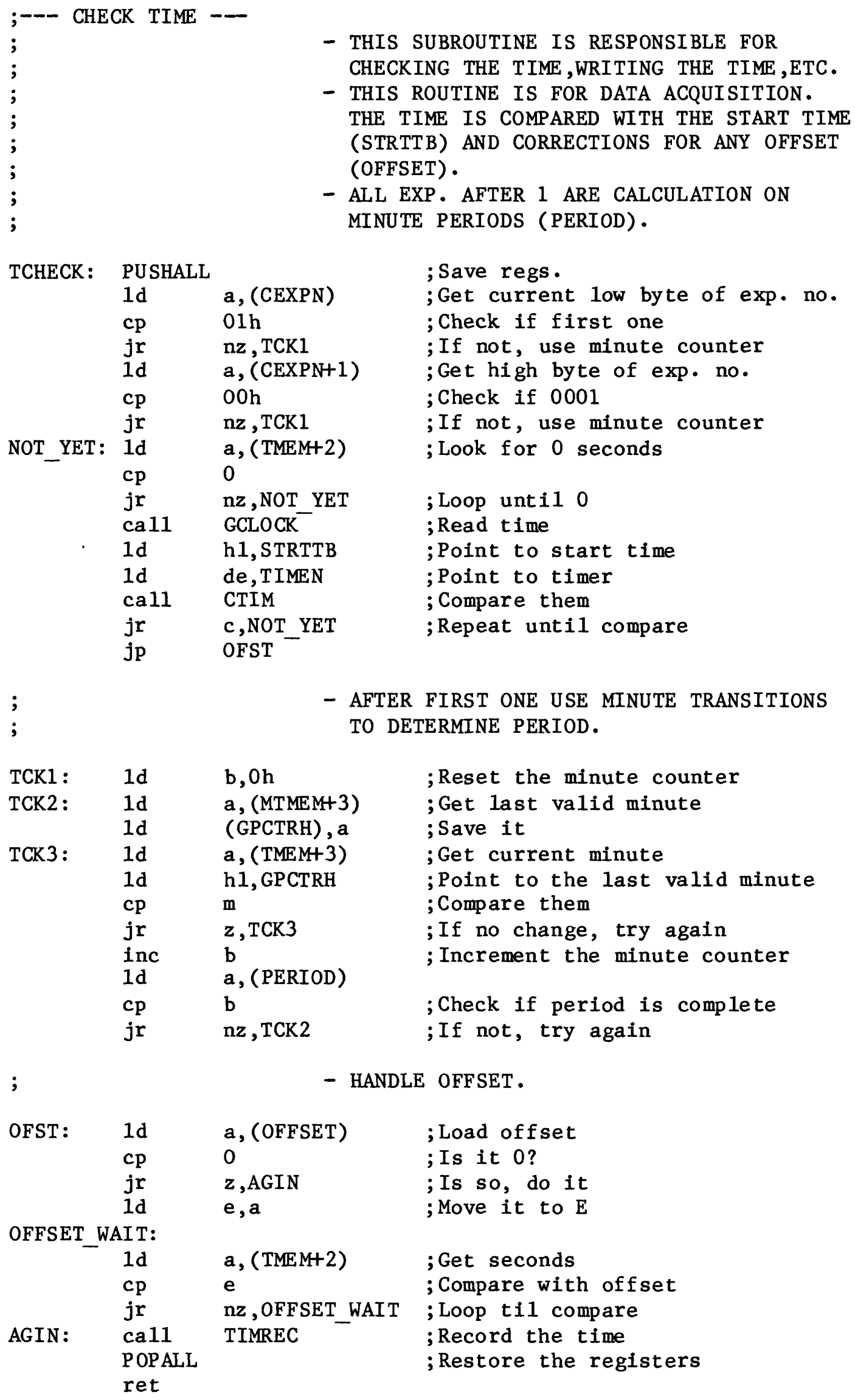




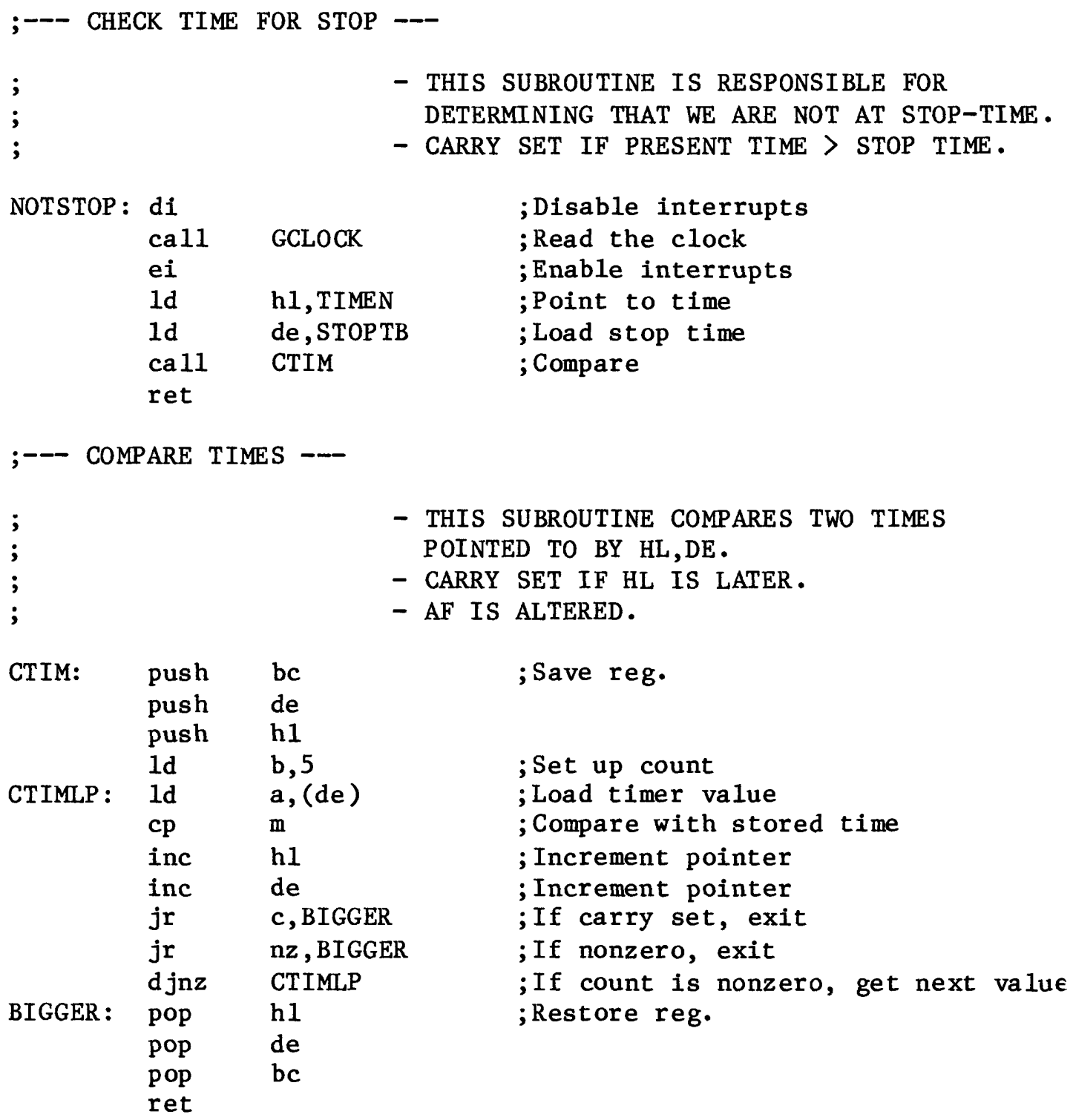




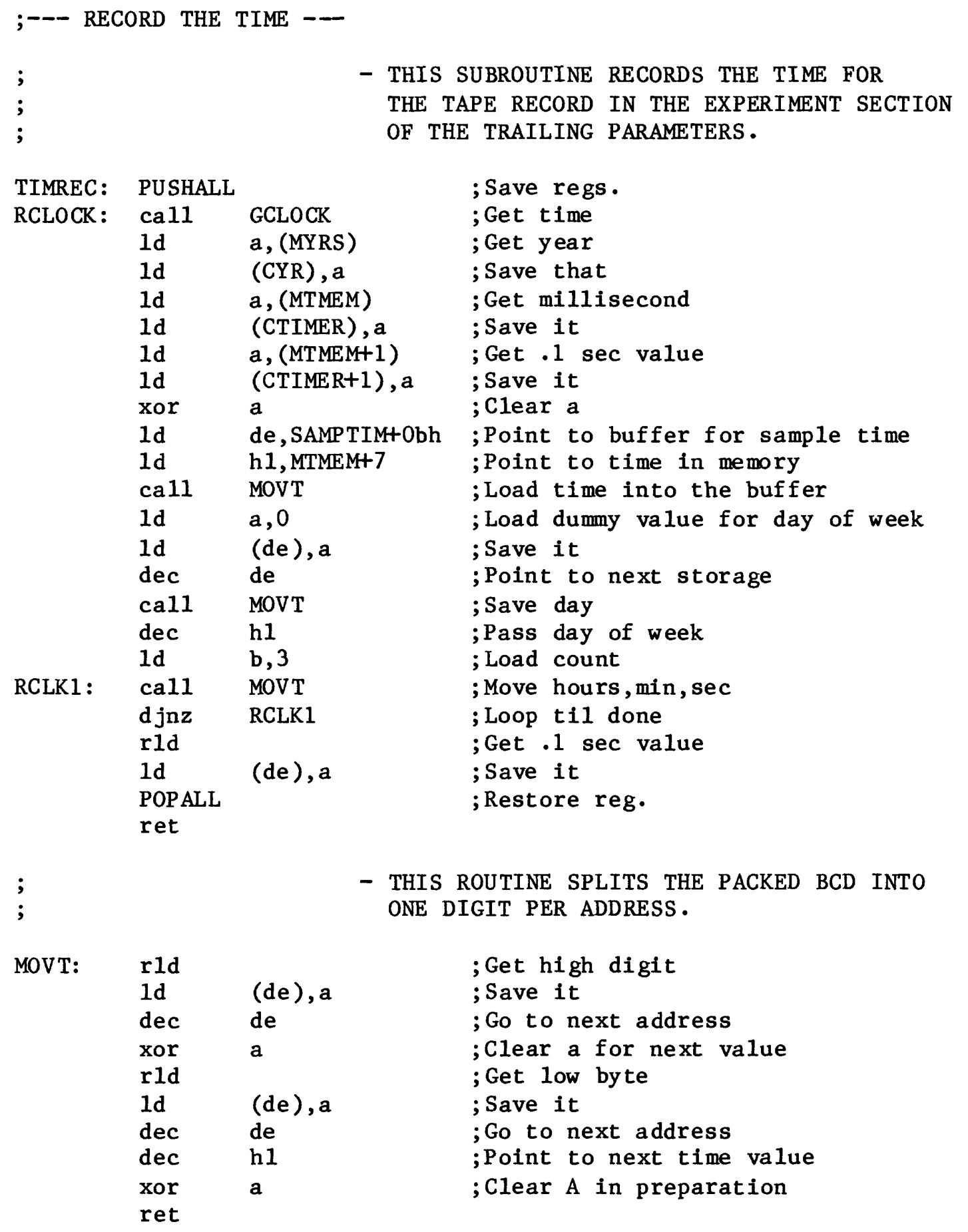


;

TIMOUT: PUSHALL push h1

pop de

inc $h 1$

ca11 PBCD

1d $a, " / "$

call PBYT

inc $\mathrm{h} 1$

cal1 PBCD

1d a, "/"

cal1 PBYT

ex de, hl

call PBCD

ex de, h1

Id $a,-$

ca11 PBYT

inc $h 1$

cal1 PBCD

Id $a,:^{\prime}$

call PBYT

inc $\mathrm{h} 1$

cal1 PBCD

ca11 CRLF

POPALL

ret

;--- PRINT SECONDS ---

SECOUT: PUSHALL

Id $a$, ' $^{-}$

ca11 PBYT

1d h1, MTMEM+2

cal1 PBCD

Id $a,{ }^{\prime} \cdot{ }^{-}$

ca11 PBYT

dec h1

cal1 PBCD

dec hl

cal1 PBCD

POPALL

ret
-THIS SUBROUTINE PRINTS OUT DATE AND TIME.

; Save reg.

; Save $\mathrm{HL}$ in $\mathrm{DE}$

; Increment pointer

; Print value

; Load the separator

;Print it

;Point to next value

;Print it

; Load the separator

;Print it

; Restore HL to year

; Print year

; Restore HL

; Load a space

;Print it

; Point to hour

;Print it

; Load a colon

;Print it

;Point to minutes

;Print it

; Print a carriage return

; Restore reg.
; Load a colon

; Print it

;Point to seconds

;Print it

; Load a decimal point

;Print it

; Point to fractional sec.

;Print it

;Point to milliseconds

; Print it 
;

CLKPRM:

SATNC:

SATC :

SETM:

SYNTM:

YMDHM: $d b$

$d b$

$\mathrm{db}$

$\mathrm{db}$

$d b$

$d b$

$d b$
'HIT RETURN WHEN LESS THAN 1 MINUTE TO GO' CR, LF , 0

'SATELLITE CLOCK NOT CONNECTED',CR,LF,O

'SATELLITE CLOCK CONNECTED', CR,LF,0

'ENTER CURRENT TIME + 1 MINUTE', CR,LF, 0

'SYNCHRONIZING TIMERS', CR,LF, 0

${ }^{-} \mathrm{YR} / \mathrm{MTH} / \mathrm{DAY} / \mathrm{HR} / \mathrm{MIN}^{-}, 0$ 
MACRO SUBROUTINES

; original code written by jhg

; UPDATE - 9/13/85 BCD handling routines were added by gkm

; 
; SEND A MESSAGE TO THE TERMINAL

;

;

- THIS SUBROUTINE MUST BE HERE TO AVOID PROBLEMS WITH MACROS.

SNDMES : push af

MESSND: $1 d$

cp 0

jp $z$,SNDRET

ca11 PBYT

inc $\mathrm{h} 1$

jr

MESSND

SNDRET: pop af

ret

; Get byte at HL.

; Test for terminator.

; Done if 0

; Else print character.

; Point at next.

; and continue.

;--- THESE SUBROUTINES ARE PART OF WPRINT MACRO --

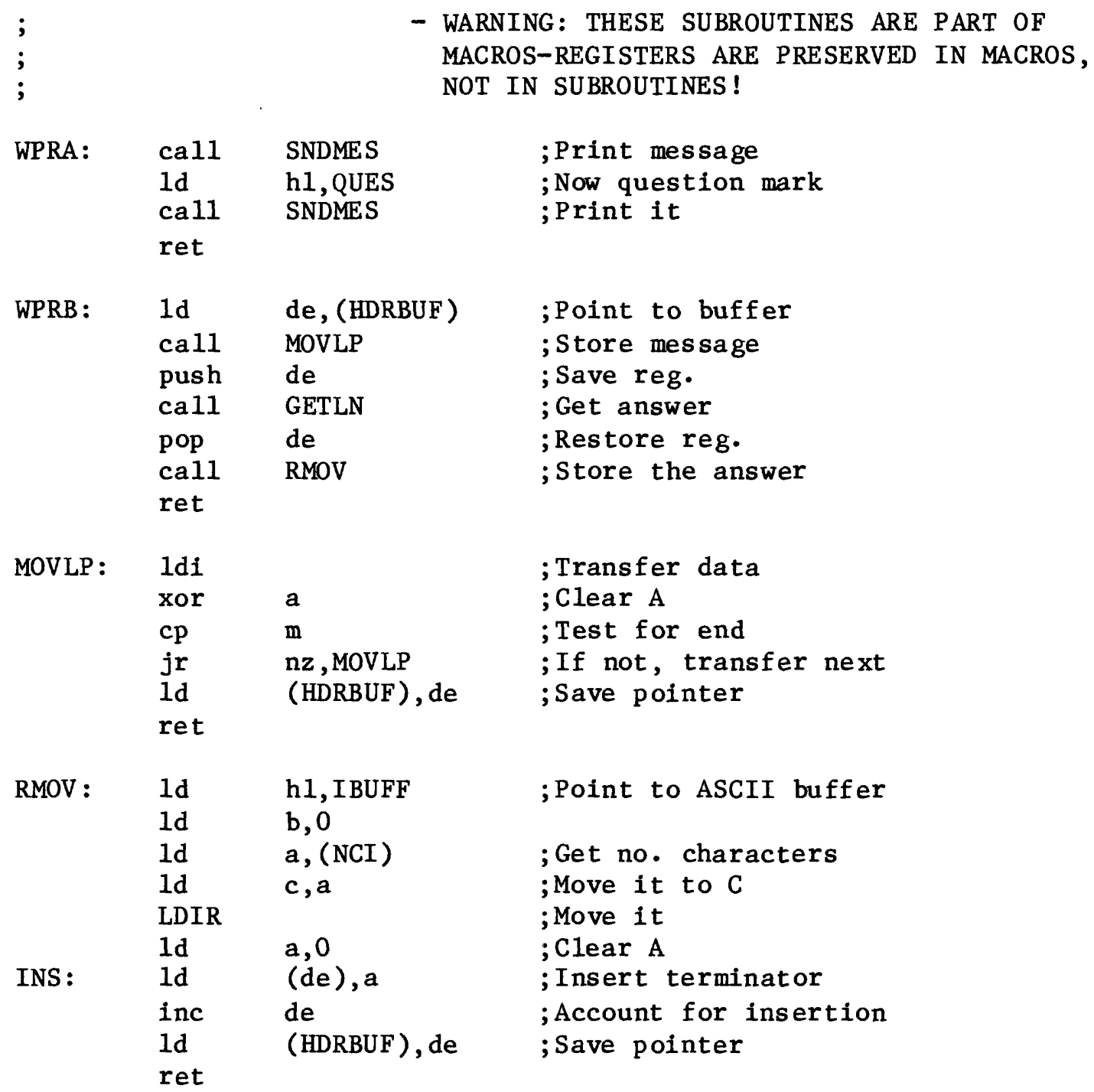


;--- DELAY ENTRY ---

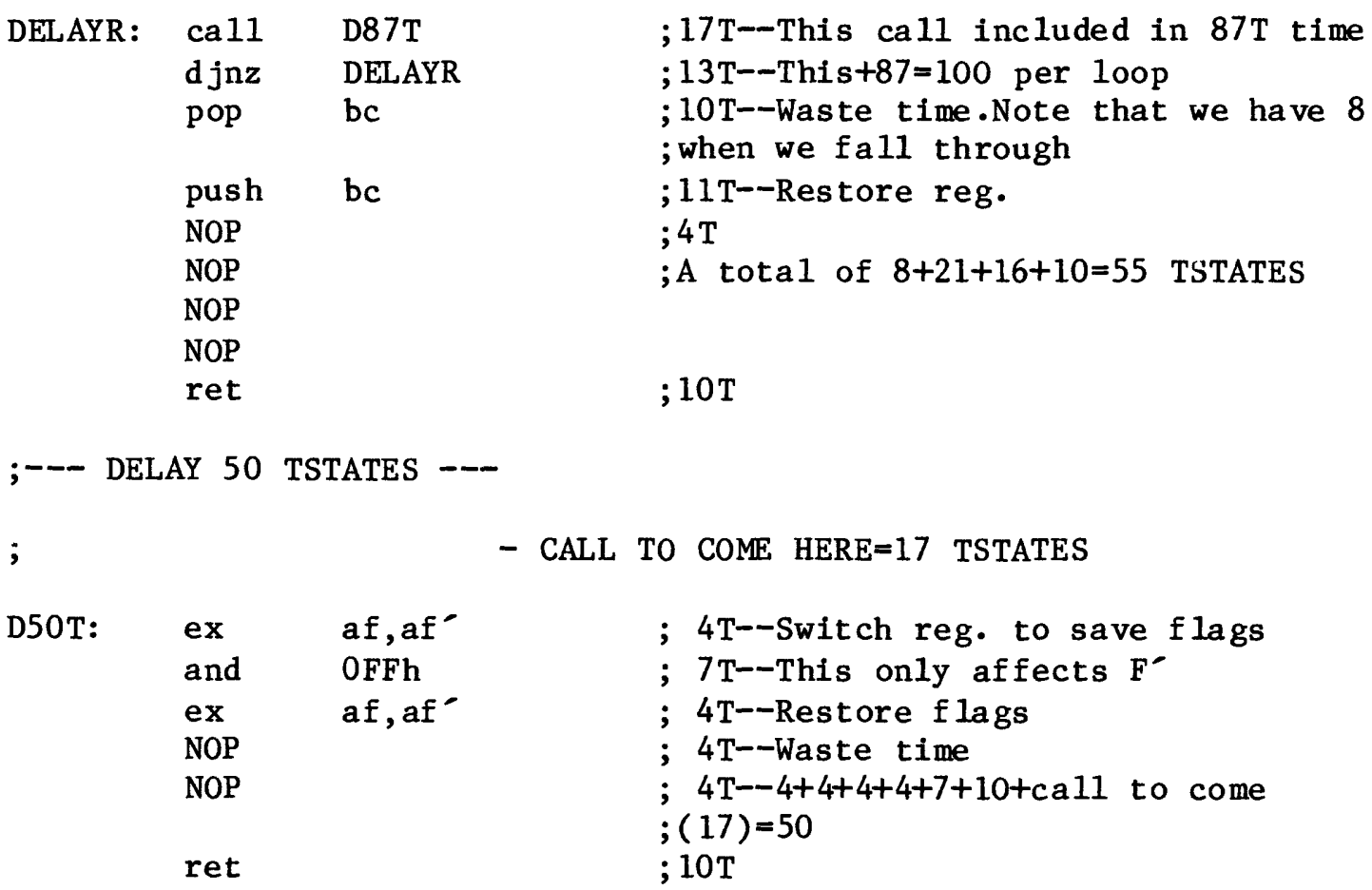

;--- 87 TSTATE DELAY ---

;

$\begin{array}{lll}\text { D87T: } & \text { jp } & \text { D77T } \\ \text { D77T: } & \text { jp } & \text { D67T } \\ \text { D67T: } & \text { jp } & \text { D57T } \\ \text { D57T: } & \text { jp } & \text { D47T } \\ \text { D47T: } & \text { jp } & \text { D37T } \\ \text { D37T: } & \text { jp } & \text { D27T } \\ \text { D27T: } & \text { ret } & \end{array}$

- CALL TO COME HERE=17 T

;10T--waste time ; 10T--here down=77 including the ; call in 10T--and so on.

; 10T--NOTE THAT THIS FITS WELL ; WITH DJNZ WHICH IS 13T

\footnotetext{
;--- 100 TSTATE DELAY ---

;

$\begin{array}{lll}\text { D100T: } & \text { call } & \text { D50T } \\ \text { ex } & \text { af, af } \\ \text { and } & \text { OFFh } \\ \text { ex } & \text { af, af } \\ \text { NOP } & \\ \text { NOP } & \\ \text { ret } & \end{array}$
}

- CALL TO COME HERE $=17 \mathrm{~T}$

; Call is included in 50T's timing ; Same tricks as in 50T 


$$
\text { ; }
$$$$
\text { ;--- DIVIDE ROUTINE -- }
$$

\begin{tabular}{|c|c|c|}
\hline ; & & - \\
\hline ; & & - \\
\hline ; & & - \\
\hline ; & & - \\
\hline \multirow[t]{4}{*}{ DIV IDE : } & or & \multirow{4}{*}{$\begin{array}{l}\mathrm{a} \\
\mathrm{nz}, \mathrm{OKTODV}\end{array}$} \\
\hline & $j r$ & \\
\hline & $\operatorname{scf}$ & \\
\hline & ret & \\
\hline \multirow[t]{3}{*}{ OKTODV : } & $1 d$ & \multirow{2}{*}{$\begin{array}{l}c, a \\
b, 16\end{array}$} \\
\hline & $1 d$ & \\
\hline & xor & a \\
\hline \multirow[t]{7}{*}{ DLOOP : } & sla & e \\
\hline & r 1 & d \\
\hline & r1 & $\mathbf{a}$ \\
\hline & $c p$ & c \\
\hline & jr & $c$, NOINC \\
\hline & inc & e \\
\hline & sub & C \\
\hline NOINC: & $\begin{array}{l}\text { djnz } \\
1 \mathrm{~d}\end{array}$ & $\begin{array}{l}\text { DLOOP } \\
b, a\end{array}$ \\
\hline
\end{tabular}

- DIVISOR=ACC

- DE=DIVIDEND

- ANSWER IN DE,CARRY SET IF /O

- REMAINDER IN B

NOINC2 : ret

; Check for 0

; If not divide

; Set carry flag

; Move divisor

; Count $=$ number of bits in divisor

; Clear A

; Shift contents left

; Same

; Same

; Divide compare

; If not greater, no increments

; Increment number

; Subtract the divisor from A

; Continue until $\mathrm{B}=0$

; Save remainder in $A$

;--- CONVERT TO PACKED BCD

$$
\text { ; }
$$

- CONVERTS THE BYTE POINTED TO BY HL TO PACKED BCD.

- IF THE BYTE IS BIGGER THAN 99 DECIMAL, THEN CARRY IS SET.

$\begin{array}{lll}\text { HTBCD : } & \text { push } & \text { bc } \\ & \text { push } & \text { af } \\ \text { ld } & \text { b, m } \\ & \text { xor } & \text { a } \\ \text { cp } & \text { b } \\ & \text { jr } & \text { z, HTRET } \\ & \text { xor } & a \\ \text { BCDL : } & \text { inc } & \text { a } \\ & \text { daa } & \\ \text { LT99: } & \text { jr } & c, \text { HTRET } \\ & \text { djnz } & \text { BCDL } \\ \text { HTRET: } & \text { pop } & \text { m, a } \\ & \text { pop } & \text { af } \\ & \text { ret } & \end{array}$

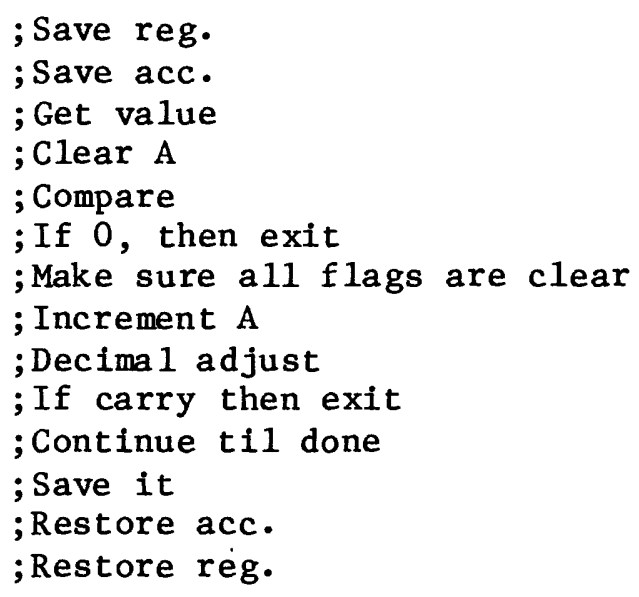




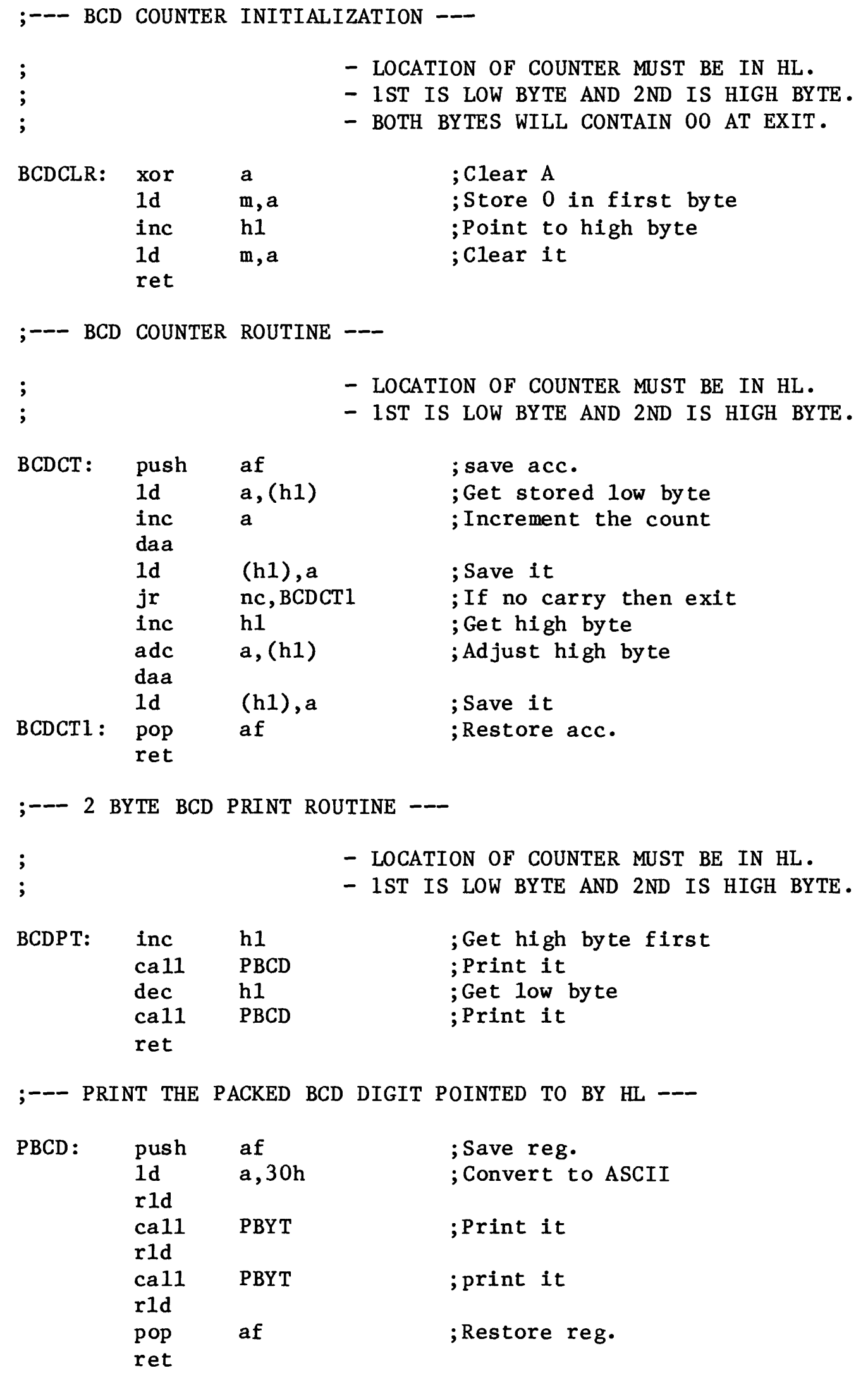

;

- LOCATION OF COUNTER MUST BE IN HL.

- 1ST IS LOW BYTE AND 2ND IS HIGH BYTE.

- BOTH BYTES WILL CONTAIN OO AT EXIT.

ret

;--- BCD COUNTER ROUTINE ---

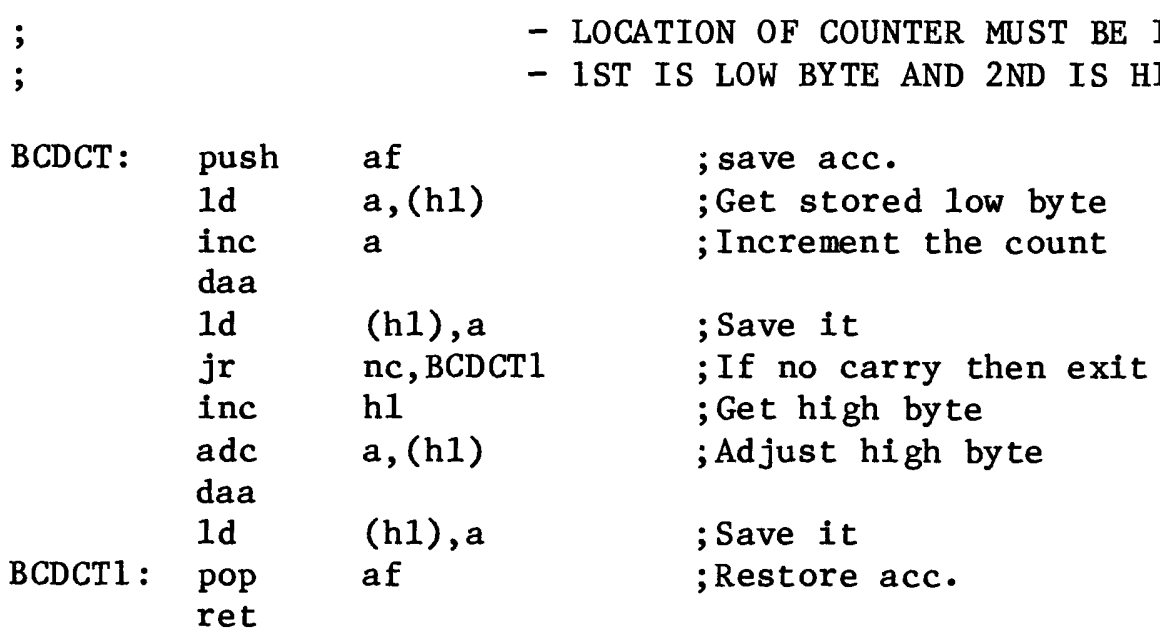

;--- 2 BYTE BCD PRINT ROUTINE ---

\begin{tabular}{|c|c|c|c|}
\hline ; & & & $\begin{array}{l}\text { - LOCATION OF COUNTER MUST BE IN HL. } \\
\text { - 1ST IS LOW BYTE AND 2ND IS HIGH BYTE. }\end{array}$ \\
\hline BCDPT: & $\begin{array}{l}\text { inc } \\
\text { ca11 } \\
\text { dec } \\
\text { cal1 }\end{array}$ & $\begin{array}{l}\text { h1 } \\
\text { PBCD } \\
\text { h1 } \\
\text { PBCD }\end{array}$ & $\begin{array}{l}\text {; Get high byte first } \\
\text {; Print it } \\
\text {; Get low byte } \\
\text {; Print it }\end{array}$ \\
\hline
\end{tabular}

;--- PRINT THE PACKED BCD DIGIT POINTED TO BY HL --

$\begin{array}{llll}\text { PBCD : } & \text { push } & \text { af } & \text {; Save reg. } \\ \text { 1d } & \text { a,30h } & \text {; Convert to ASCII } \\ \text { rld } & & \\ \text { call } & \text { PBYT } & \text {;Print it } \\ \text { rld } & & \text {; print it } \\ \text { ca11 } & \text { PBYT } & \\ \text { rld } & & \text {; Restore reg. } \\ \text { pop } & \text { af } & \end{array}$




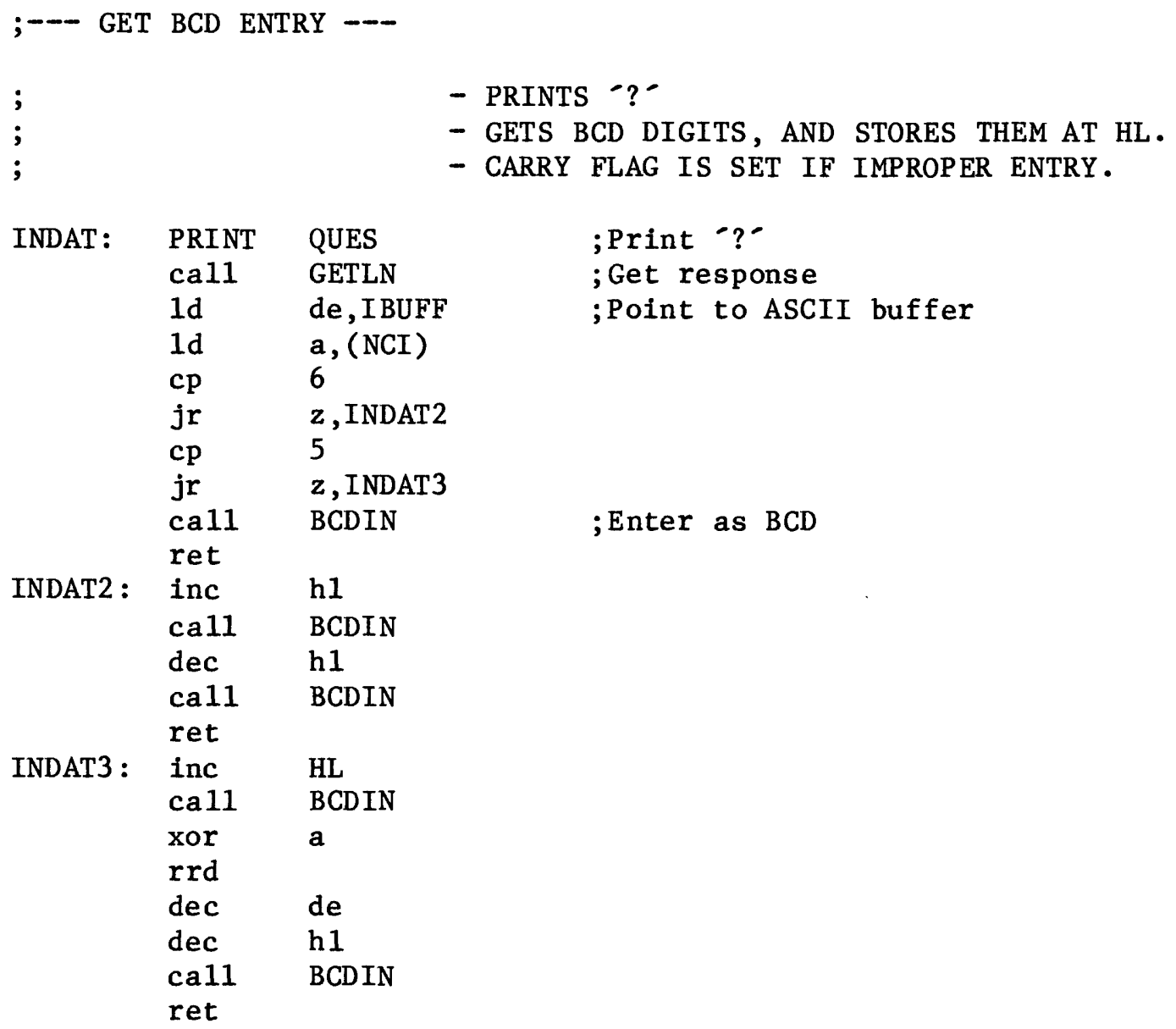




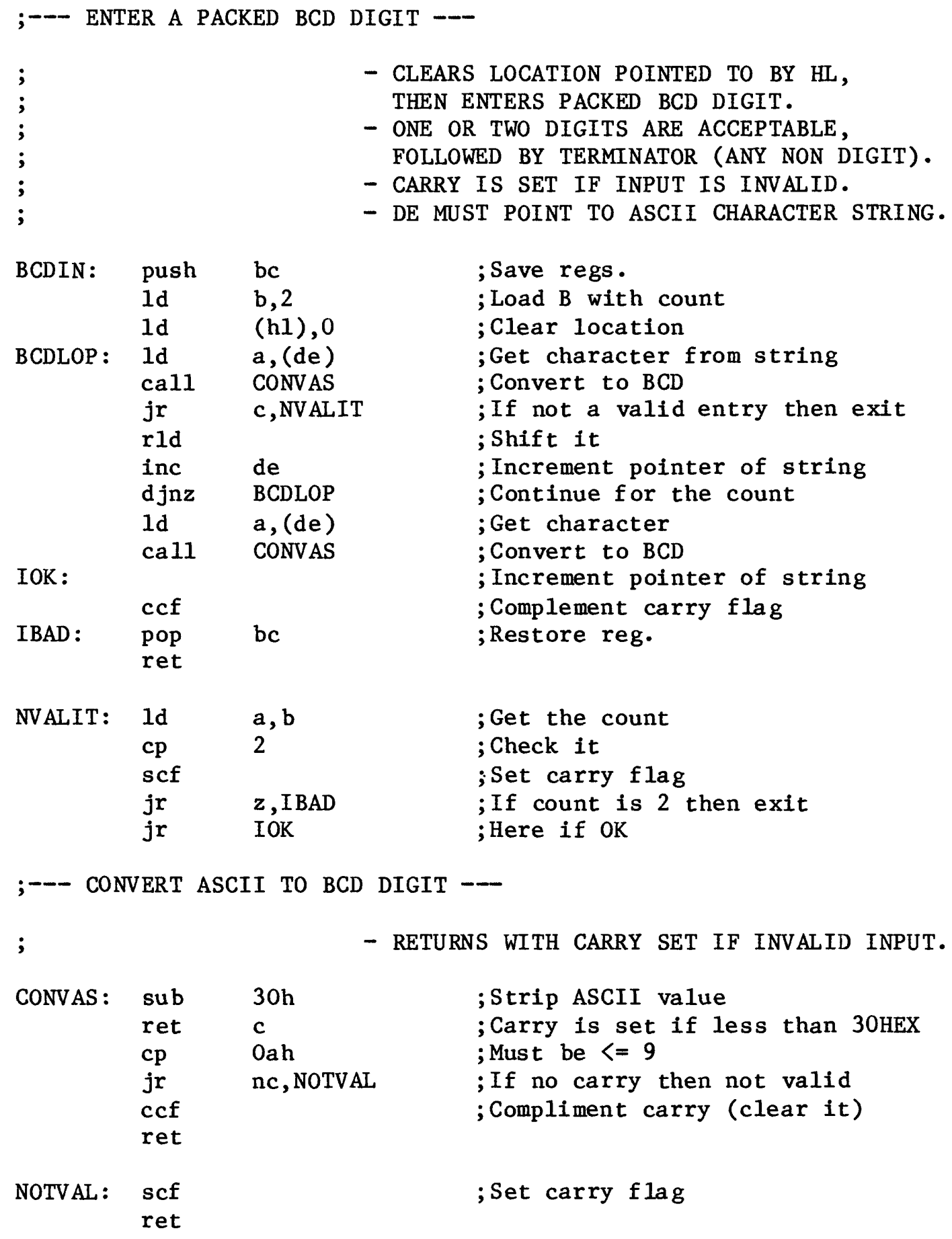


;--- COMPARE TWO BCD NUMBERS --

;

- ENTRY REQUIRES HL POINT TO HIGH BYTE.

- CARRY IS SET IF CONTENTS OF HL EXCEED DE.

\begin{tabular}{|c|c|c|c|}
\hline \multirow[t]{5}{*}{$\mathrm{BCDCP}:$} & $1 d$ & $a,(d e)$ & \\
\hline & ret & & $\begin{array}{l}\text {; Compare byte } \\
\text {; If no compare then exit }\end{array}$ \\
\hline & dec & & ; Get low byte \\
\hline & $1 d$ & $a,(d e)$ & \\
\hline & $\begin{array}{l}\mathrm{cp} \\
\text { ret }\end{array}$ & (h1) & ; If larger carry is set \\
\hline
\end{tabular}


TERMINAL ROUTINES

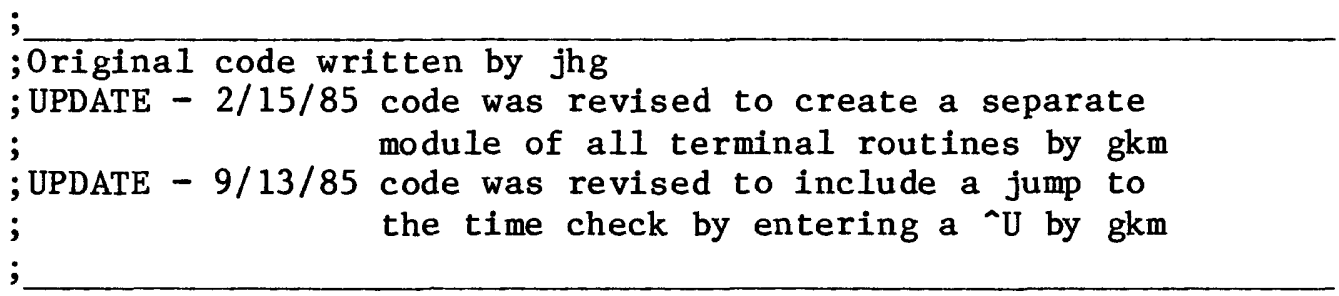


;-- GET BYTE AND ECHO IF ACC=0 ---

$\begin{array}{lll}\text { GBYTNE : } & \text { 1d } & \mathrm{a}, 1 \\ & \text { jr } & \mathrm{NE} \\ \text { GBYT: } & \text { ld } & \mathrm{a}, 0 \\ \text { NE: } & \text { push } & \mathrm{bc} \\ & \text { push } & \text { af } \\ \text { FRAMERR: } & \text { 1d } & \mathrm{b}, 8\end{array}$

; No echo

; Jump over echo

; Echo entry

; No echo entry

; Save reg.

$\mathrm{b}, 8$

; Set index for no. of bits input.

- WE MUST DETECT THE BEGINNING OF THE START BIT-SO THE FIRST STEP IS TO MAKE SURE THAT IT HAS NOT BEGUN!

MARK : $\quad 1 d$

a, (PBDATA)

; Get input and make sure it is ; a mark

rla

jp nc, MARK

; Input to carry(IS INVERTED)

; Wait till mark

;

- NOW GET TRANSITION

GTSTRT: $\quad 1 d$

rla

a, (PBDATA)

; 13T-- Look for start bit.

jp

$c$, GTSTRT

; 4T-- Move to carry flag.

;10T-- IF start bit not present

; THEN go back and look again.

- MAXIMUM ERROR IN START BIT TIME IS 27 T-STATES .

- FOR THIS SYSTEM THE CLOCK IS $1.0486 * 10^{\wedge} 6$

- AND THE NO. OF T-STATES IN ONE BIT TIME FOR COMMON BAUD RATES ARE:

$\begin{array}{lr}9600 & 109.23 \text { T-STATES } \\ 4800 & 218.46 \\ 2400 & 436.92 \\ 1200 & 873.83 \\ 300 & 3495.30\end{array}$

- FOR NOW, RUNNING AT 1200 BAUD, FIXED.

- 1/2 BIT TIME = 437 TSTATES FOR ALL INTENTS AND PURPOSES.

- WE NOW HAVE A HYPOTHETICAL START BIT.

- SO NOW WAIT 1/2 BIT TIME AND SEE IF IT IS STILL THERE.

- TIME NOW=TRANSITION+14 T.

$\begin{array}{ll}\text { DELAY } & 4 \\ \text { jp } & \text { CHSTRT }\end{array}$

$$
\begin{aligned}
& \text {; Delay } 400 \text { TSTATES } \\
& \text {; 10T }
\end{aligned}
$$

- TIME NOW=TRANS .+424T(13T TO READ LINE MAKES 437). 


\begin{tabular}{|c|c|c|}
\hline CHSTRT: & $\begin{array}{l}1 d \\
\text { rla } \\
\text { jp }\end{array}$ & $\begin{array}{l}\text {; } 13 \mathrm{~T}-\text { - Look for start bit again. } \\
; 4 \mathrm{~T}-- \text { Move it to carry flag. } \\
\text {;10T-- IF start bit is gone, } \\
\text {; TRY AGAIN }\end{array}$ \\
\hline $\begin{array}{l}; \\
; \\
; \\
; \\
;\end{array}$ & & $\begin{array}{l}\text { - PREPARE TO ECHO START BIT. } \\
\text { - TIME IS } 451 \text { TSTATES AFTER START BIT } \\
\text { EDGE DETECTED. } \\
\text { - WE WILL NOW NEED TO DELAY ABOUT } 1 \text { BIT } \\
\text { TIME SO THAT WE CONTINUE TO HIT THE } \\
\text { MIDDLE OF EACH BIT AND SO THAT THE BITS } \\
\text { WE ECHO ARE THE RIGHT LENGTH. }\end{array}$ \\
\hline & $\begin{array}{l}1 \mathrm{~d} \\
\text { call } \\
1 \mathrm{~d} \\
\text { call }\end{array}$ & $\begin{array}{ll}\text { a }, 1 & ; 7 \mathrm{~T}-- \text { Prepare A as start bit } \\
\text { D50T } & ; 50 \mathrm{~T}-- \text { Delay } 50 \mathrm{~T} \text { states } \\
\text { (PBSETB), a } & ; 13 \mathrm{~T}-- \text { and send it.(NO LONGER) } \\
\text { D27T } & ; 27 \mathrm{~T}-- \text { Wait } 27 \mathrm{~T}\end{array}$ \\
\hline ; & & $\begin{array}{l}\text { - TIME IS NOW } 111 \text { T-STATES AFTER MIDDLE } \\
\text { OF BIT } 763 \text { TO GO BEFORE WE READ NEXT,847 } \\
\text { (IDEALLY) BEFORE NEXT ECHO. }\end{array}$ \\
\hline XMIT: & $\begin{array}{l}\text { DELAY } \\
\text { call }\end{array}$ & $\begin{array}{l}\text {; Delay } 700 \text { T-STATES } \\
\text {; Delay } 50 \text { more }\end{array}$ \\
\hline ; & & $\begin{array}{l}\text { - 763-750=13 WHICH IS HOW LONG IT TAKES } \\
\text { TO READ. }\end{array}$ \\
\hline & $\begin{array}{l}1 d \\
\text { rlca } \\
\text { rr } \\
\text { and } \\
1 d \\
\text { NOP } \\
\text { NOP }\end{array}$ & $\begin{array}{l}\text {; } 13 \mathrm{~T} \text { Get receive bit } 7 \text { in } \mathrm{A} . \\
; 84 \mathrm{~T} \text { to echo } \\
; 4 \mathrm{~T} \text { Rotate into carry flag+BIT } 0 \\
; 8 \mathrm{~T} \text { then into C. } \\
\text {; } 7 \mathrm{~T} \text { Mask other bits and set flags } \\
\text {; for test } \\
\text {; } 7 \mathrm{~T} \text { Prepare A to set/reset line. } \\
\text {; Flags unaltered from AND above } \\
\text {; } 8 \text { more to add }\end{array}$ \\
\hline ; & & $\begin{array}{l}\text { - } 50 \text { T-STATES TO GO .LESS 13T TO DO IT } \\
\text { AND 10T FOR THE JUMP LEAVES } 27 .\end{array}$ \\
\hline & $\begin{array}{l}\text { cal1 } \\
\text { jp }\end{array}$ & $\begin{array}{l}; 27 \mathrm{~T} \text { delay } \\
; 10 \mathrm{~T} \text { test flag and goto } \\
\text {; appropriate echo }\end{array}$ \\
\hline
\end{tabular}


- THESE ROUTINES NO LONGER DO AN ECHO-LEFT HERE FOR TIMING (IF ECHO DESIRED PLEASE RESTORE PBCLRB WHERE APPROPRIATE).

- ECHO A ONE.NOTE THAT BOTH INPUT AND OUTPUT ARE INVERTED SO THAT THIS IS REALLY A ZERO.

\begin{tabular}{|c|c|c|}
\hline GTSETB: & $\begin{array}{l}\text { ld } \\
\text { jp }\end{array}$ & $\begin{array}{l}; 13 \mathrm{~T} \text { set output high } \\
\text {; 10T and continue, keep timing } \\
\text {; the same }\end{array}$ \\
\hline $\begin{array}{l}; \\
;\end{array}$ & & $\begin{aligned} & \text { - } 23 \text { T-STATES FOR THIS BRANCH. } \\
& \text { - THESE ROUTINES NO LONGER DO AN ECHO-- } \\
& \text { LEFT HERE FOR TIMING (IF ECHO DESIRED } \\
& \text { PLEASE RESTORE PBCLRB WHERE APPROPRIATE). }\end{aligned}$ \\
\hline GTCLRB : & $\begin{array}{l}1 d \\
j p\end{array}$ & $\begin{array}{ll}\text { (PBSETB), a } & ; 13 \mathrm{~T} \text { Set output low } \\
\text { GTREST } & ; 10 \mathrm{~T} \text { and keep timing constant. }\end{array}$ \\
\hline $\begin{array}{l}; \\
; \\
; \\
; \\
; \\
;\end{array}$ & $\begin{array}{l}\text { NOP } \\
\text { djnz }\end{array}$ & 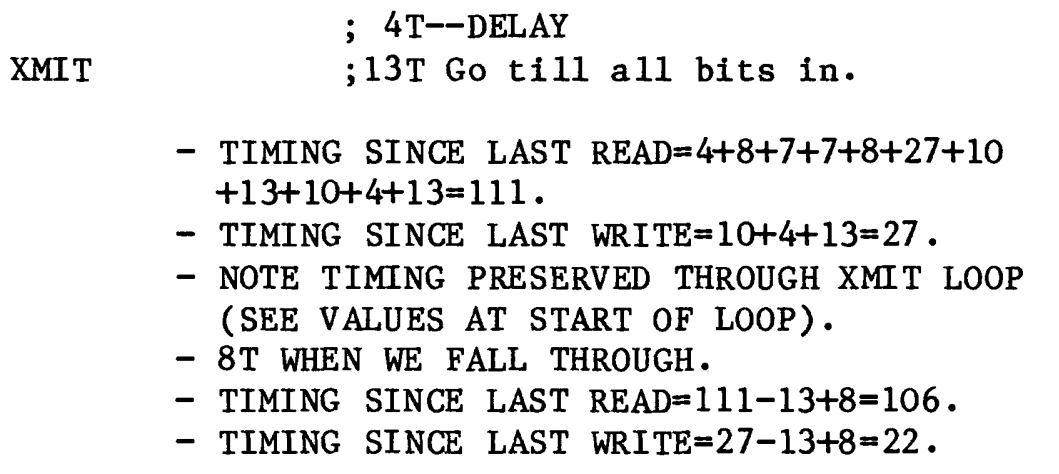 \\
\hline & $\begin{array}{l}\text { DELAY } \\
\text { cal1 } \\
\text { NOP } \\
\text { NOP }\end{array}$ & $\begin{array}{l}7 \\
\mathrm{D} 47 \mathrm{~T}\end{array}$ \\
\hline ; & & $\begin{array}{l}\text { - TIMING }=755+106=861 \text { SINCE LAST READ }(+13 \\
\text { FOR READ }=874) \text {. } \\
\text { - TIMING }=755+22=777 \text { SINCE LAST WRITE. }\end{array}$ \\
\hline & $\begin{array}{l}1 d \\
\text { rla } \\
\text { jp }\end{array}$ & $\begin{array}{ll}\text { a, (PBDATA) } & ; 13 \mathrm{~T} \text { Get receive bit } 7 \text { in } \mathrm{A} . \\
& ; 4 \mathrm{~T} \text { to carry } \\
\text { nc, FRAMERR } & ; 10 \mathrm{~T} \text { Framing error if not a stop } \\
& ; \mathrm{bit}\end{array}$ \\
\hline
\end{tabular}




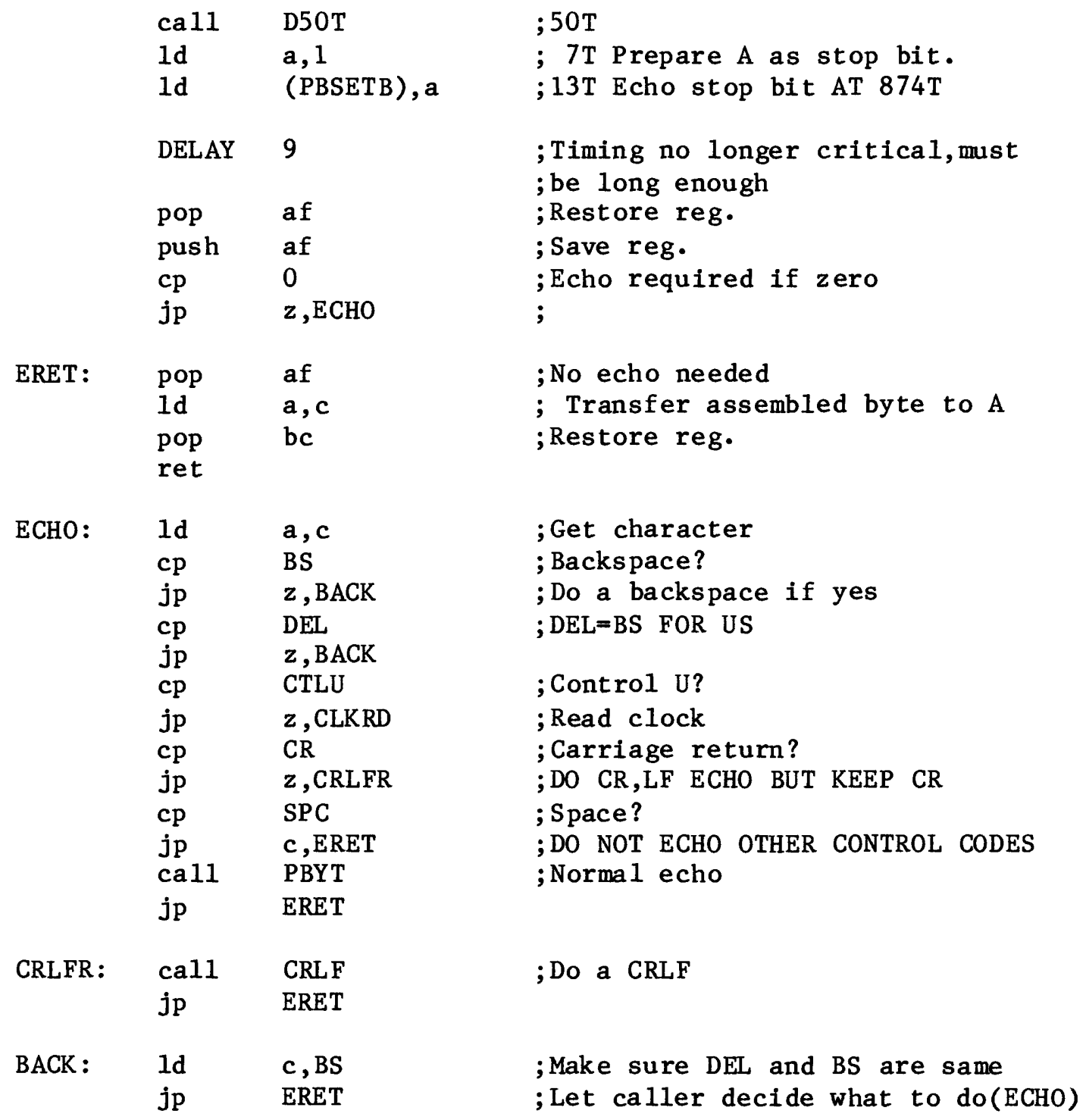




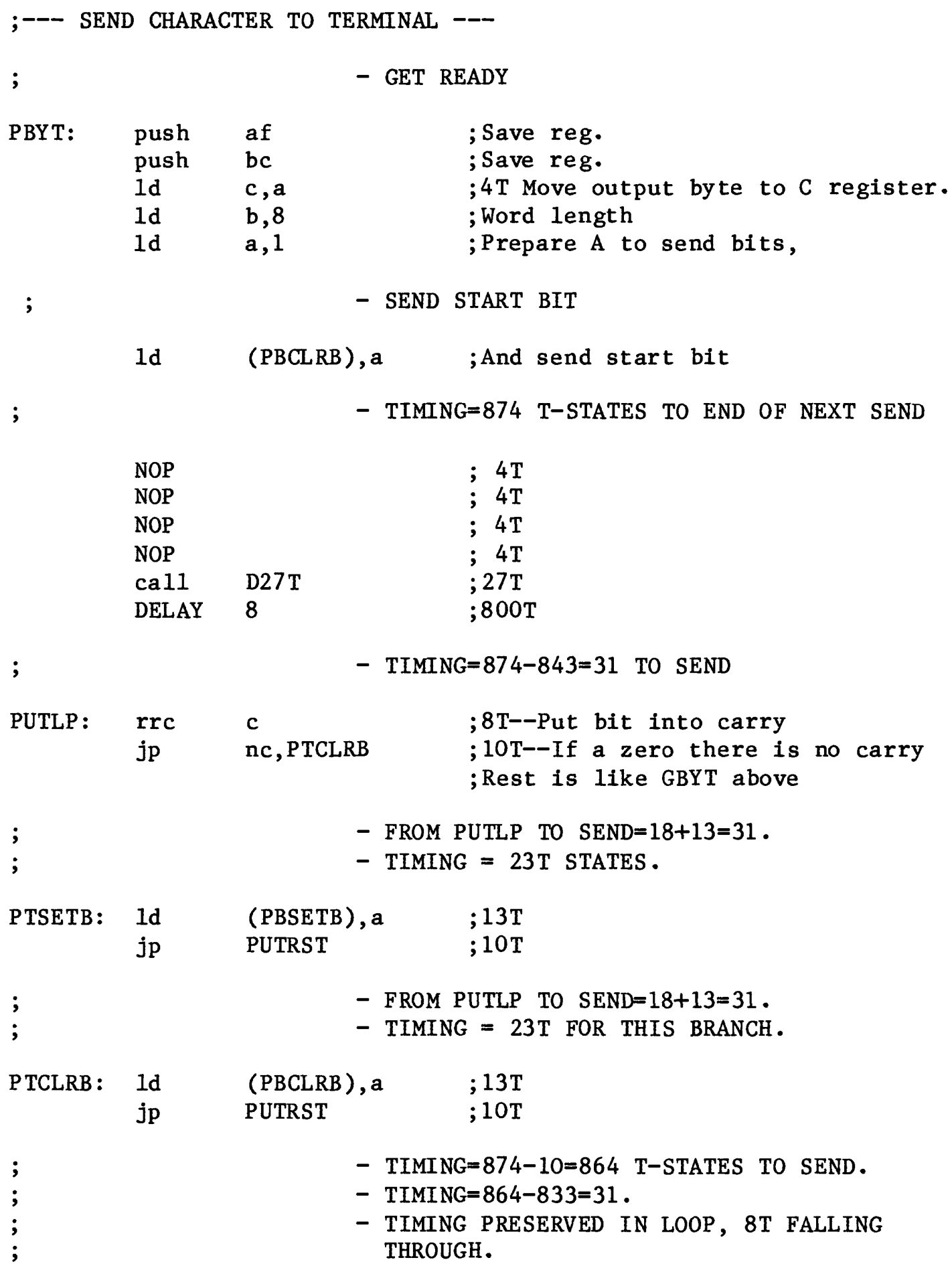




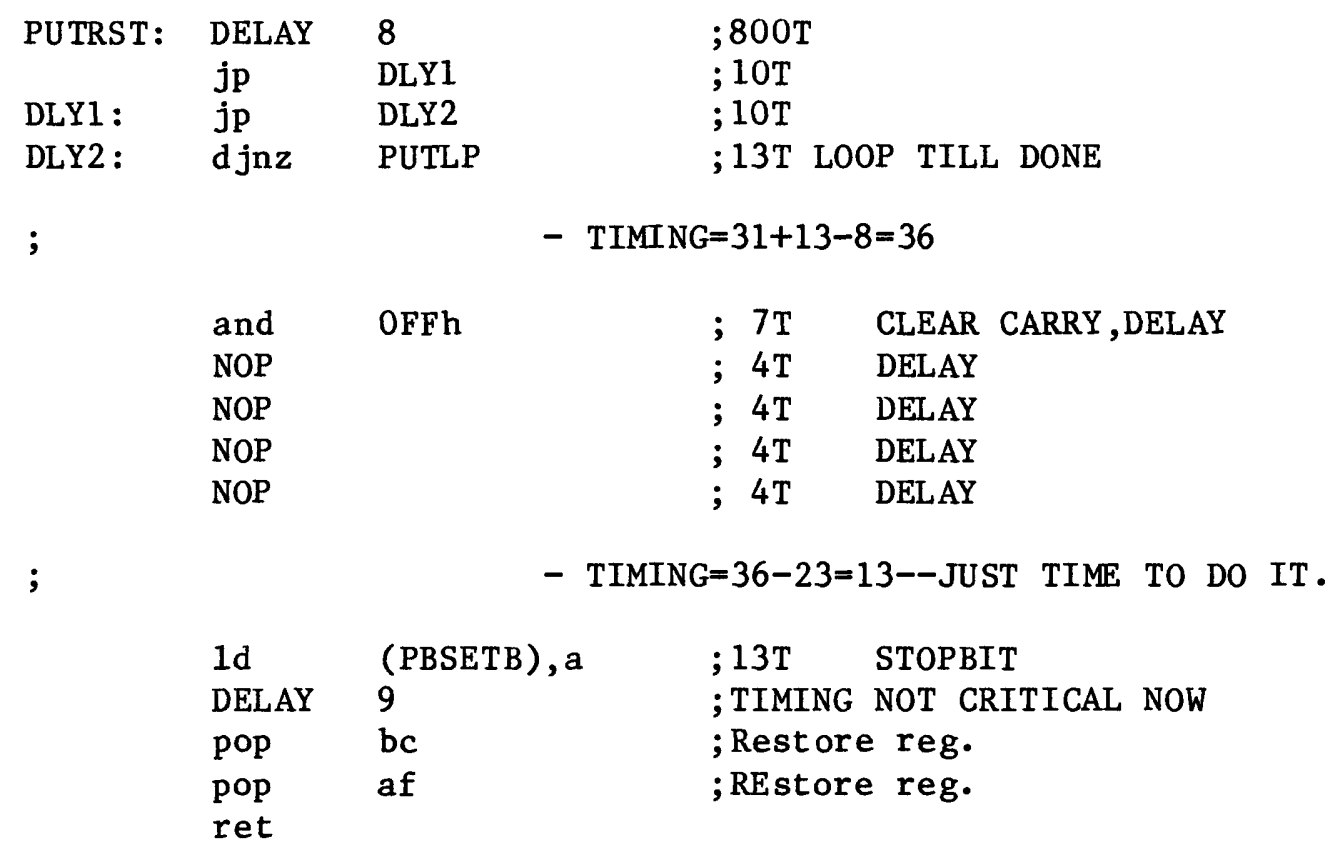

;--- BACK SPACE AND ERASE ROUTINE---

$\begin{array}{llll}\text { BSPCR }: & \text { 1d } & \text { a,BS } & \text {; BS/SPC/BS } \\ \text { cal1 } & \text { PBYT } & \text {;Print it } \\ \text { 1d } & \text { a,SPC } & \text {; Get space } \\ \text { call } & \text { PBYT } & \text {;Print it } \\ \text { 1d } & \text { a, BS } & \text {; Get backspace } \\ \text { call } & \text { PBYT } & \text {;Print it } \\ \text { ret } & & \end{array}$

;--- SEND A CARRIAGE RETURN LINE FEED TO TERMINAL --

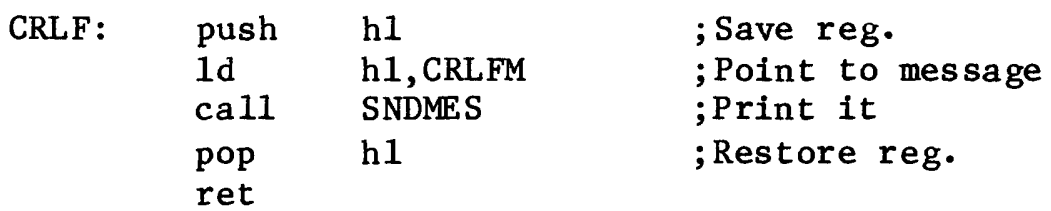

;--- PAUSE BEFORE CLEARING SCREEN ---

$\begin{array}{llll}\text { CONT: } & \text { PRINT } & \text { CONTIN } & \text {; Print continue message } \\ \text { call } & \text { GBYTNE } & \text {; Look for key } \\ & & & \end{array}$


GETLN: PUSHALL

\begin{tabular}{|c|c|c|}
\hline \multirow[t]{3}{*}{ GLN1 : } & $1 d$ & h1, IBUFF \\
\hline & $1 d$ & $c, 0$ \\
\hline & $1 d$ & $\mathrm{~b}, \mathrm{MAXB}$ \\
\hline \multirow[t]{11}{*}{ GLN2 : } & cal1 & GBYT \\
\hline & $c p$ & BS \\
\hline & jp & $\mathrm{nz}$, NOBS \\
\hline & $1 d$ & $a, b$ \\
\hline & cp & MAXB \\
\hline & jp & z, GLN1 \\
\hline & ca11 & BSPCR \\
\hline & inc & b \\
\hline & dec & c \\
\hline & dec & h1 \\
\hline & jr & GLN2 \\
\hline \multirow[t]{8}{*}{ NOBS : } & $c p$ & CTLX \\
\hline & jp & $z$, CTLXR \\
\hline & $c p$ & CTLU \\
\hline & jp & $\mathrm{z}$, CLKRD \\
\hline & $\mathrm{cp}$ & CR \\
\hline & $j r$ & $z$, NOTST \\
\hline & $c p$ & SPC \\
\hline & $j r$ & $\mathrm{c}$, GLN2 \\
\hline
\end{tabular}

NOTST: 1

inc $h \mathrm{l}$

inc $c$

cp $\quad \mathrm{CR}$

jp $\quad z$,GLEND

djnz GLN2

jp CTLXR

GLEND: 18

inc $c$

1d $a, c$

1d (NCI), a

POPALL

ret

CTLXR: $\quad 1 \mathrm{~d}$

cp

jr

1d

BLOOP : $\quad$ cal1

djnz

jr a, c

0

z, GLN1

$\mathrm{b}, \mathrm{c}$

BLOOP

GLN1
BSPCR
; ASCII input buffer

; No. of characters

; Get max buffer length

; Get character

; Backspace?

; NO

; Compare size

; Ignore at beginning

; Backs pace

; Restore character count

; No. of characters

; Try again

; CONTROL X?

; Do it if so

;CONTROL U?

; Read clock

; Carriage return?

; Space?

; NO OTHER CONTROL CHARACTERS

; RECOGNIZED

; Store character

; Increase pointer

; Increase character count

; Look for carriage return

; DONE SO EXIT PROPERLY

; Get next

; INPUT TOO LONG,MUST BE ERROR

; Add line feed

; Inc. character count

; Save it

; Restore reg.

; Get character count

; Check if zero

; If so, no action needed

; Clean up screen 


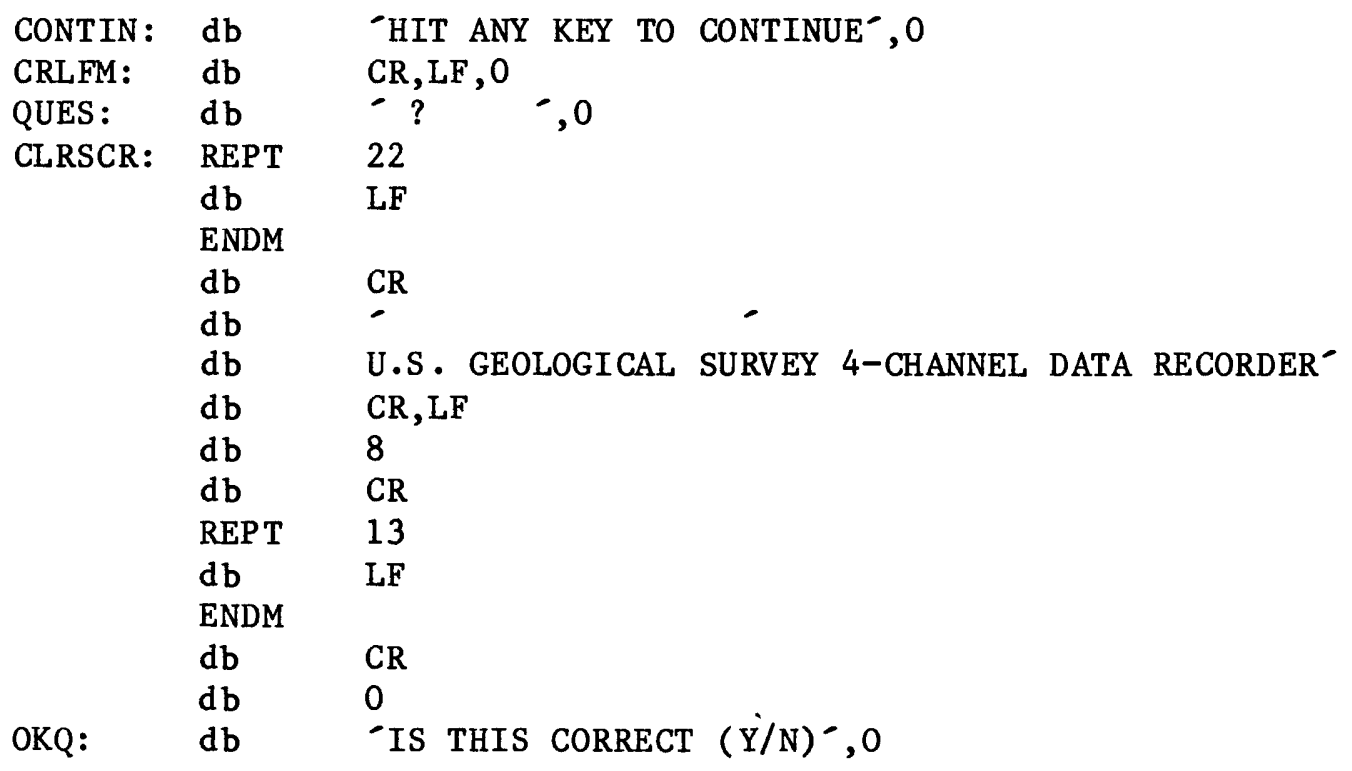


TAPE ROUTINES

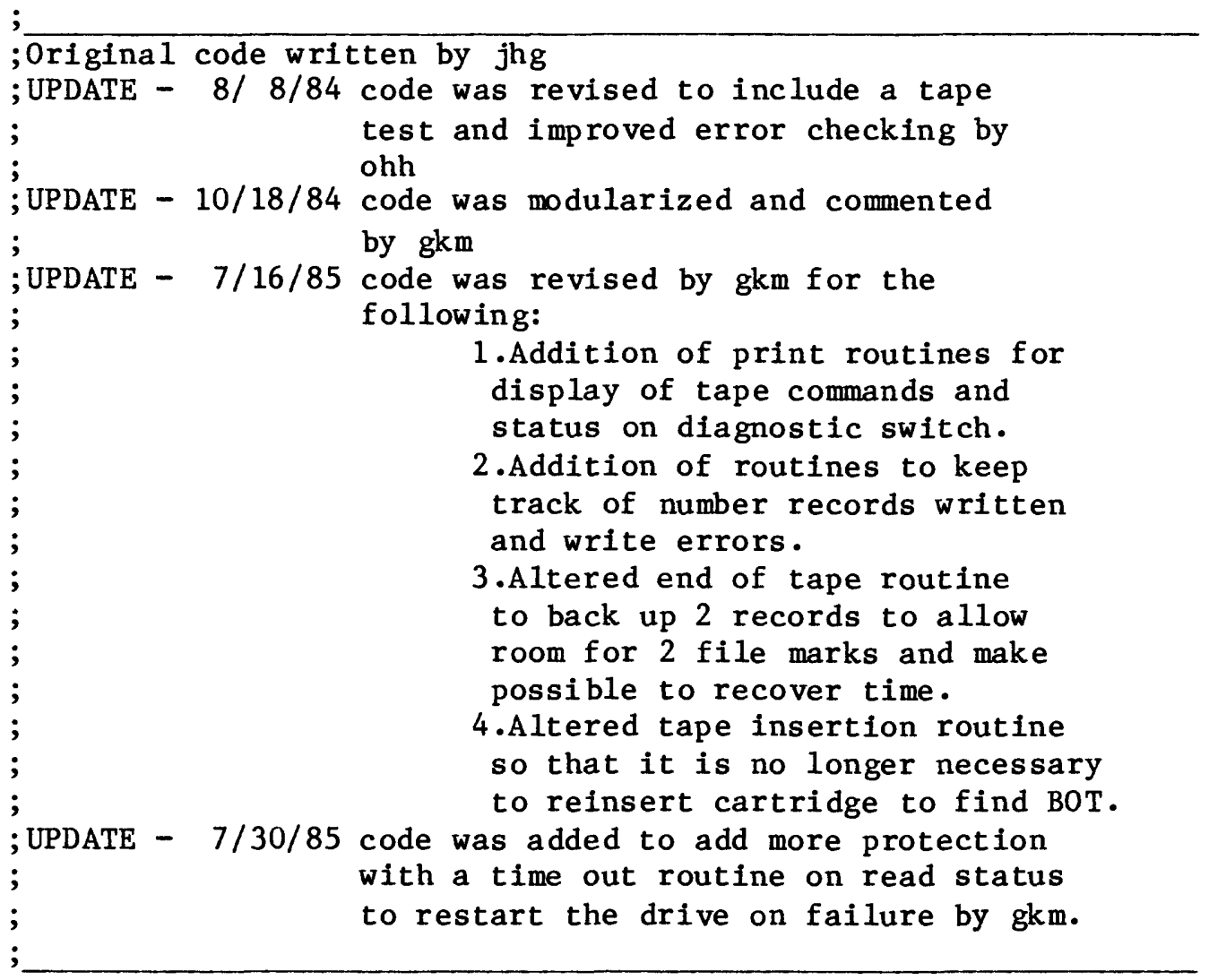


; POWER CONTROL FOR TAPE DRIVE

;

;--- TURN OFF POWER TO TAPE DRIVE --

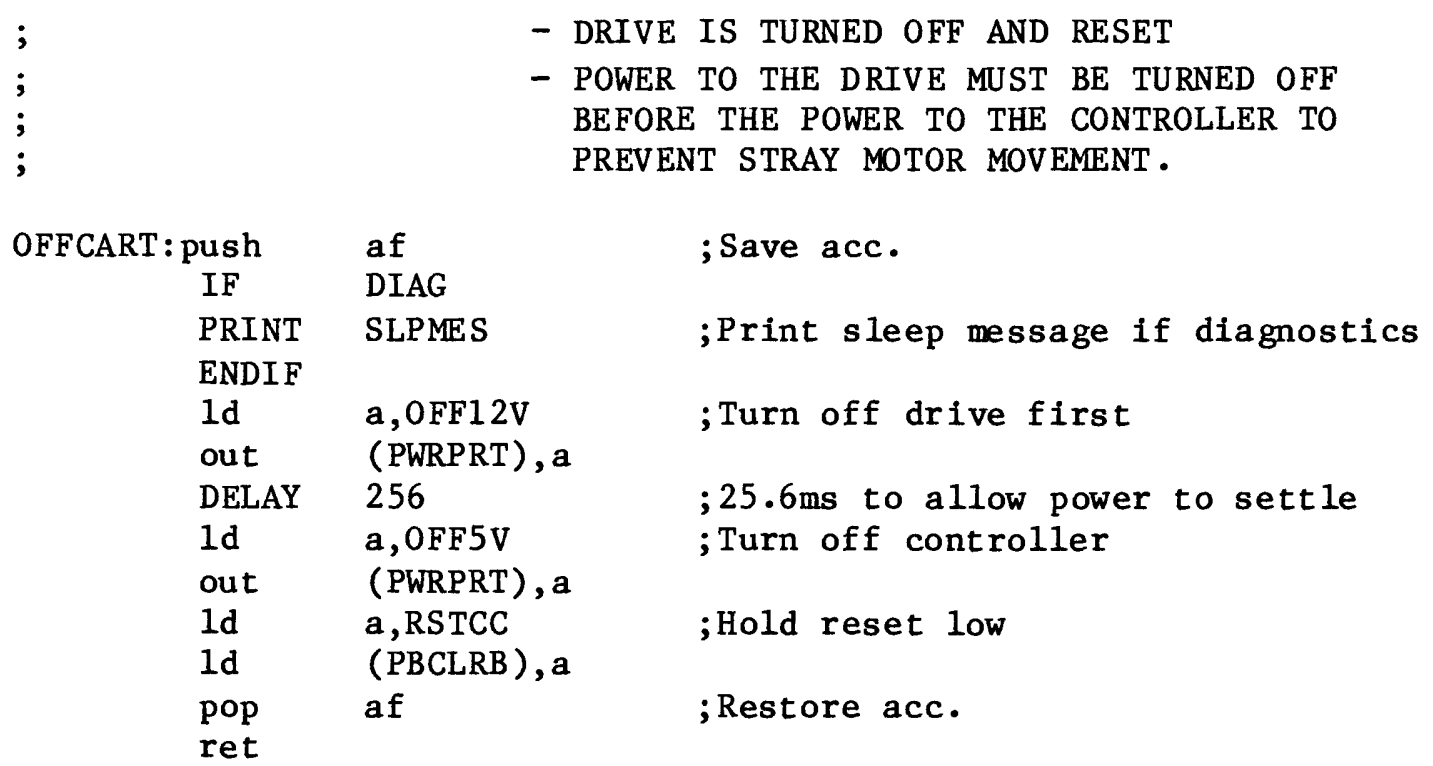




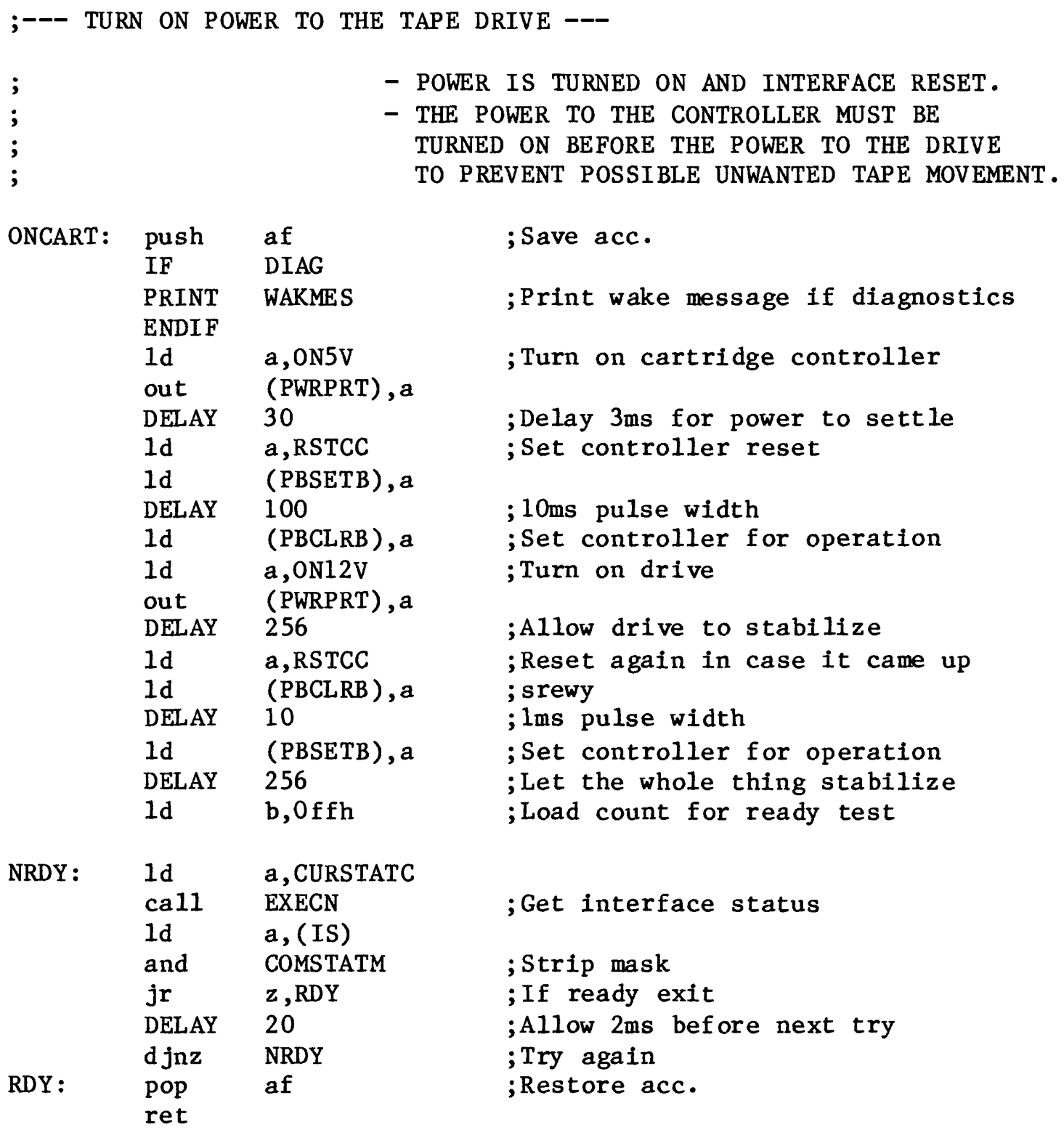


; COMMANDS SPECIFIC TO OBS/TIP FORMAT

;

;--- WRITE DATA RECORD FOR WINDOW MODE ---

WDR: call ONCART

ca11 NOBLOCK

; Turn on the drive

Id a, (BSTART)

; Determine no. blocks to write

$1 d$

(WBSTART), a

cal1 FIXNOS

ca11 WRITED

ca11 OFFCART

; Get start address

; Save it

; Create TIP header

; Write the data

ret

; Turn off the drive

;--- WRITE DATA RECORD FOR EVENT MODE ---

EWDR: ca11 ONCART ; Turn on the drive

call NOBLOCK ; Determine how many blocks

1d h1, (BSTART)

1d (WBSTART), h1 ; Save beginning of buffer

1d h1, (BEND)

1d (WBUFSAV), h1 ; Save beginning of data

ca11 FIXNOS

ca11 WRITED

cal1 OFFCART

; Create TIP header

; Write the data

ret 


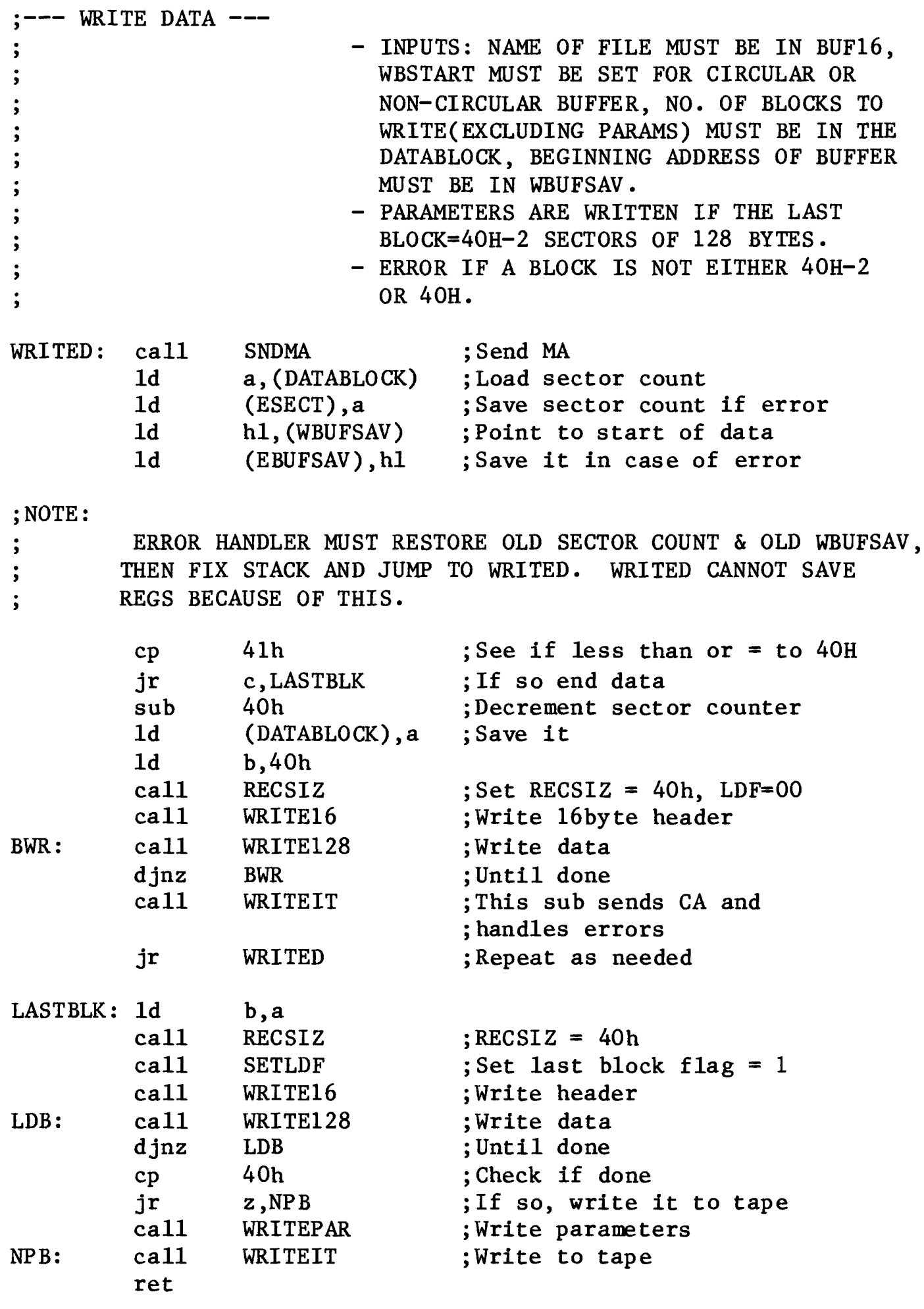




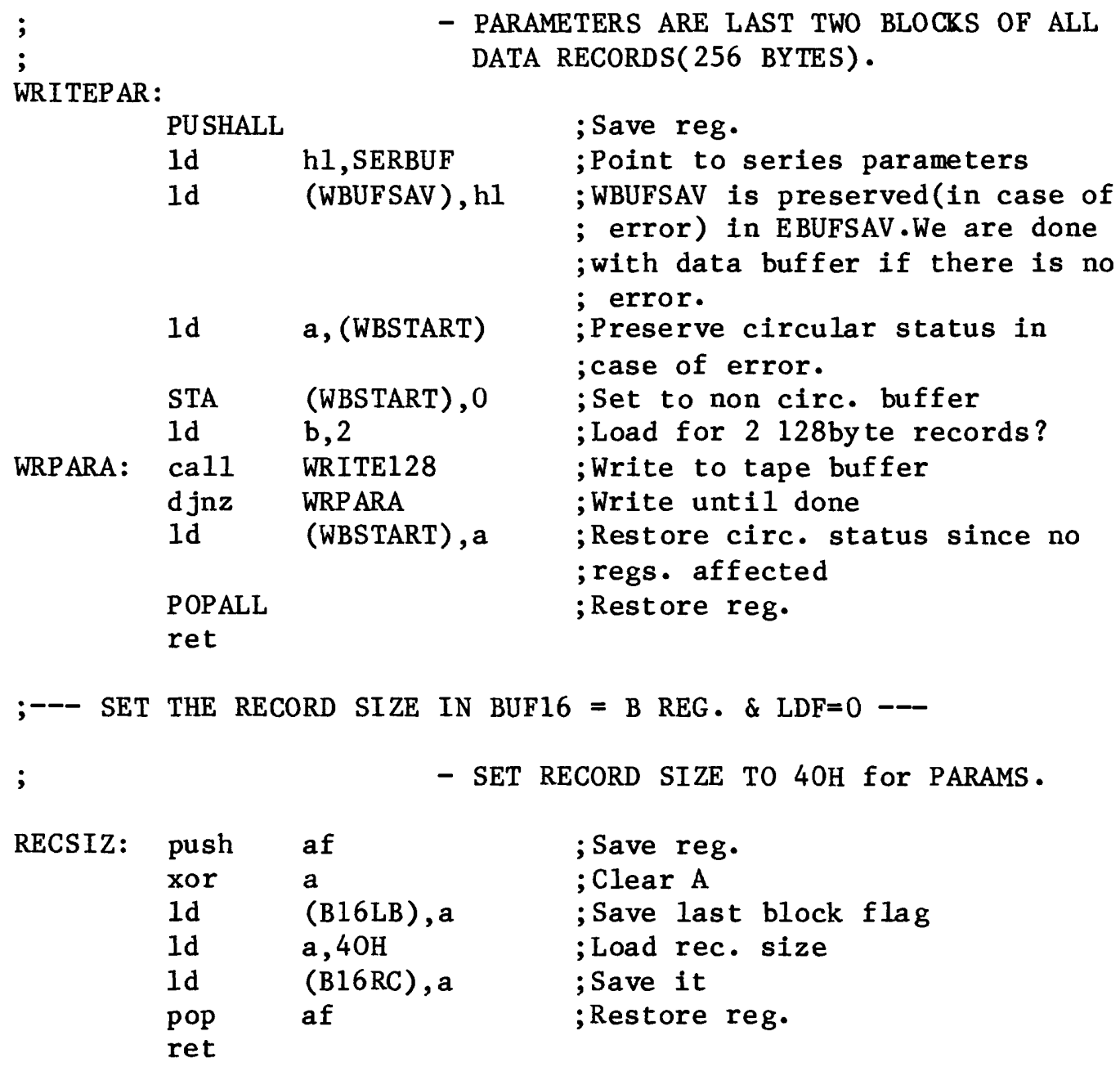

WRITEPAR :

PUSHALL

Id h1, SERBUF

; Save reg.

; Point to series parameters

Id (WBUFSAV), h1

; WBUFSAV is preserved(in case of ; error) in EBUFSAV.We are done ; with data buffer if there is no ; error.

Id a,(WBSTART) ;Preserve circular status in ; case of error.

STA (WBSTART), 0 ; Set to non circ. buffer

1d b,2 ; Load for 2 128byte records?

WRPARA: cal1 WRITE128

djnz WRPARA ; Write until done

Id (WBSTART), a ; Restore circ. status since no

POPALL

; regs. affected

ret

; Restore reg.

;--- SET THE RECORD SIZE IN BUF16 = B REG. \& LDF=0 ---

;

- SET RECORD SIZE TO 40H for PARAMS.

RECSIZ:

push af

xor a

1d (B16LB), a

Id $a, 40 \mathrm{H}$

ld (B16RC), a

pop af

ret

; Save reg.

; Clear A

; Save last block flag

; Load rec. size

; Save it

; Restore reg.

;--- SET LAST BLOCK FLAG ---

SETLDF : STA

(B16LB), 1

; Load last block flag

ret

;--- COMPUTE \# OF SECTORS OF 128B FROM BUFSIZ --

;

- CALL BEFORE WRITING ANY DATA RECORD.

$\begin{array}{llll}\text { NOBLOCK }: & \text { push } & \text { af } & \text {; Save reg. } \\ \text { push } & \text { bc } & \text {; Save reg. } \\ \text { Id } & a,(B U F S I Z) & \text {; Load buffer size } \\ \text { Id } & \text { b,a } & \text {; Move it to B } \\ \text { xor } & \text { a } & \text {; Clear A } \\ \text { ADDREC: } & \text { add } & \text { a, } 40 H & \text {; Add } 64 \text { by te groups } \\ \text { djnz } & \text { ADDREC } & \text {; Until filled } \\ \text { sub } & 2 & \text {; Allow for parameters } \\ \text { ld } & \text { (DATABLOCK),a } & \text {; Save it } \\ \text { pop } & \text { bc } & \text {; Restore reg. } \\ \text { pop } & \text { af } & \text {; Restore reg. } \\ \text { ret } & & \end{array}$


;--- WRITE A 128 BYTE RECORD TO TAPE BUFFER ---

;

- INPUT PARAMETERS : WBSTART,WBUFSAV .

WRITE128:

PUSHALL

ld h1,(WBUFSAV) ; Get pointer

ld b,128 ; Load no. bytes

call WBLOCK ; Write it

ld (WBUFSAV), h1 ; Save pointer

POPALL ; Restore reg.

ret

;--- MOVE NAME TO 16 BYTE HDR BUFFER ---

;

- CALL WITH HL SET TO APPROPRIATE NAME.

MNAME : PUSHALL

1d de, B16NAME

; Save reg.

ld $\quad b c, 8$

ldir

; Point to name

POPALL

; Load no. bytes

ret

; Fill buffer

; Restore reg.

;--- FIX EXP \# AND SERIES 非 IN 16 BYTE BUFFER --

;

- SERIES NO. IS LIMITED TO 4 BYTES.

;

- EXP. NUMBER IS LIMITED TO 4 BYTES.

FIXNOS: PUSHALL

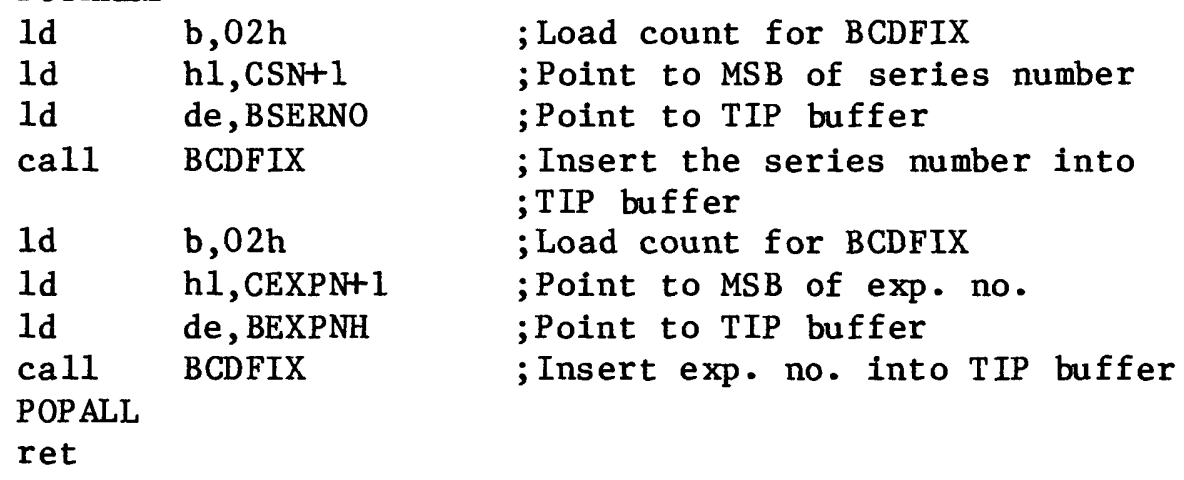




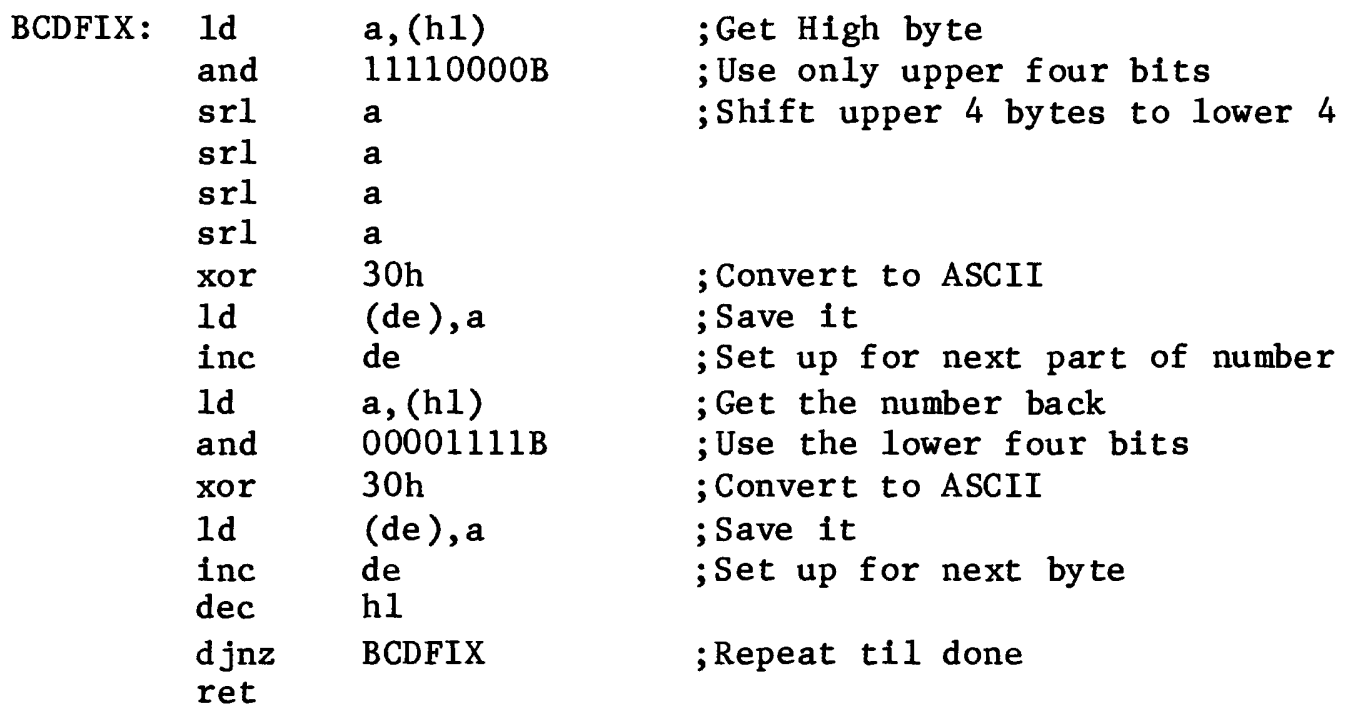

;--- WRITE THE 16 BYTE TIP HEADER TO TAPE BUFFER ---

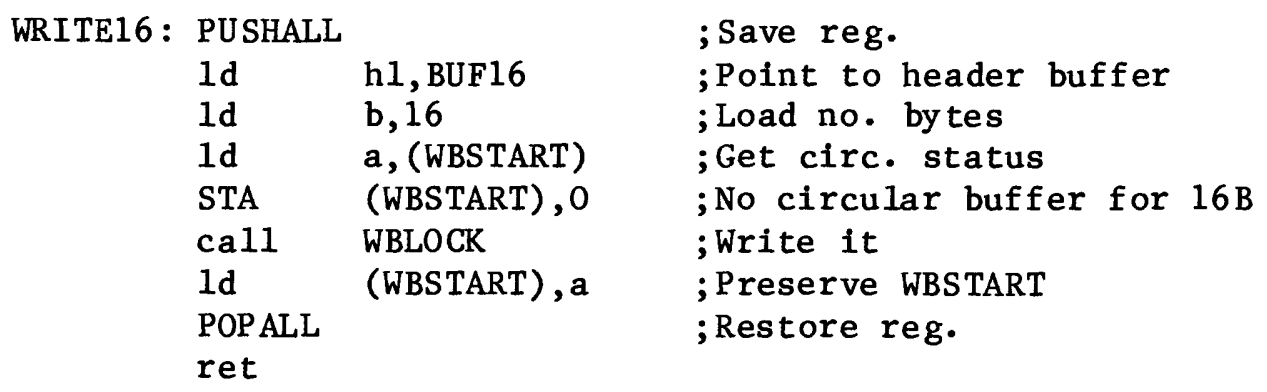

;--- CLEAR THE 16 BYTE HEADER BUFFER ---

BLNKB16: PUSHALL

$\begin{array}{ll}\text { 1d } & \text { bc, } 16 \\ \text { 1d } & \text { h1, BLANK16 } \\ \text { 1d } & \text { de, BUF16 } \\ \text { 1dir } & \\ \text { POPALL } & \\ \text { ret } & \end{array}$

; Save regs.

; Load number of by tes to clear

; Point at clear data

; Point to header buffer

;Fill buffer with spaces

; Restore reg. 


$$
\text { ; }
$$

- B MUST CONTAIN BYTE COUNT.

- HL MUST POINT TO FIRST BYTE TO WRITE.

- WBSTART MUST BE LOADED WITH ZERO IF NOT CIRCULAR OR WITH BSTART IF CIRC.

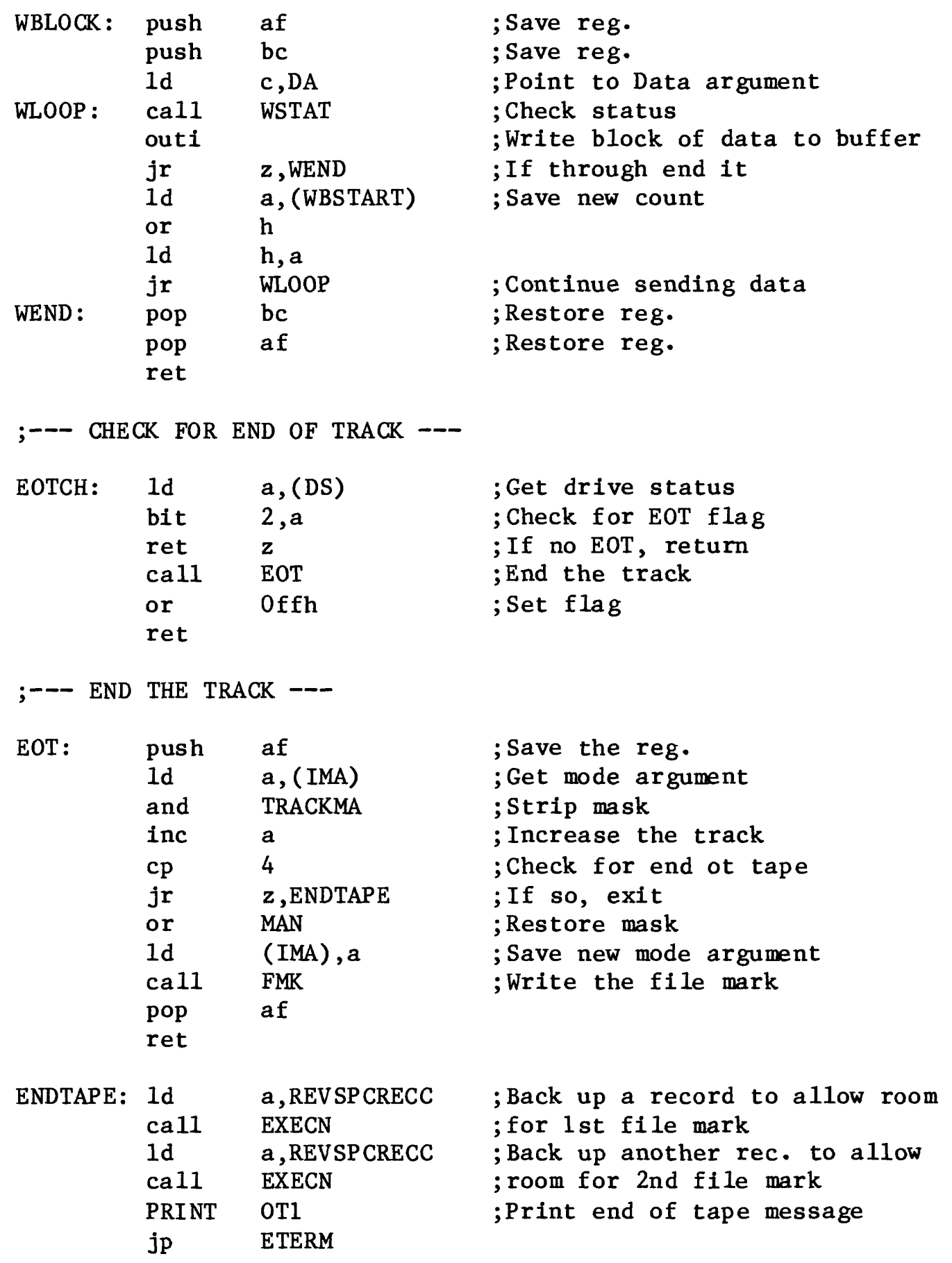




$$
\text { ; }
$$

$$
\text { ; }
$$

- IF TAPE IS ALREADY IN THE DRIVE AT POWER UP, THE TAPE WILL REWIND TO BOT.

- THIS ROUTINE ALSO CHECKS FOR WRITE PROTECT.

- ALL OTHER ERRORS WILL SIMPLY RESTART THE

\begin{tabular}{|c|c|c|c|}
\hline STAPE: & $\begin{array}{l}1 d \\
1 d \\
\text { call } \\
\text { STA } \\
\text { call }\end{array}$ & $\begin{array}{l}\mathrm{h} 1,0000 \mathrm{~h} \\
\text { (ABRTV), h1 } \\
\text { ONCART } \\
\text { (IMA), MAN } \\
\text { BLNKB16 }\end{array}$ & $\begin{array}{l}\text {; Save abort vector } \\
\text {; Turn on drive } \\
\text {; Update normal mode argumen } \\
\text {; Clear TIP header buffer }\end{array}$ \\
\hline ; & & $-N$ & ?E IN DRIVE? \\
\hline STAP1 : & $\begin{array}{l}\text { ld } \\
\text { call } \\
\text { ld } \\
\text { cp } \\
\text { jr }\end{array}$ & $\begin{array}{l}\text { a, CURSTATC } \\
\text { EXECN } \\
\text { a, (IS) } \\
92 \mathrm{~h} \\
\mathrm{nz}, \text { STAP4 }\end{array}$ & $\begin{array}{l}\text {; Get interface status } \\
\text {; Look if tape in drive } \\
\text {; If there, check tape }\end{array}$ \\
\hline NOTAPE: & $\begin{array}{l}\text { PRINT } \\
1 d \\
\text { cal1 } \\
1 d \\
\text { cp } \\
\text { jr }\end{array}$ & $\begin{array}{l}\text { INTAPE } \\
\text { a, CURSTATC } \\
\text { EXECN } \\
a,(\text { IS) } \\
92 \mathrm{~h} \\
\mathrm{z}, \text { NOTAPE }\end{array}$ & $\begin{array}{l}\text {; Loop til tape is inserted } \\
\text {; Get interface status } \\
\text {; Look if tape in drive }\end{array}$ \\
\hline
\end{tabular}
ROUTINE.

;

-MAKE SURE TAPE IS AT BOT AND NOT SAFE.

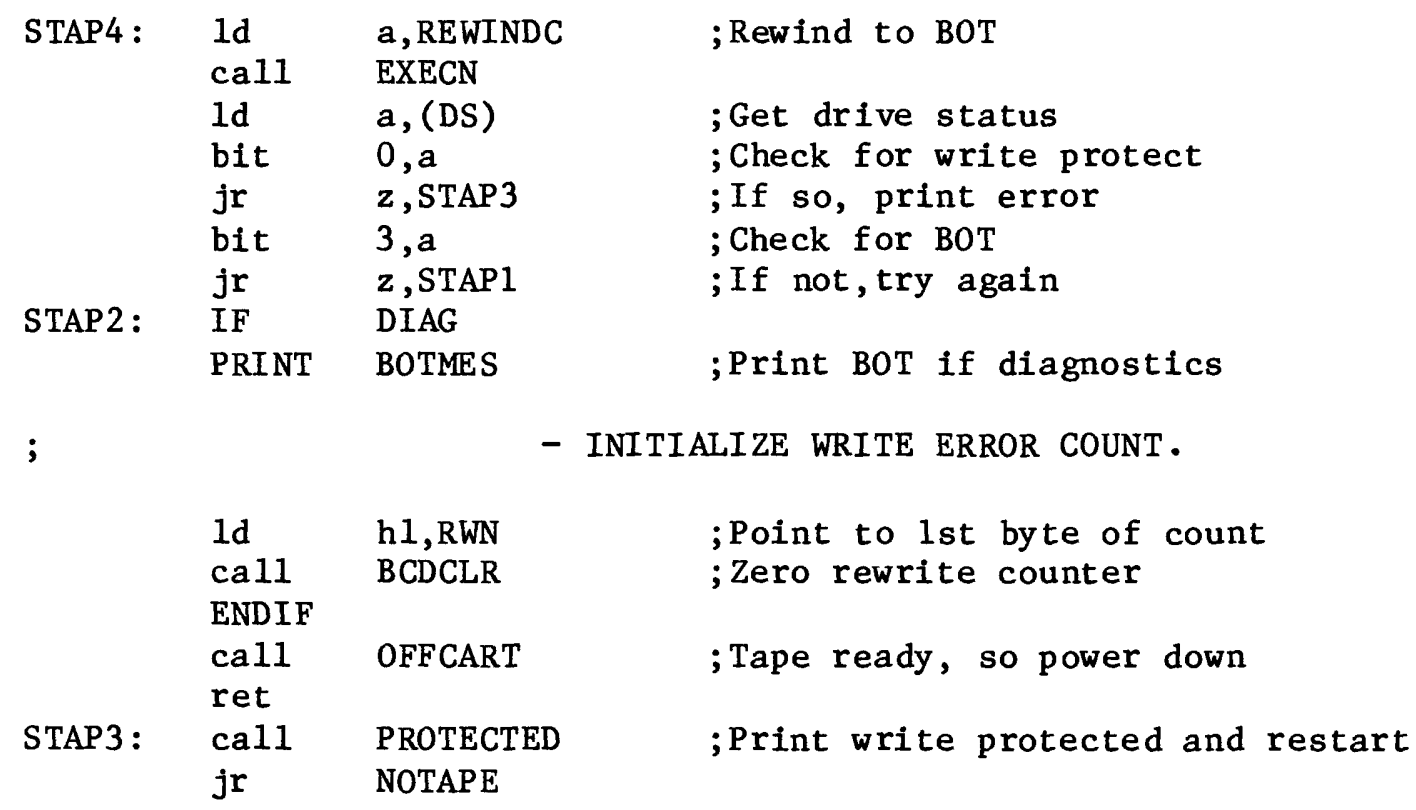




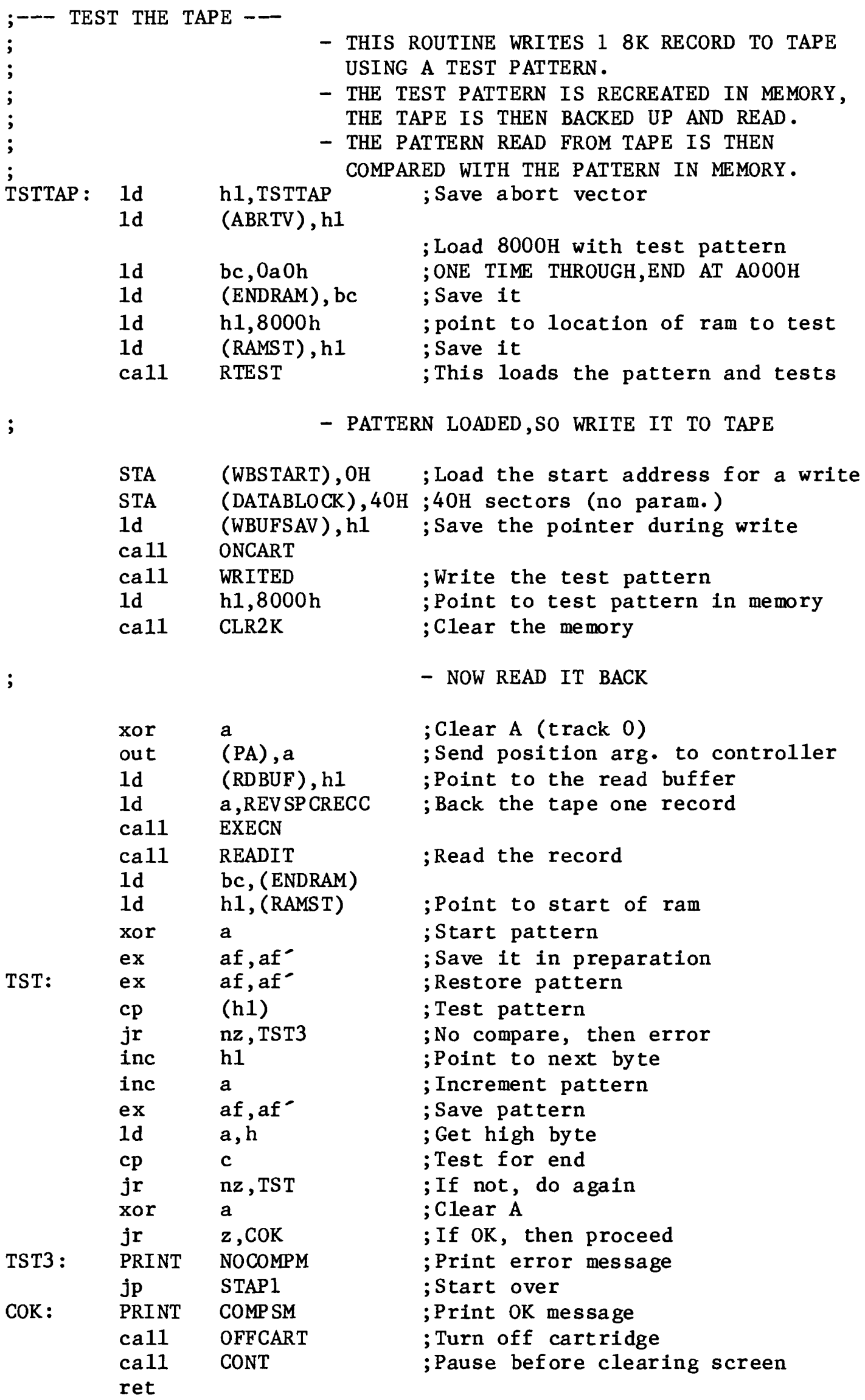




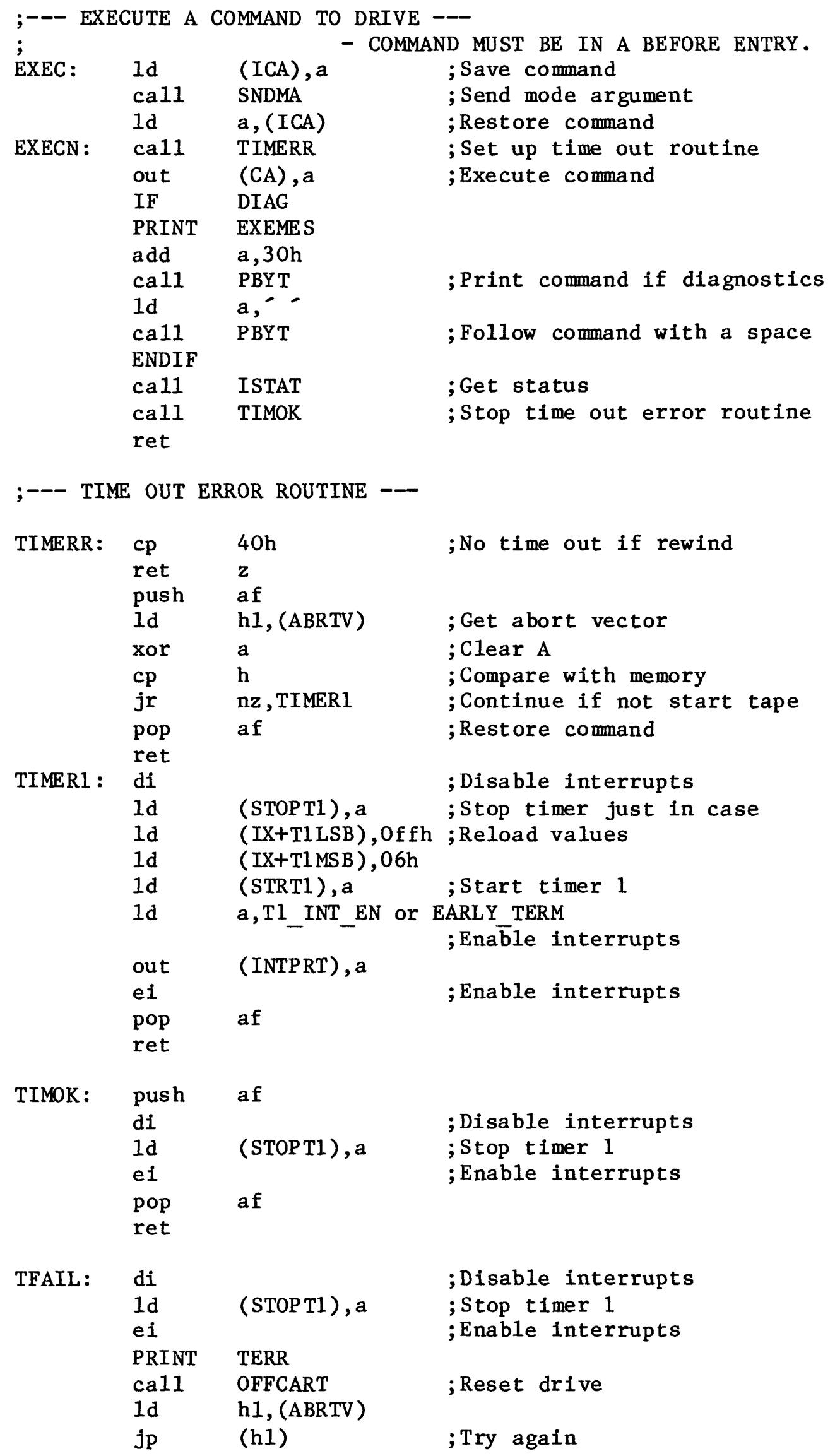




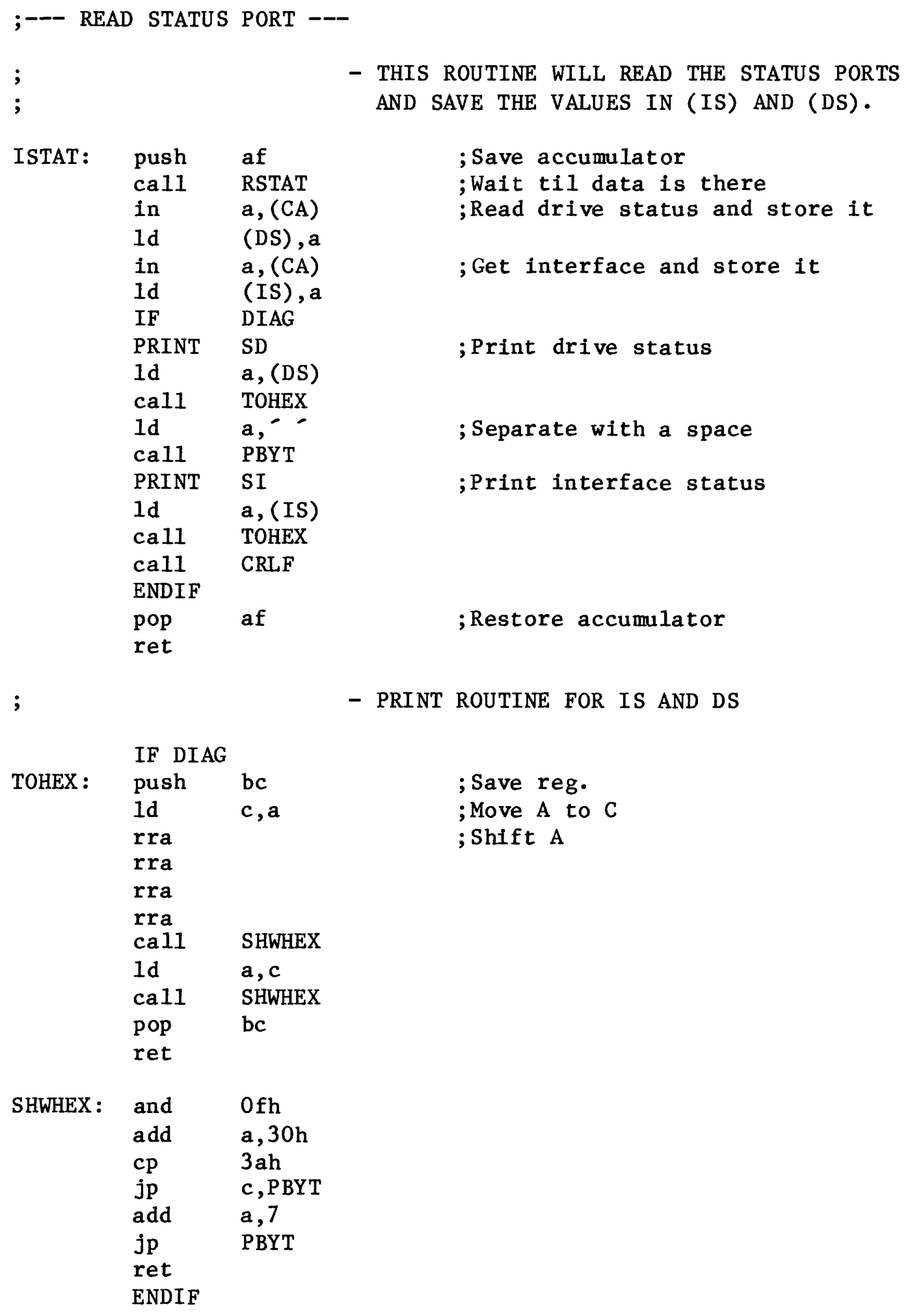

;

;

ISTAT: push af cal1 RSTAT in $a,(C A)$ Id (DS), a in $a,(\mathrm{CA})$ Id (IS), a IF DIAG

PRINT SD Id $a$, (DS) call TOHEX ld $a,{ }^{-}$ call PBYT PRINT SI Id $a$, (IS) call TOHEX call CRLF ENDIF pop af ret

;

\begin{tabular}{lll} 
& \multicolumn{2}{l}{ IF DIAG } \\
TOHEX : & push & bc \\
& Id & $c, a$ \\
& rra & \\
rra & \\
rra & \\
rra & \\
call & SHWHEX \\
ld & a, c \\
call & SHWHEX \\
pop & bc \\
ret & \\
& \\
and & 0fh \\
add & a, 30h \\
cp & 3 ah \\
jp & c,PBYT \\
add & a, 7 \\
jp & PBYT \\
ret & \\
ENDIF &
\end{tabular}

- THIS ROUTINE WILL READ THE STATUS PORTS AND SAVE THE VALUES IN (IS) AND (DS).

; Save accumulator ; Wait til data is there ; Read drive status and store it ; Get interface and store it ; Print drive status ; Separate with a space ;Print interface status ; Restore accumulator

- PRINT ROUTINE FOR IS AND DS ; Save reg. ; Move $\mathrm{A}$ to $\mathrm{C}$ ; Shift A 


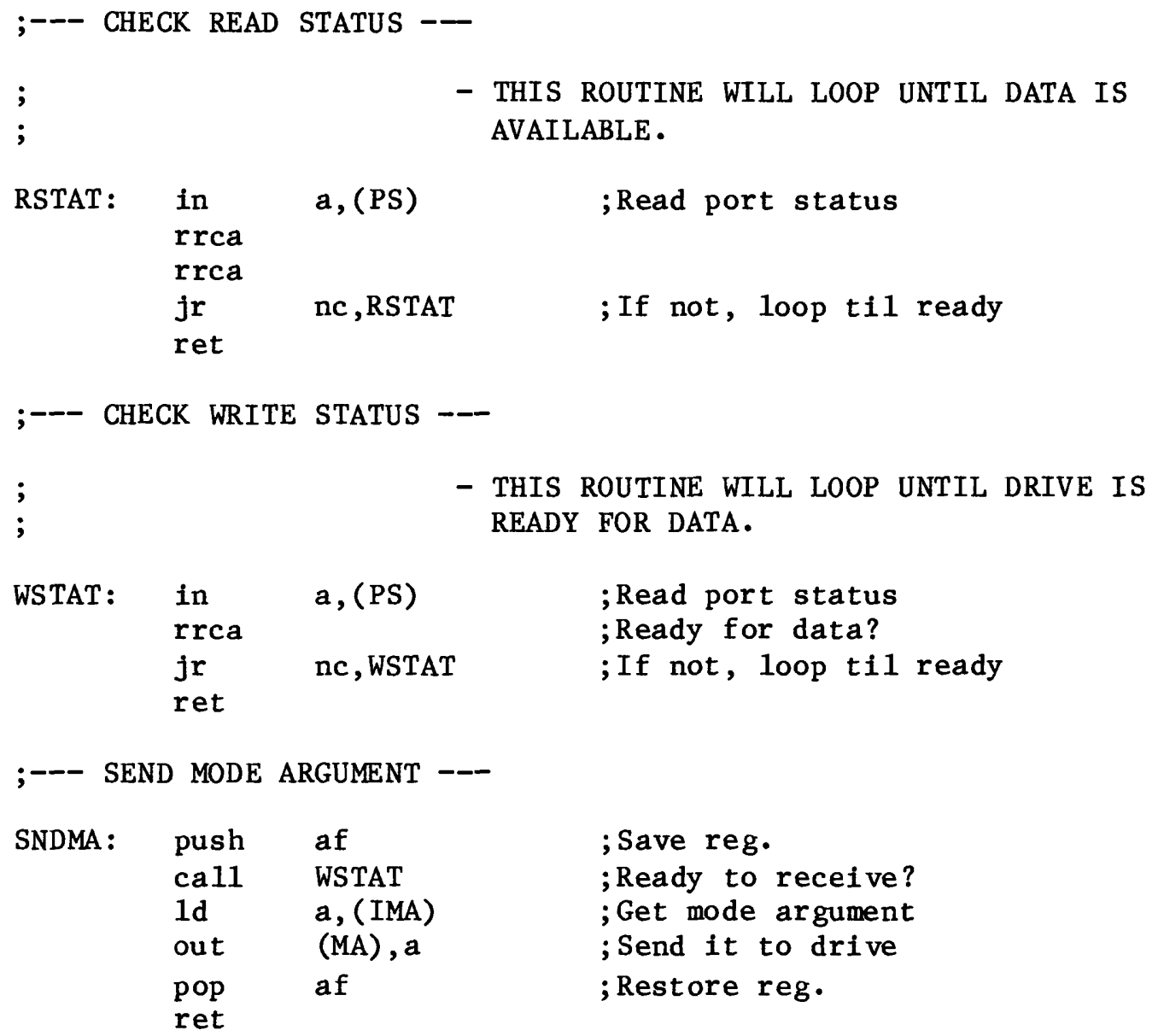

$\begin{array}{lll}\text { SNDMA : } & \text { push } & \text { af } \\ & \text { call } & \text { WSTAT } \\ \text { ld } & \text { a, (IMA) } \\ \text { out } & \text { (MA), a } \\ \text { pop } & \text { af } \\ \text { ret } & \end{array}$


- READ AN 8K BLOCK FROM TAPE

- HEADER IS READ TO TIPBUF

- BODY TO ADDRESS IN RDBUFF WHICH MUST BE SET BEFORE CALLING.

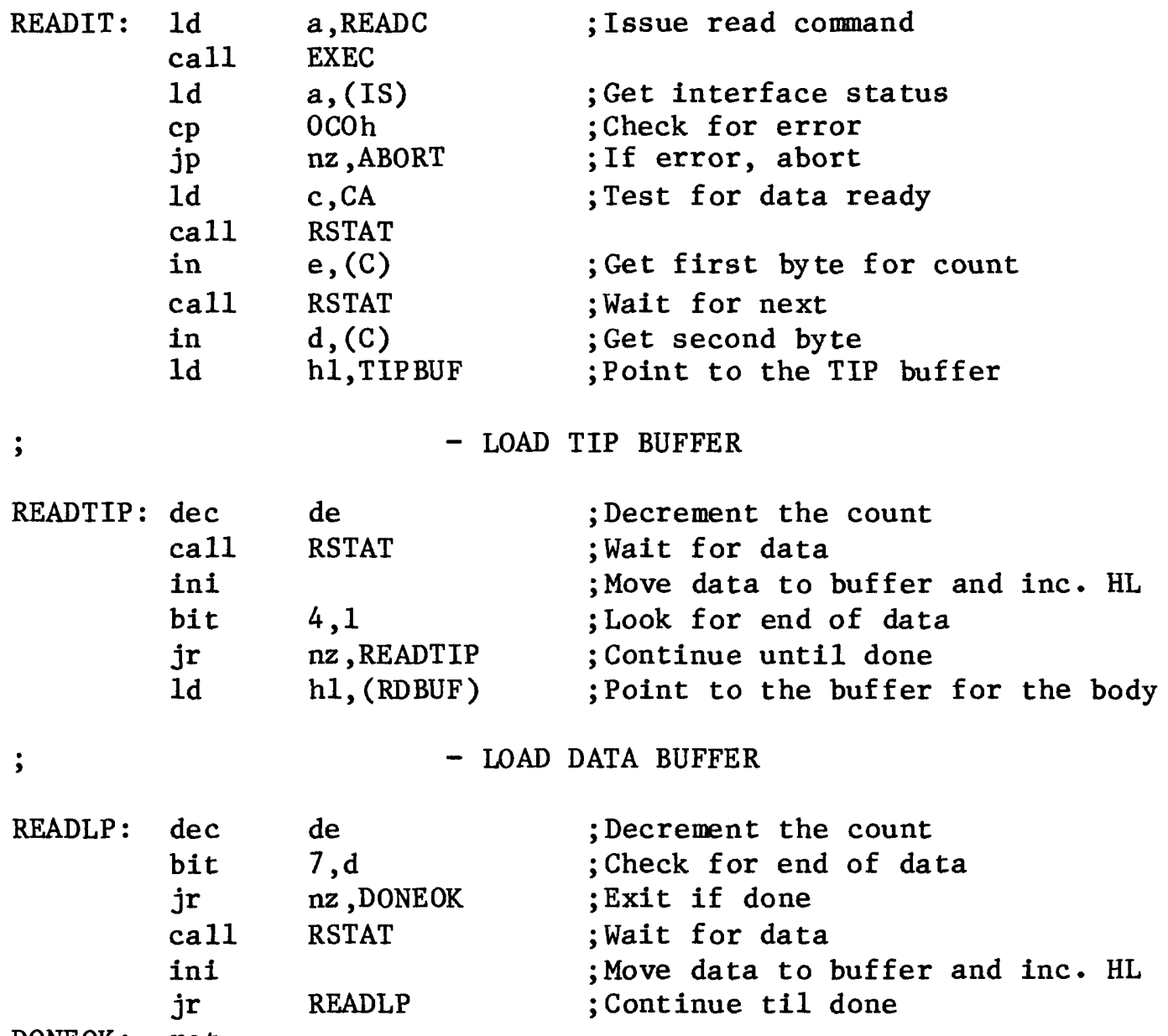

DONEOK: ret 
;WRITE A FILE MARK

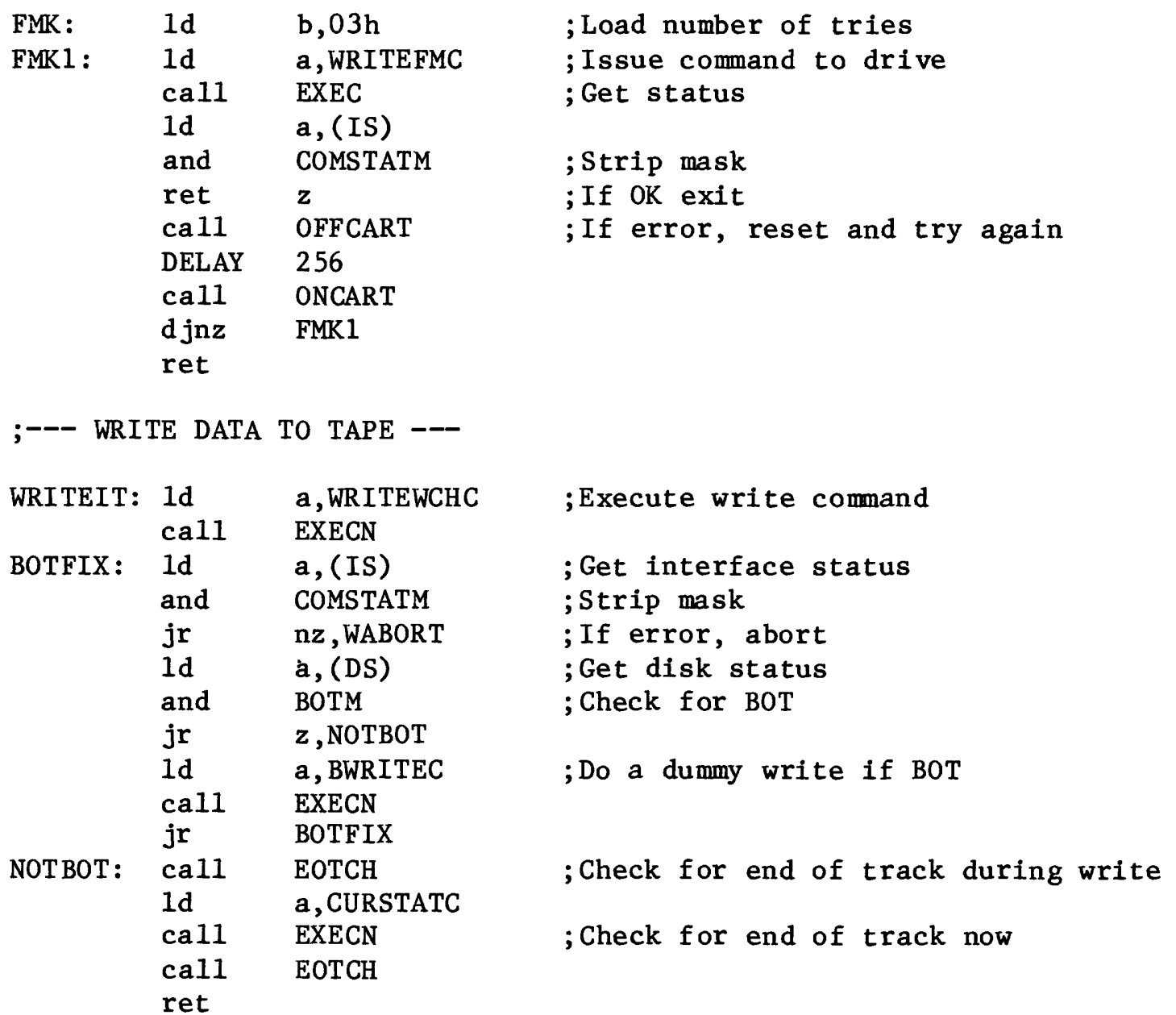


;--- WRITE ABORT HANDLER ---

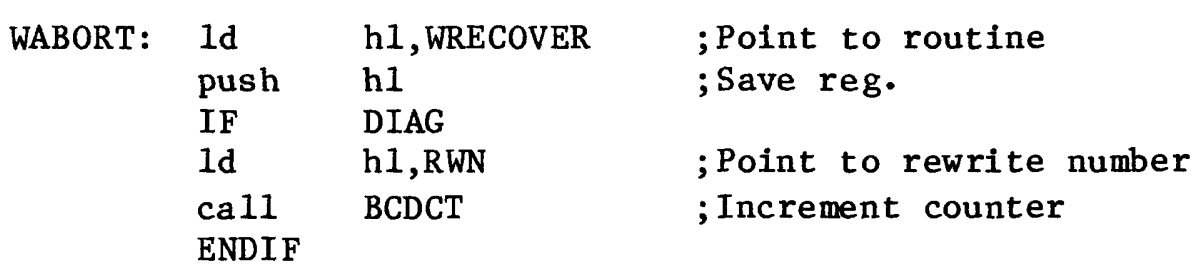

;--- GENERAL ABORT HANDLER --

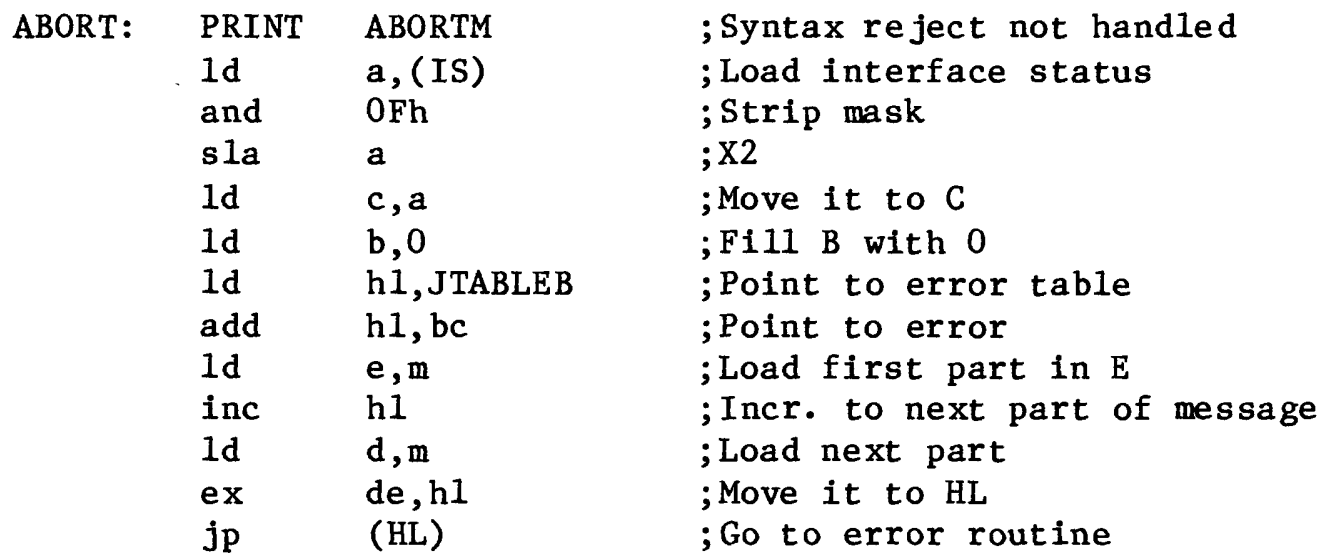

;--- RECOVER A WRITE ERROR ---

;

- SECTOR COUNT AND BUFFER PTR RESTORED.

WRECOVER:

$\begin{array}{lll}\text { cal1 } & \text { OFFCART } & \text {; Turn off cartridge } \\ \text { DELAY } & 256 & \\ \text { cal1 } & \text { ONCART } & \text {; Turn on cartridge } \\ \text { 1d } & \text { a,(ESECT) } & \text {; Load sector count } \\ \text { 1d } & \text { (DATABLOCK),a } & \text {; Save it } \\ \text { 1d } & \text { h1,(EBUFSAV) } & \text {; Point to saved pointer } \\ \text { ld } & \text { (WBUFSAV), h1 } & \text {; Save it } \\ \text { pop } & \text { hl } & \\ \text { jp } & \text { WRITED } & \text {; Continue writing }\end{array}$




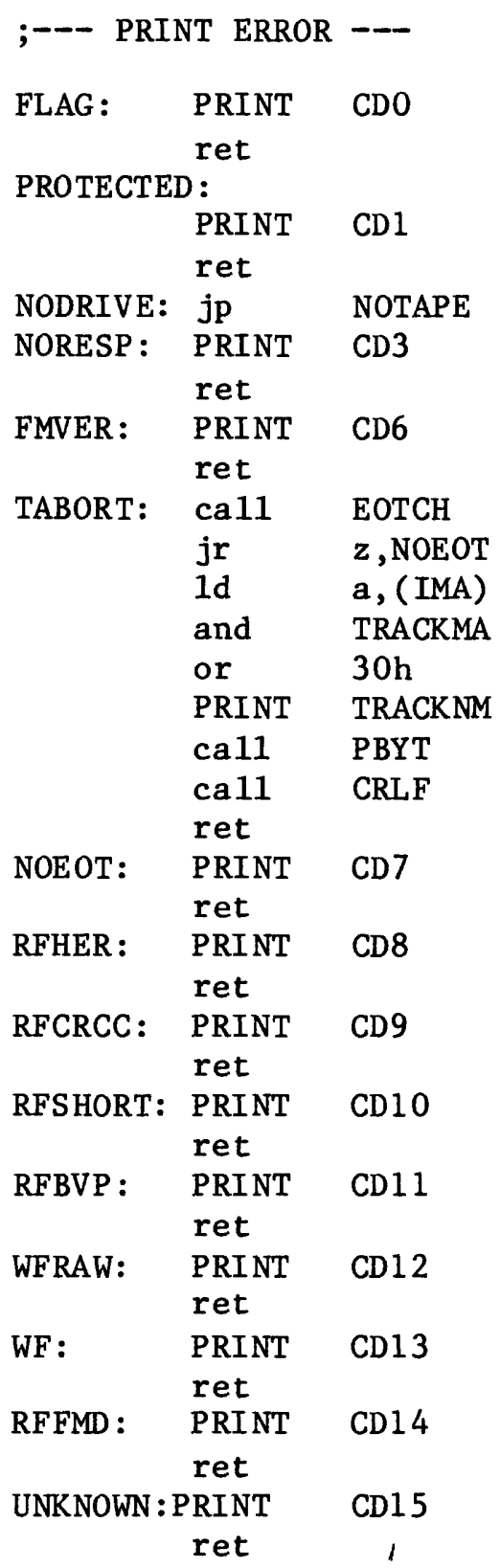


;--- PRINT MESSAGES

\begin{tabular}{|c|c|c|}
\hline ABORTM: & $\mathrm{db}$ & ${ }^{-} \mathrm{ABORT}{ }^{\circ}, 0$ \\
\hline BDTAHDR: & $\mathrm{db}$ & ${ }^{-} \mathrm{S} 0000 \mathrm{E} 0000^{-}$ \\
\hline BLANK16: & $\begin{array}{l}d b \\
d b\end{array}$ & $\begin{array}{l}0,20 \mathrm{H}, 2 \mathrm{OH}, 2 \mathrm{OH}, 20 \mathrm{H}, 20 \mathrm{H}, 2 \mathrm{OH}, 2 \mathrm{OH}, 2 \mathrm{OH} \\
20 \mathrm{H}, 2 \mathrm{OH}, 2 \mathrm{H}, 0,0,0,0\end{array}$ \\
\hline CDO : & $\mathrm{db}$ & ${ }^{-} \mathrm{CODE} 0$ FLAG $\mathrm{COND} .^{-}, \mathrm{CR}, \mathrm{LF}, 0$ \\
\hline $\mathrm{CD1}:$ & $\mathrm{db}$ & - CODE 1 WRITE PROTECTED', CR, LF, 0 \\
\hline CD3: & $\mathrm{db}$ & 'CODE 3 DRIVE DID NOT DO IT", CR, LF, 0 \\
\hline CD6 : & $\mathrm{db}$ & ${ }^{-}$CODE 6 FILE MARK VER. ERR. ${ }^{-}, \mathrm{CR}, \mathrm{LF}, 0$ \\
\hline $\begin{array}{l}\text { CD7 : } \\
\text { CD8 : }\end{array}$ & $\begin{array}{l}\mathrm{db} \\
\mathrm{db}\end{array}$ & 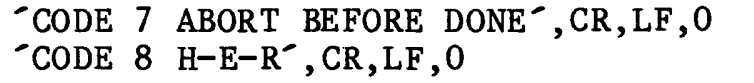 \\
\hline $\begin{array}{l}\text { CD9: } \\
\text { CD10: } \\
\text { CD11: }\end{array}$ & $\begin{array}{l}d b \\
d b \\
d b\end{array}$ & $\begin{array}{l}\text {-CODE } 9 \text { BAD CRCC', CR, LF, } 0 \\
\text {-CODE } 10 \text { SHORT REC.- , CR, LF, } 0 \\
{ }^{-} \text {CODE } 11 \text { BAD V. PAR. }{ }^{-}, \mathrm{CR}, \mathrm{LF}, 0\end{array}$ \\
\hline $\begin{array}{l}\text { CD12: } \\
\text { CD13: } \\
\text { CD14: }\end{array}$ & $\begin{array}{l}\mathrm{db} \\
\mathrm{db} \\
\mathrm{db}\end{array}$ & 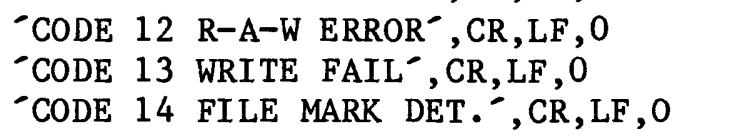 \\
\hline CD15: & $\begin{array}{l}d b \\
d b\end{array}$ & $\begin{array}{l}\text { 'CODES } 4,5,15 \text { IMPROPER ABORT CODES' } \\
\text { CR,LF, } 0\end{array}$ \\
\hline COMPSM: & $\mathrm{db}$ & ${ }^{-T A P E}$ DRIVE $\mathrm{OK}^{\prime}, \mathrm{CR}, \mathrm{LF}, 0$ \\
\hline HEADER : & $\mathrm{db}$ & 'GPHEADER'- \\
\hline INTAPE: & $\mathrm{db}$ & 'INSERT TAPE CARTRIDGE',CR,LF, 0 \\
\hline NOCOMPM: & $\mathrm{db}$ & 'BAD TAPE OR DRIVE', CR,LF,O \\
\hline OT1 : & $\mathrm{db}$ & 'OUT OF TAPE', CR, LF, O \\
\hline ; REMTAPE : & $\mathrm{db}$ & 'REMOVE TAPE CARTRIDGE', CR, LF, 0 \\
\hline TERR: & $\mathrm{db}$ & 'TIME OUT ERROR',CR,LF,0 \\
\hline TRACKNM: & $\begin{array}{l}\mathrm{db} \\
\mathrm{db}\end{array}$ & $\begin{array}{l}\text { CR,LF } \\
\text {-TRACK \#- } 0\end{array}$ \\
\hline TSTTAPM: & $\mathrm{db}$ & "TESTING TAPE - ,CR,LF, 0 \\
\hline
\end{tabular}

;--- ERROR TABLE ---

$\begin{array}{ll}\text { dw } & \text { FLAG } \\ \text { dw } & \text { PROTECTED } \\ \text { dw } & \text { NODRIVE } \\ \text { dw } & \text { NORESP } \\ \text { dw } & \text { UNKNOWN } \\ \text { dw } & \text { UNKNOWN } \\ \text { dw } & \text { FMVER } \\ \text { dw } & \text { TABORT } \\ \text { dw } & \text { RFHER } \\ \text { dw } & \text { RFCRCC } \\ \text { dw } & \text { RFSHORT } \\ \text { dw } & \text { RFBVP } \\ \text { dw } & \text { WFRAW } \\ \text { dw } & \text { WF } \\ \text { dw } & \text { RFFMD } \\ \text { dw } & \text { UNKNOWN }\end{array}$


;--- DIAGNOSTIC MESSAGES ---

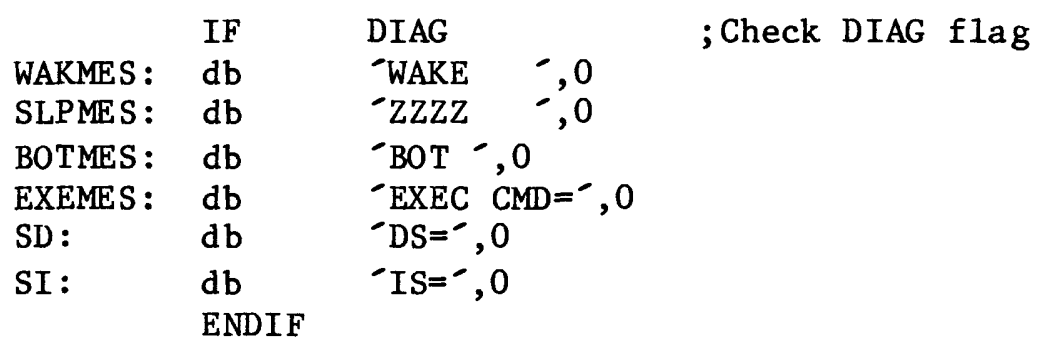




\section{PARAMETER ENTRY}

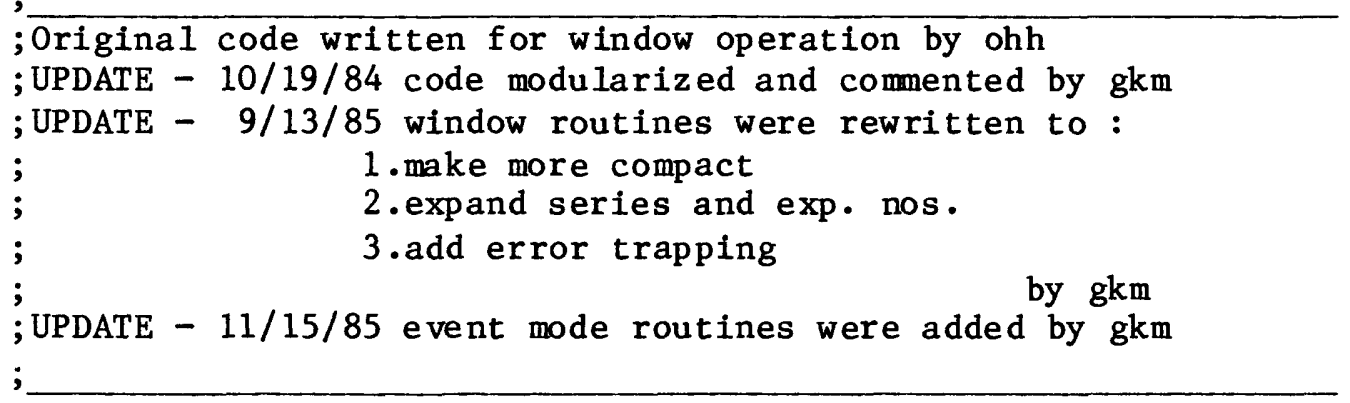




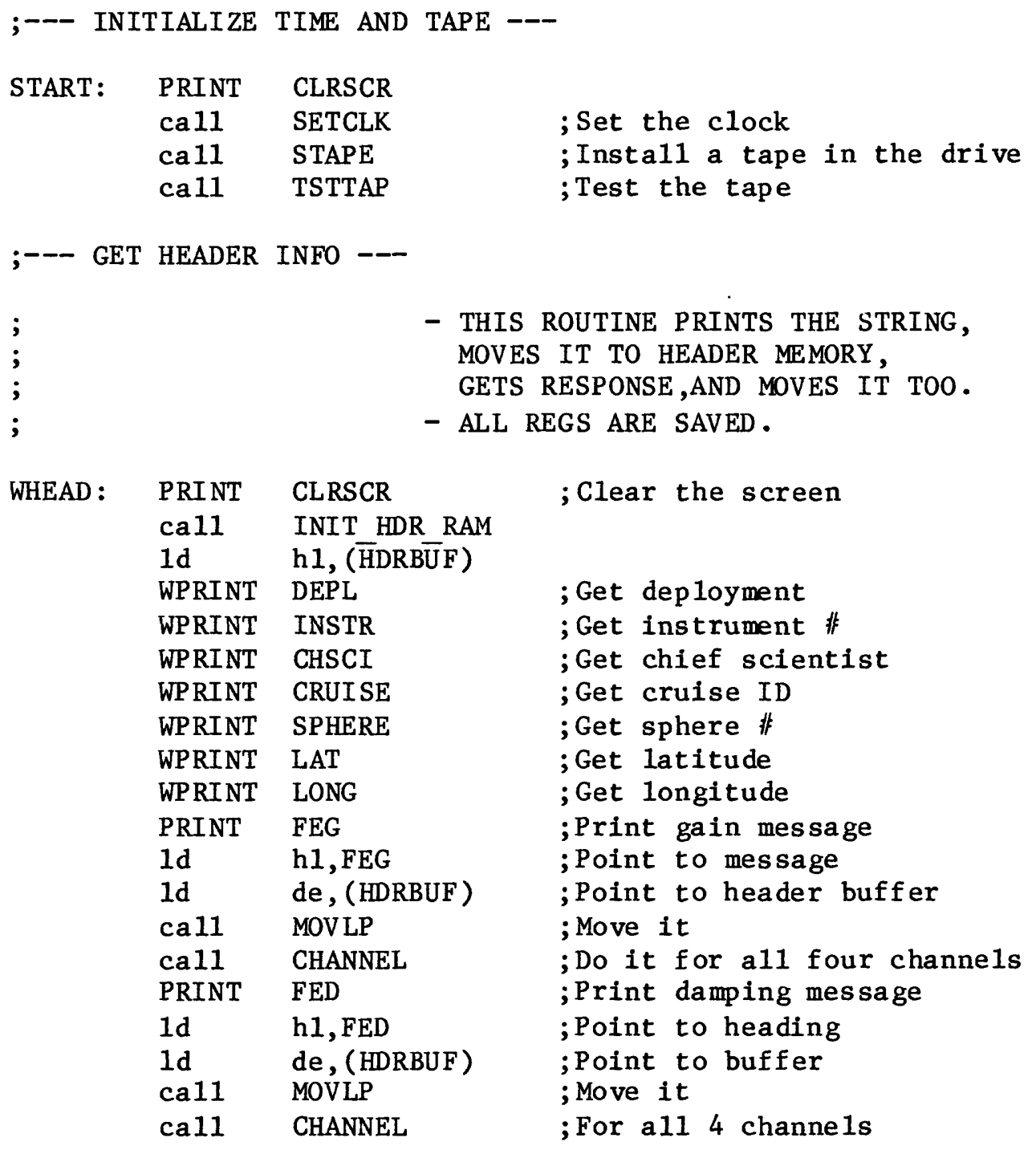


- ADD TERMINATOR AND INSERT INTO GPHEADER .

$\begin{array}{lll}\text { 1d } & \text { a, CTLZ } & \text {; ASCII buffer terminator } \\ \text { 1d } & \text { de, (HDRBUF) } & \text {; Point to buffer } \\ \text { ca11 } & \text { INS } & \text {; Put it in and fix DE }\end{array}$

;

- PLAY DATA BACK FOR VERIFICATION.

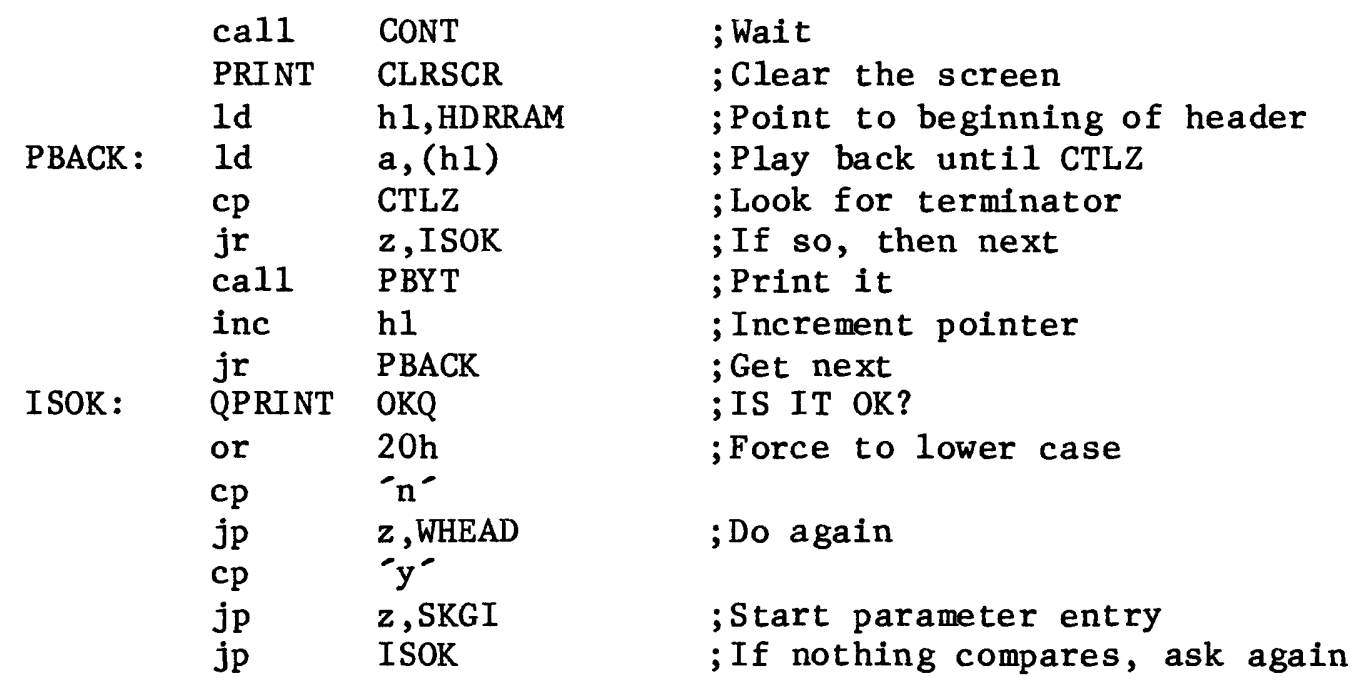


INITIALIZE THE SERIES NUMBER

- CLEAR THE SERIES COUNT.

SKGI : $\quad 1 d \quad h 1, C S N$ ; Point to current series number cal1 BCDCLR ; Clear series count

Id de, SERBUF ; Point to parameter storage

ld

(PARBUF), de ; Save it

;--- INCREMENT THE SERIES NUMBER ---

;

NSERIES :

- ONLY 9 SERIES SUPPORTED.

- THIS LIMITATION IS DUE TO THE AMOUNT OF STORAGE ALLOCATED IN THE 256 BYTE TRAILER.

1d h1,CSN ; Get current series number

call BCDCT ; Increment count

1d a, (CSN) ; Get the series number

cp $\quad 09 \mathrm{~h} \quad$; Support only 9 series

jp $z, E X E C U \quad$; If max, then start

;

- ENTER HERE ON RETRY.

$\begin{array}{lll}\text { REPENT: } & \text { PRINT } & \text { CLRSCR } \\ \text { cal1 } & \text { SNPT } & \text {; Clear the screen } \\ & \text {; Print the series number }\end{array}$

;--- ENTER NUMBER CHANNELS ---

; - SUPPORTS UP TO 4 CHANNELS.

NCHAN : PRINT NCAP

1d h1, NCX2

ca11 INDAT

jr $\quad c, N C H A N$

Print channel message

; Point to channel storage

; Get answer

ld $\quad a, 4$

; Invalid entry if carry

cp m

;4 to ACC

jr $\quad c, N C H A N$

; Compare to input

ld $\quad a, 0$

; If input $>4$,ERROR

cp m

; Check if entry is 0

jr

$z$, NCHAN

; If so, try again 


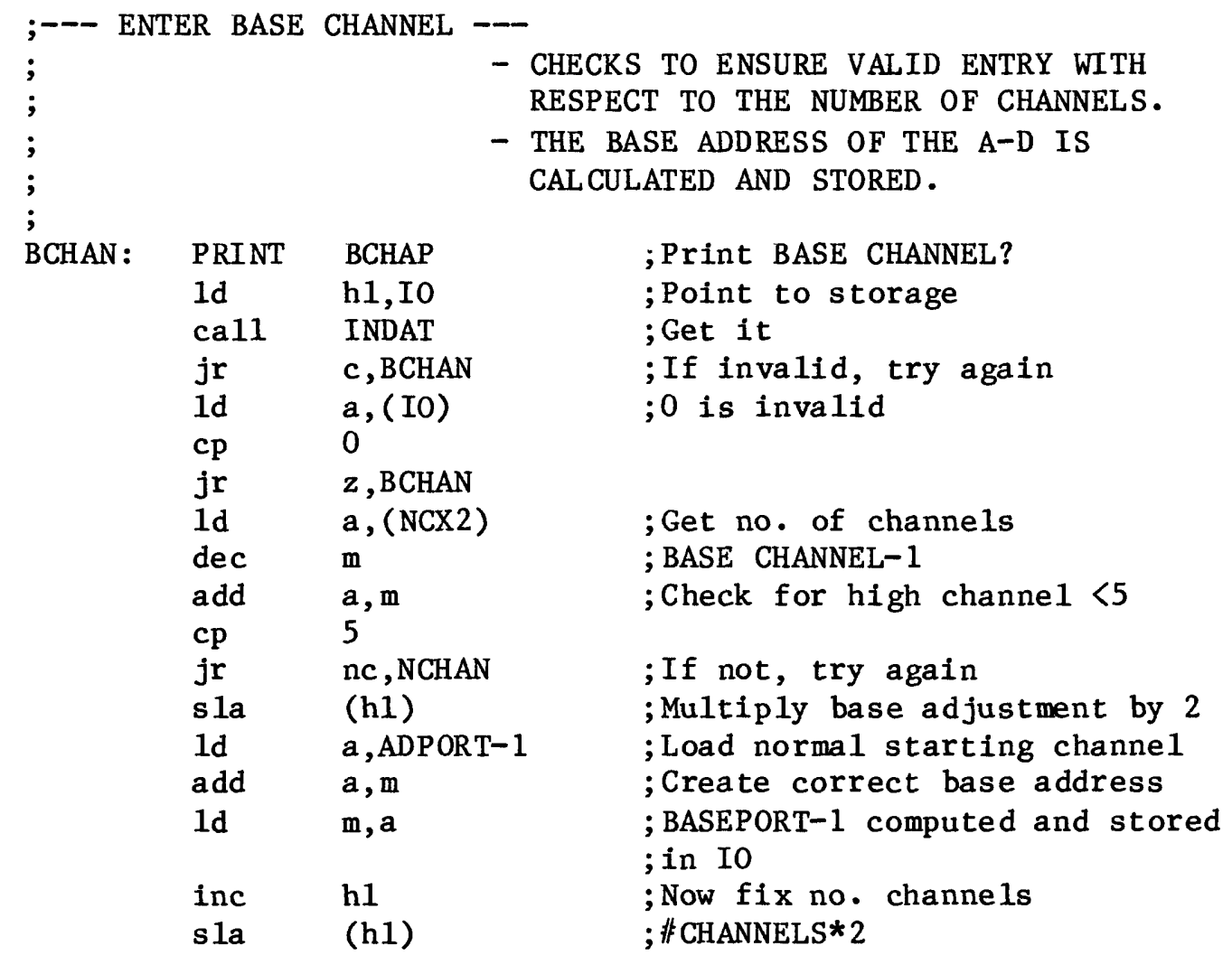




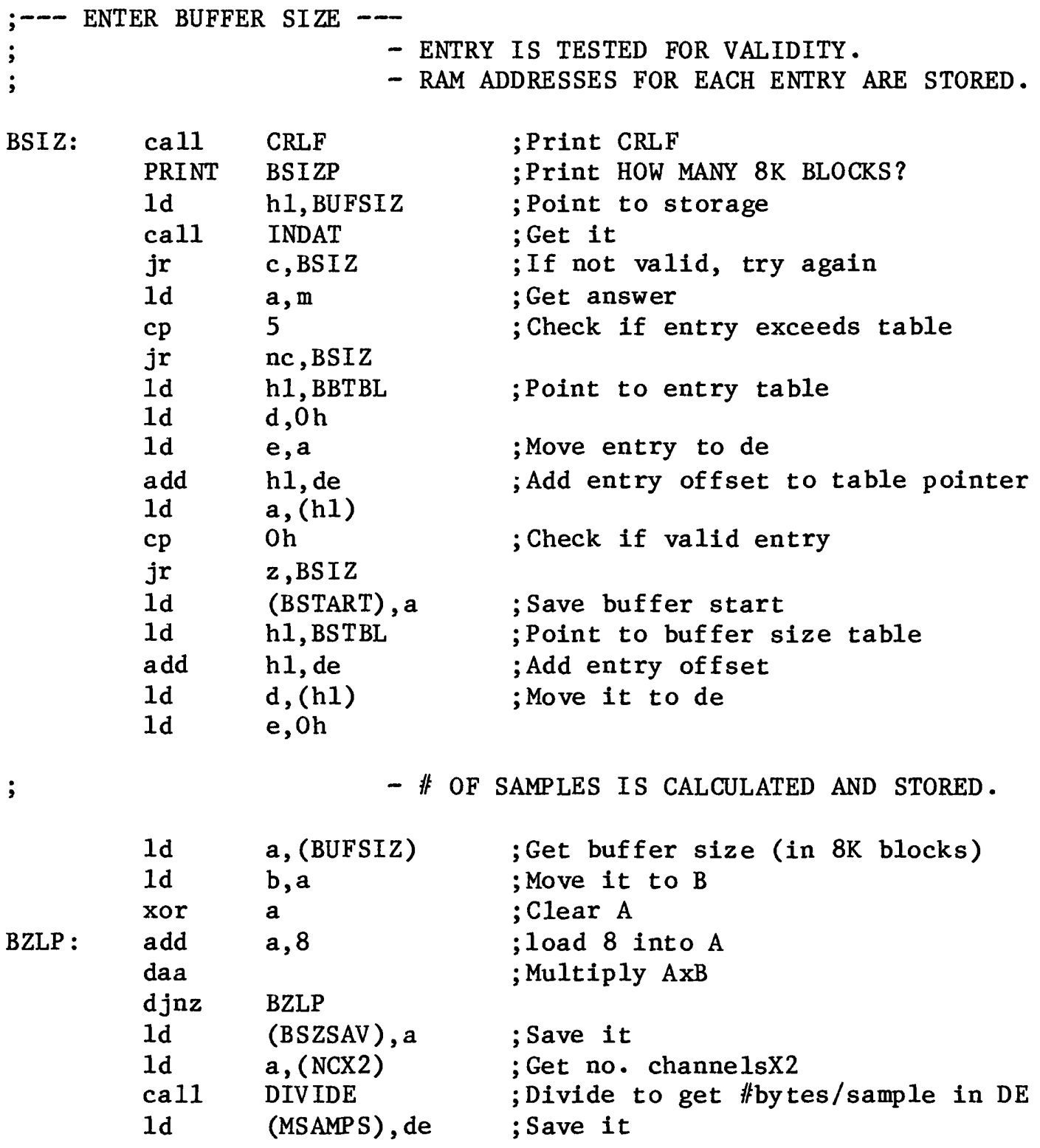




\begin{tabular}{|c|c|c|c|}
\hline$;$ & $\mathrm{E} R$ & $\begin{array}{l}\text { - ENTRY } \\
\text { - AD CODI } \\
\text { - SHIFTE }\end{array}$ & $\begin{array}{l}\text { IS CHECKED. } \\
\text { E IS SAVED. } \\
\text { R VALUE FOR RECORD TIME IS SAVED. }\end{array}$ \\
\hline SAMRAT: & $\begin{array}{l}\text { ca11 } \\
\text { PRINT } \\
1 d \\
c a 11 \\
j r \\
1 d \\
c p \\
j r \\
1 d \\
c a 11 \\
c p \\
j r \\
1 d \\
1 d \\
\text { add } \\
1 d \\
1 d\end{array}$ & $\begin{array}{l}\text { CRLF } \\
\text { SINTV } \\
\text { h1, SRATE } \\
\text { INDAT } \\
c, \text { SAMRAT } \\
\text { a,m } \\
9 \\
\text { nc, SAMRAT } \\
\text { h1,ADTBL } \\
\text { TBLAD } \\
0 \\
\text { z, SAMRAT } \\
\text { (ADVAL), a } \\
\text { h1, SHTBL } \\
\text { h1, de } \\
\text { a, (h1) } \\
\text { (SHIFTER), a }\end{array}$ & $\begin{array}{l}\text {; Print CRLF } \\
\text {; Print sample rate message } \\
\text {; Get answer } \\
\text {; If not valid, try again } \\
\text {; Check entry is within the table } \\
\text {; Point to AD entry table } \\
\text {; Check for valid entry } \\
\text {; Save buffer start } \\
\text {; Point to shifter table } \\
\text {; Add entry offset } \\
\text {; Save it }\end{array}$ \\
\hline $\begin{array}{l};---P R \\
;\end{array}$ & $\mathbf{T} \mathrm{W}_{\mathrm{L}}$ & $\begin{aligned} \text { NG MESSAGE FOR SAI } \\
\text { - PRINTS } \\
\text { RESISTOR } \\
\text { BOARD. }\end{aligned}$ & $\begin{array}{l}\text { MPLE RATE --- } \\
\text { WARNING TO ENSURE THAT THE PROPER } \\
\text { HEADER IS INSTALLED ON THE ANALOG }\end{array}$ \\
\hline WARNM: & $\begin{array}{l}\text { cal1 } \\
1 d \\
c p \\
\text { jr } \\
\text { PRINT } \\
\text { jr }\end{array}$ & $\begin{array}{l}\text { CRLF } \\
\text { a, ( SRATE) } \\
8 \\
\text { nz, NAD8 } \\
\text { WARN8 } \\
\text { NEXP }\end{array}$ & $\begin{array}{l}\text {; Get sample rate } \\
\text {; Look for } 8 \mathrm{~ms} \text { rate } \\
\text {; 8ms warning is a little different } \\
\text {; Print warning message for } 8 \mathrm{~ms}\end{array}$ \\
\hline NAD8 : & $\begin{array}{l}\text { 1d } \\
\text { ca11 } \\
1 d \\
1 d \\
\text { ca11 } \\
\text { PRINT }\end{array}$ & $\begin{array}{l}\text { h1, WNT BL } \\
\text { TBLAD } \\
\text { (GPCTRL), a } \\
\text { h1, GPCTRL } \\
\text { PBCD } \\
\text { WARN1 }\end{array}$ & $\begin{array}{l}\text {; Point to warning table } \\
\text {; Find the right value } \\
\text {; Cannot print unless in memory } \\
\text {; Print value from table } \\
\text {; Print rest of message }\end{array}$ \\
\hline ; & & - PRINT & RECORD TIME. \\
\hline NEXP: & $\begin{array}{l}\text { cal1 } \\
\text { cal1 } \\
\text { cal1 }\end{array}$ & $\begin{array}{l}\text { CRLF } \\
\text { RTIME } \\
\text { CRLF }\end{array}$ & $\begin{array}{l}\text {; Print CRLF } \\
\text {; Print record time } \\
\text {;Print CRLF }\end{array}$ \\
\hline
\end{tabular}


;--- ENTER WINDOW OR EVENT ---

\begin{tabular}{|c|c|c|}
\hline EVENT: & $\begin{array}{l}\text { PRINT } \\
\text { call } \\
\text { 1d } \\
\text { 1d } \\
\text { or } \\
1 d \\
c p \\
\text { jr } \\
c p \\
\text { jp } \\
\text { jp }\end{array}$ & $\begin{array}{l}\text { WE } \\
\text { GETLN } \\
\mathrm{h} 1, \text { I BUFF } \\
\mathrm{a},(\mathrm{h} 1) \\
20 \mathrm{~h} \\
\text { (SERTYP), a } \\
{ }^{\prime} \text { ' } \\
\mathrm{z}, \text { WNEXP } \\
\text { e' } \\
z, \text { PES } \\
\text { EVENT }\end{array}$ \\
\hline
\end{tabular}

; Is it WINDOW or EVENT?

; Get response

; Force to lower case

;If timer, go do that

; If event, go do that

; If not, entry not valid try again 
;

;--- ENTER NO. EXPERIMENTS

$$
\text { ; }
$$

- MAXIMUM NUMBER IS 9999.

WNEXP :

$\begin{array}{ll}\text { 1d } & \text { h1, EXPN } \\ \text { ca11 } & \text { BCDCLR } \\ \text { ca11 } & \text { CRLF } \\ \text { PRINT } & \text { NEXPP } \\ \text { ld } & \text { h1, EXPN } \\ \text { ca11 } & \text { INDAT }\end{array}$

; Clear exp. number

; Print NO. OF EXPERIMENTS IN SERIES

; Point to parameter storage

; Get response

WEXP4: jr $\quad$, WNEXP

; If carry, then invalid entry

;--- ENTER START AND STOP TIME -

$\begin{array}{lll}\text { cal1 SAVTIME } & \text {; Save the previous stop time for } \\ \text {; check } & \text {; Enter start and stop time }\end{array}$

;--- ENTER OFFSET ---

- OFFSET CAN BE ANY WHOLE SEC LESS THAN 1 MIN.

WOFFSET: call CRLF

PRINT WOFF1

1d h1,OFFSET

cal1 INDAT

jr $\quad c$,WOFFSET

1d a,m

cp $\quad 60 \mathrm{H}$

jr nc, WOFFSET

; Print message

; Point to storage

; Get answer

; If error, try again

; Load answer

; Check for valid response (<1min)

; If not, try again

;--- ENTER PERIOD ---

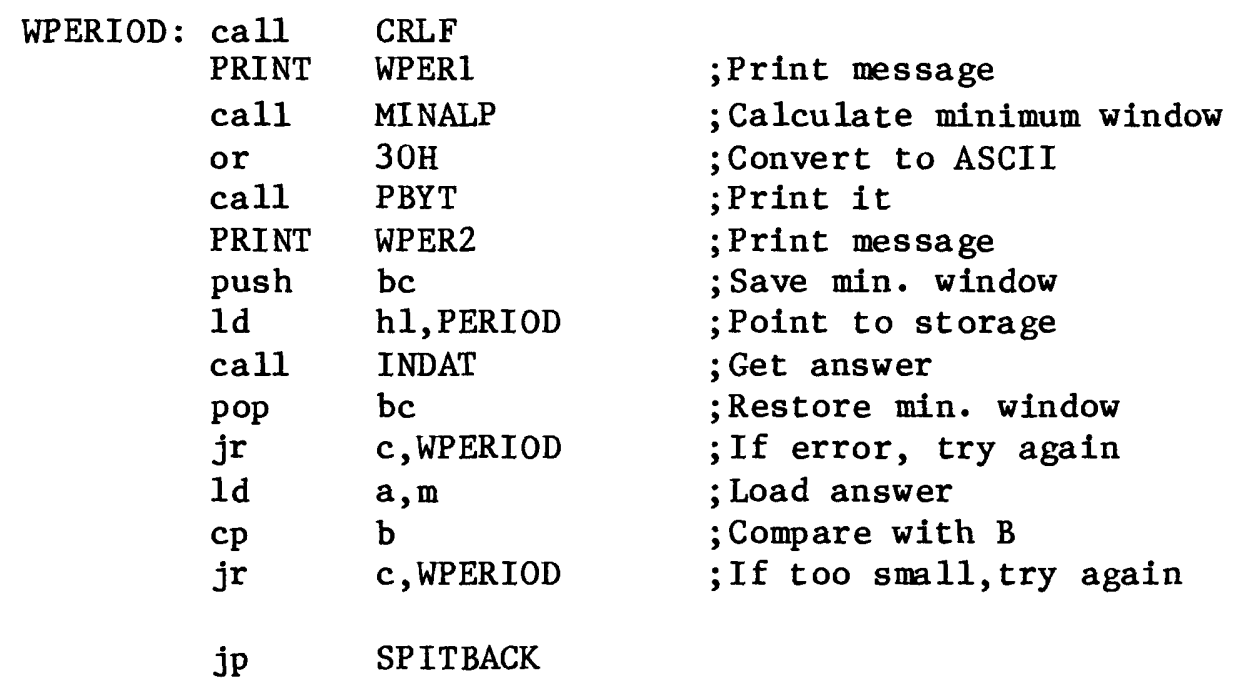


;

;--- ENTER POST EVENT SAMPLES --

\begin{tabular}{|c|c|c|c|}
\hline PES : & $1 \mathrm{~d}$ & (SERTYP), a & \\
\hline & PRINT & PESP & ;Print POST- EVENT SAMPLES \\
\hline & Id & $\mathrm{h} 1, \mathrm{PESAMS}$ & ; Point to storage \\
\hline & ca11 & INDAT & ; Get it \\
\hline & jr & $c$, PES & ; If invalid, try again \\
\hline & Id & $a, m$ & $\begin{array}{l}\text {; Answer in ACC, look at prompt in } \\
\text {; WMESS. }\end{array}$ \\
\hline & $1 d$ & de, (MSAMPS) & ; Get no. samples \\
\hline & push & & ; Save in $\mathrm{HL}$ \\
\hline & pop & h1 & \\
\hline & or & a & ;Clear carry \\
\hline & $\mathrm{rr}$ & d & ; Divide DE by 2 \\
\hline & rr & e & ; DE is now $50 \%$ total no. samples \\
\hline & $\mathrm{cp}$ & $50 \mathrm{H}$ & ; For choice $3, \mathrm{DE}=50 \%$ \\
\hline & jr & $z$, PESDON & ; So done for choice 3 \\
\hline & or & a & ; Clear carry \\
\hline & $\mathbf{r r}$ & d & ; Divide $\mathrm{DE}$ by 2 \\
\hline & $\mathbf{r r}$ & e & ; $\mathrm{DE}$ is now $25 \%$ tota 1 no. samples \\
\hline & $\mathrm{cp}$ & $25 \mathrm{H}$ & $;(25 \%=$ choice 4$)$ \\
\hline & jr & $z$, PESDON & ; Done for choice 4 \\
\hline & $\mathrm{cp}$ & $75 \mathrm{H}$ & ; NOTE:Carry cleared if equal \\
\hline & jr & $\mathrm{nz}, \mathrm{PES} 1$ & ; If no jump, then choice 2 \\
\hline & sbc & hl, de & $; 100 \%-25 \%=75 \%=$ CHOICE 2 \\
\hline & ex & $\mathrm{de}, \mathrm{hl}$ & ; Load into $\mathrm{DE}$ \\
\hline & jr & PESDON & ; Done for choice 2 \\
\hline PES1 : & $\mathrm{cp}$ & $87 \mathrm{H}$ & ; Compare and clear carry if $=$ \\
\hline & jr & $c$, PES & $\begin{array}{l}\text {; Zero not valid- } \\
\text {; make sure carry is clear }\end{array}$ \\
\hline & jr & $\mathrm{nz}, \mathrm{PES}$ & ; Not a valid answer \\
\hline & $\mathbf{r r}$ & d & ; Divide by 2 \\
\hline & $\mathbf{r r}$ & e & ; $\mathrm{DE}=12.5 \%$ \\
\hline & or & a & ; Clear carry \\
\hline & sbc & h1, de & ; Subtract \\
\hline & ex & de, hl & ; DE now has $87.5 \%$ for choice 1 \\
\hline $\mathrm{ON}:$ & $1 d$ & (PESAMPS $), \mathrm{de}$ & ; Store post event samples \\
\hline
\end{tabular}


SHORTERM:

\begin{tabular}{|c|c|}
\hline PRINT & STA \\
\hline $1 d$ & h1, STASAV \\
\hline PRINT & QUES \\
\hline $\begin{array}{l}\text { call } \\
1 d \\
\text { call }\end{array}$ & $\begin{array}{l}\text { GETLN } \\
\text { de, IBUFF+1 } \\
\text { BCDIN }\end{array}$ \\
\hline jr & $c$, SHORTERM \\
\hline Id & $a, m$ \\
\hline$c p$ & $5 \mathrm{H}$ \\
\hline jr & $\mathrm{nz}, \mathrm{P} 10$ \\
\hline ld & $\mathrm{a}, 10 \mathrm{H}$ \\
\hline jr & SHOREND \\
\hline cp & $10 \mathrm{H}$ \\
\hline $\mathrm{jr}$ & $\mathrm{nz}, \mathrm{P} 25$ \\
\hline $1 d$ & $\mathrm{a}, 2 \mathrm{OH}$ \\
\hline jr & SHOREND \\
\hline cp & $25 \mathrm{H}$ \\
\hline$j r$ & $\mathrm{nz}, \mathrm{P} 50$ \\
\hline $1 d$ & $\mathrm{a}, 40 \mathrm{H}$ \\
\hline jr & SHOREND \\
\hline $\mathrm{cp}$ & $50 \mathrm{H}$ \\
\hline $\mathrm{jr}$ & $\mathrm{nz}$, SHORTERM \\
\hline ld & $\mathrm{a}, 80 \mathrm{H}$ \\
\hline $1 d$ & (ANVAL), $a$ \\
\hline
\end{tabular}

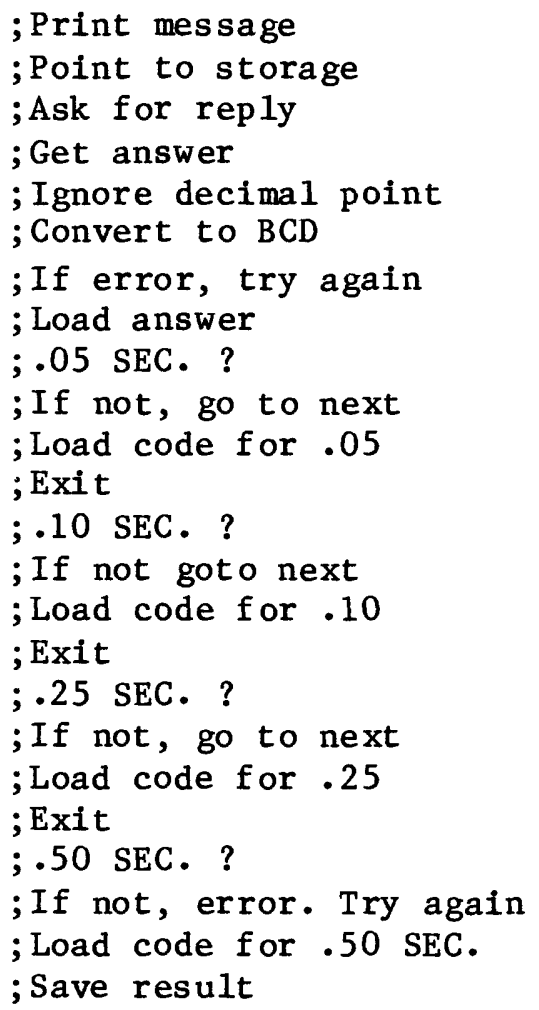


THRESHOLD :

\begin{tabular}{|c|c|c|c|}
\hline & PRINT & THRSH & ; Print message \\
\hline & & h1, THRSHSV & ; Point to storage \\
\hline & call & INDAT & ; Get answer \\
\hline & jr & $c$, THRESHOLD & ; If error, try again \\
\hline & Id & $a, m$ & ; Load answer \\
\hline & $c p$ & $6 \mathrm{H}$ & ;6DB？ \\
\hline & jr & $\mathrm{nz}, \mathrm{DB} 12$ & ; If not, goto next \\
\hline & $1 d$ & $a, 1$ & ; Load code for $6 \mathrm{db}$ \\
\hline & jr & THREND & ;Exit \\
\hline \multirow[t]{4}{*}{ DB12: } & $\mathrm{cp}$ & $12 \mathrm{H}$ & ; 12DB？ \\
\hline & $j r$ & $\mathrm{nz}, \mathrm{DB} 18$ & ; If not, goto next \\
\hline & Id & $a, 2$ & ; Load code for $12 \mathrm{db}$ \\
\hline & jr & THREND & ;Exit \\
\hline \multirow[t]{4}{*}{ DB18: } & $c p$ & $18 \mathrm{H}$ & ; 18DB？ \\
\hline & jr & $\mathrm{nz}, \mathrm{DB} 24$ & ; If not, goto next \\
\hline & ld & $a, 4$ & ; Load code for $18 \mathrm{db}$ \\
\hline & jr & THREND & ; Exit \\
\hline \multirow[t]{2}{*}{ DB24: } & cp & $24 \mathrm{H}$ & ; 24DB? \\
\hline & $\begin{array}{l}\text { jr } \\
\text { Id }\end{array}$ & $\begin{array}{l}\mathrm{nz}, \text { THRESHOLD } \\
\mathrm{a}, 8\end{array}$ & $\begin{array}{l}\text {; If not, error. Try again } \\
\text {; Load code for } 24 \mathrm{db}\end{array}$ \\
\hline \multirow[t]{3}{*}{ THREND: } & ld & $\mathrm{b}, \mathrm{a}$ & ; Move it to $\mathrm{B}$ \\
\hline & $1 d$ & $a,($ ANVAL) & ; Retrieve STA code \\
\hline & $\begin{array}{l}\text { or } \\
\text { ld }\end{array}$ & $\begin{array}{l}\mathrm{b} \\
(\text { ANVAL }), a\end{array}$ & $\begin{array}{l}\text {; Combine them } \\
\text {; Save result }\end{array}$ \\
\hline
\end{tabular}


;--- ENTER NO. EXPERIMENTS

;

- MAXIMUM NUMBER IS 9999.

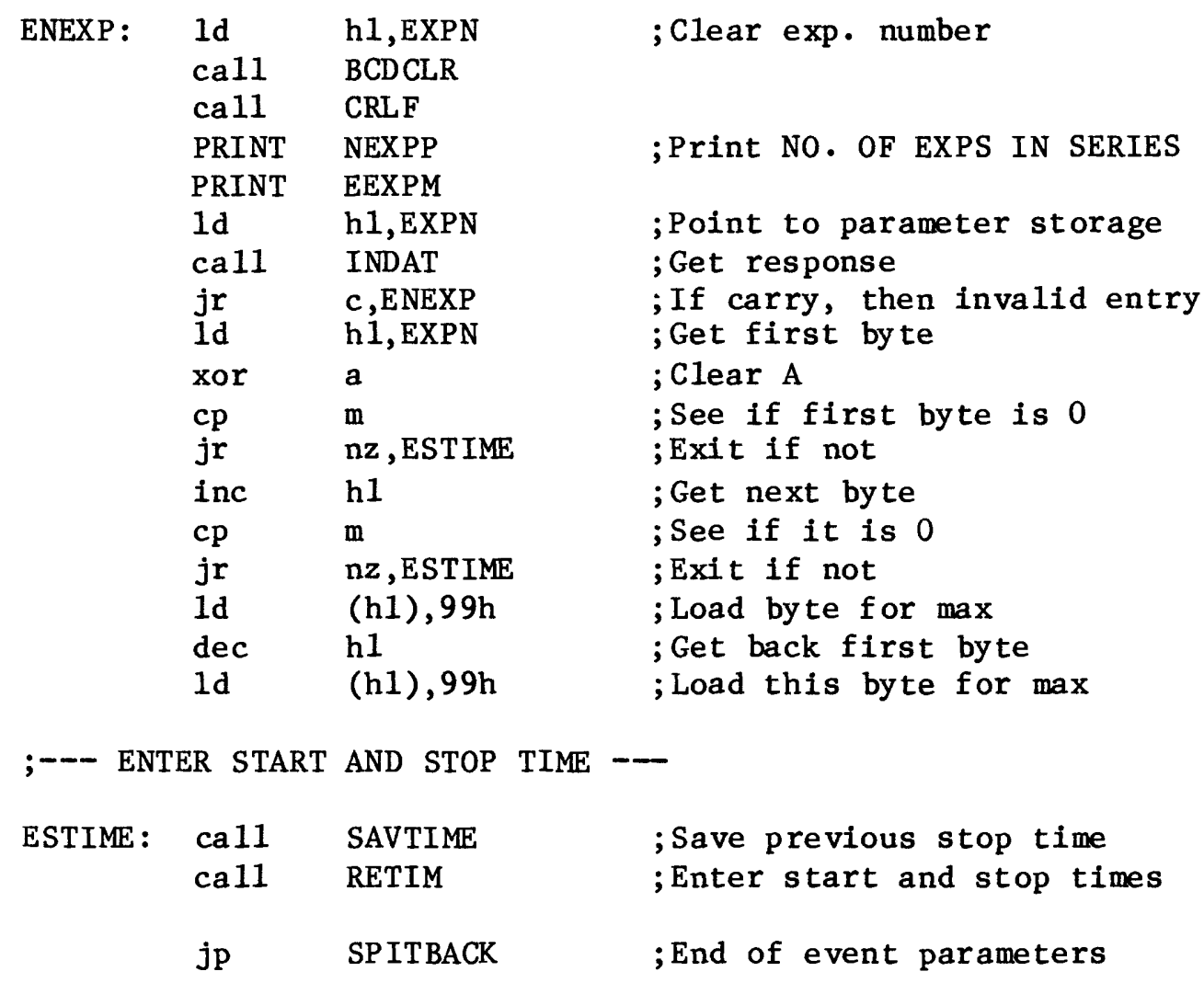




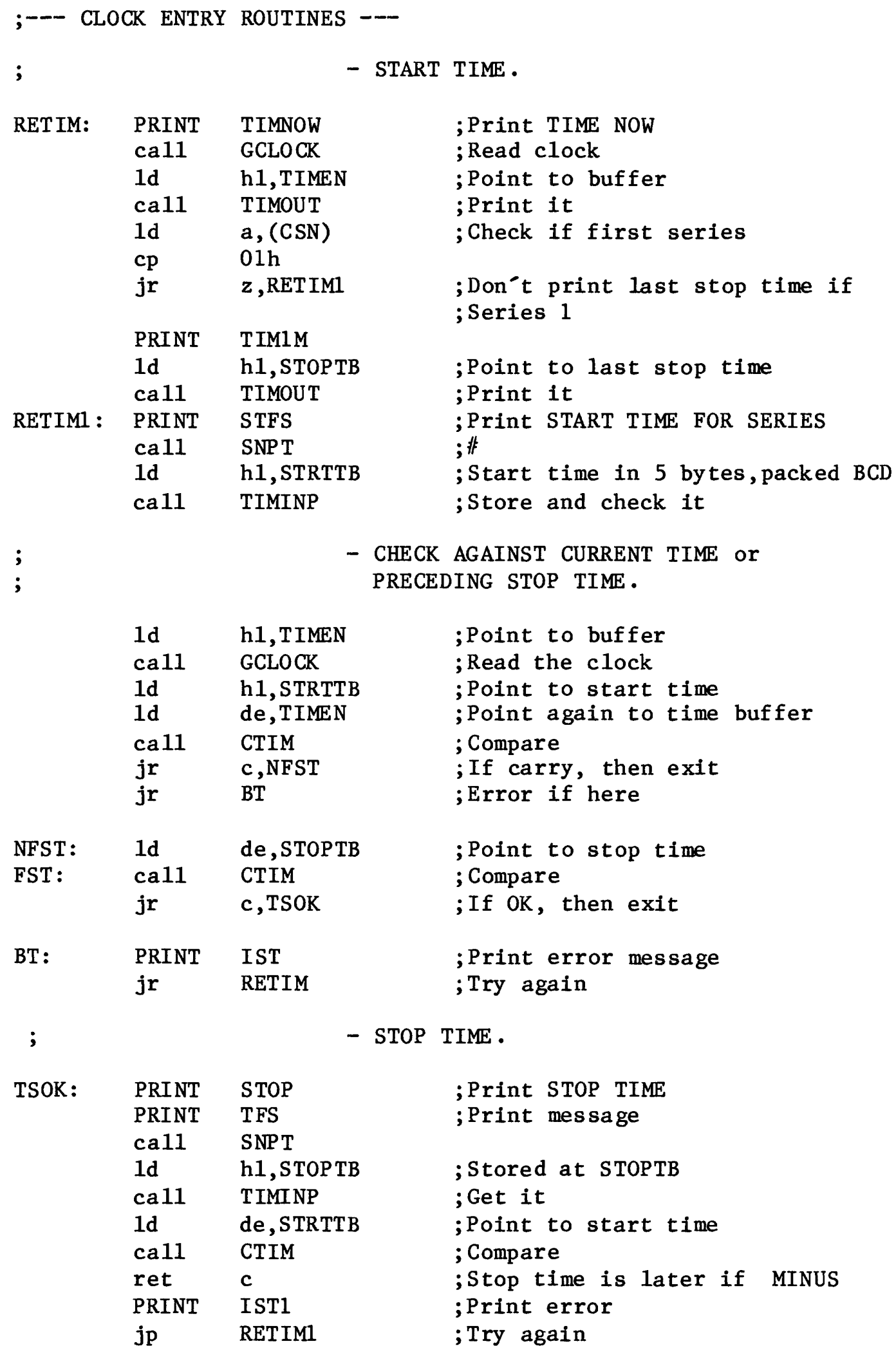


;

;--- EVENT PARAMETER CHECK ---

SPITBACK :

$\begin{array}{lll}\text { cal1 } & \text { CRLF } & \text {; Print CRLF } \\ \text { ca11 } & \text { CONT } & \text {; Wait } \\ \text { ca11 } & \text { SPITP } & \text {; Print common series info } \\ \text { ld } & \text { a, (SERTYP) } & \text {; Get Series type } \\ \text { cp } & -e^{-} & \text {; Check if event mode } \\ \text { jp } & \text { nz, WINDSPIT } & \text {; If not, goto window routine }\end{array}$

;

- POST EVENT SAMPLES.

\begin{tabular}{|c|c|c|c|}
\hline PESTO : & PRINT & PESPP & ; Print message \\
\hline & PRINT & EQUALS & ;Print $=-$ \\
\hline & $1 d$ & $\mathrm{~h} 1, \mathrm{PESAMS}$ & ; Point to value \\
\hline & ca 11 & $\mathrm{PBCD}$ & ;Print value \\
\hline & $1 d$ & $a, 87 \mathrm{H}$ & ; If post event is 87 add .5 \\
\hline & $\mathrm{cp}$ & m & \\
\hline & jr & $\mathrm{nz}, \mathrm{PESTY}$ & \\
\hline & $1 d$ & $a, \cdot-{ }^{\prime}$ & ; Load a '." \\
\hline & ca 11 & PBYT & ; Print it \\
\hline & & $a,-5^{-}$ & ; Load a ${ }^{-5} 5^{-}$ \\
\hline & cal1 & PBYT & ; Print it \\
\hline PESTY : & $1 d$ & $a,-\%$ & ; Load a $-\%$ \\
\hline & cal1 & PBYT & ;Print it \\
\hline & ca 11 & CRLF & ; Print CRLF \\
\hline ; & & & TERM AVERAGE. \\
\hline
\end{tabular}

SHORTSPIT:

PRINT STAl

ld $a,{ }^{\prime} \cdot$

cal1 PBYT

1d h1, STASAV

ca11 PBCD

PRINT SECOND

call CRLF
; Print message

; Load a '.'

; Print it

; Point to value

;Print it

;Print 'seconds"

;Print CRLF

;

- THRESHOLD.

THRESHSPIT:

$\begin{array}{lll}\text { PRINT } & \text { THRSH1 } & \text {; Print message } \\ \text { 1d } & \text { h1,THRSHSV } & \text {; Point to value } \\ \text { ca11 } & \text { PBCD } & \text {; Print it } \\ \text { PRINT } & \text { DBP } & \text {; Print message } \\ \text { cal1 } & \text { CRLF } & \text {; Print CRLF } \\ \text { jr } & \text { OKPARAM } & \text {; Goto verify routine }\end{array}$


;-- WINDOW PARAMETER CHECK --
$; \quad$ OFFSET.

WINDSPIT :

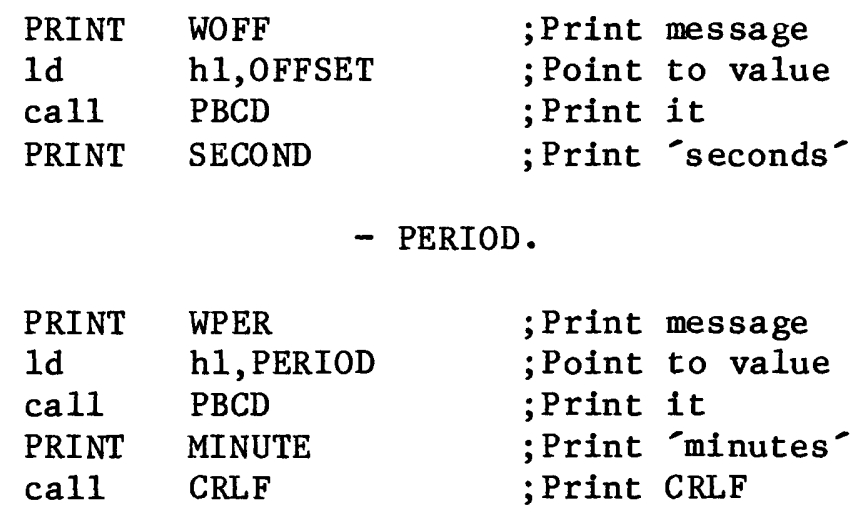




\begin{tabular}{|c|c|c|c|}
\hline OKPARAM: & QPRINT & OKQ & \\
\hline & or & $20 \mathrm{~h}$ & ; Force to lower case \\
\hline & $\mathrm{cp}$ & ${ }^{\prime} y^{\prime}$ & ;A11 OK? \\
\hline & $\begin{array}{l}\text { jr } \\
\text { cal1 }\end{array}$ & $\begin{array}{l}\text { z,PARSTOR } \\
\text { RESTIME }\end{array}$ & ; If so, store them \\
\hline & jp & REPENT & ; Start over if not \\
\hline PARSTOR: & $1 d$ & $\mathrm{de},($ PARBUF $)$ & ; Point to buffer \\
\hline & $1 d$ & h1, NSCRAM & ; Point to NSCRAM \\
\hline PARMOV : & LDI & & ; Move data \\
\hline & $1 d$ & a, 1 & ; Get low by te of parameter pointer \\
\hline & $\mathrm{cp}$ & LOW(ENDPARA) & ; Compare \\
\hline & jr & nz ,PARMOV & ; If not end, do some more \\
\hline & $\begin{array}{l}1 d \\
\text { cal1 }\end{array}$ & $\begin{array}{l}\text { (PARBUF), de } \\
\text { CRLF }\end{array}$ & ; Save pointer \\
\hline & QPRINT & NEXTSER & \\
\hline & or & $20 \mathrm{~h}$ & ; Force to lower case \\
\hline & $\mathrm{cp}$ & $' n{ }^{\prime}$ & \\
\hline & jp & $\mathbf{z}$, EXECU & \\
\hline & $\begin{array}{l}\text { jp } \\
\text { ret }\end{array}$ & NSERIES & ; Goto to next \\
\hline
\end{tabular}

;--- COMMON PARAMETERS ---

$\begin{array}{lll}\text { SPITP : } & \text { PUSHALL } \\ & \text { PRINT } & \text { CLRSCR } \\ \text { ca11 } & \text { SNPT } \\ \text { ca11 } & \text { CRLF } \\ \text { PRINT } & \text { NEXPP } \\ \text { 1d } & \text { h1, EXPN } \\ \text { ca11 } & \text { BCDPT } \\ \text { ca11 } & \text { CRLF } \\ \text { 1d } & \text { a, (SERTYP) } \\ \text { cp } & \text {-e' } \\ & \text { jr } & \text { nz, SWIND } \\ & \text { PRINT } & \text { EVENTP } \\ & \text { jr } & \text { SPIT2 } \\ & \text { PRINT } & \text { WPRMT }\end{array}$

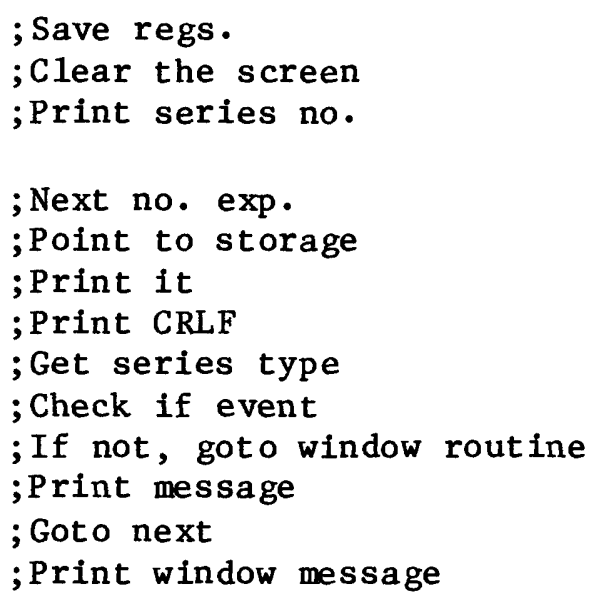




\begin{tabular}{|c|c|c|c|}
\hline \multirow[t]{13}{*}{ SPIT2: } & $\begin{array}{l}\text { PRINT } \\
1 \mathrm{~d} \\
\text { ca11 }\end{array}$ & $\begin{array}{l}\text { STFS } \\
\text { h1,STRTTB } \\
\text { TIMOUT }\end{array}$ & $\begin{array}{l}\text {; Print 'start' } \\
\text {; Point to storage } \\
\text {; Get time }\end{array}$ \\
\hline & $\begin{array}{l}\text { PRINT } \\
\text { PRTNT }\end{array}$ & STOP & ;Print 'stop' \\
\hline & PRINT & TFS & ; Print message \\
\hline & $1 d$ & h1,STOPTB & ; Point to storage \\
\hline & cal1 & TIMOUT & ; Get time \\
\hline & ca11 & CRLF & ; Print CRLF \\
\hline & PRINT & ACHAN & ;Print no. active channels \\
\hline & $\begin{array}{l}1 \mathrm{~d} \\
\operatorname{rrca}\end{array}$ & $a,(\operatorname{NCX} 2)$ & $\begin{array}{l}\text {; Get value } \\
\text {; Shift it }\end{array}$ \\
\hline & $1 d$ & $\mathrm{~b}, \mathrm{a}$ & ; Move it to $\mathrm{B}$ \\
\hline & $1 d$ & $a,(I 0)$ & ; Get base channel \\
\hline & $\begin{array}{l}\text { sub } \\
\text { or }\end{array}$ & $\begin{array}{l}\text { ADPORT-1 } \\
\text { a }\end{array}$ & $\begin{array}{l}\text {; Remove port address } \\
\text {; Clear carry }\end{array}$ \\
\hline & rrca & & ; Divide by 2 (2 PORTS/CHAN) \\
\hline & $\begin{array}{l}\text { inc } \\
\text { or }\end{array}$ & $\begin{array}{l}\mathrm{a} \\
30 \mathrm{H}\end{array}$ & $\begin{array}{l}\text {; First channel }=1 \text { for user } \\
\text {; Convert to ASCII }\end{array}$ \\
\hline \multirow[t]{9}{*}{ PCHLO: } & call & PBYT & ;Print it \\
\hline & push & & ; Save acc. \\
\hline & $1 d$ & $a,{ }^{\prime},-$ & ; Load a ',’ \\
\hline & call & PBYT & ;Print it \\
\hline & pop & af & ; Restore regs. \\
\hline & inc & a & ; Increment $\mathrm{A}$ \\
\hline & djnz & PCHLO & ;For all channels \\
\hline & ca11 & BSPCR & ; Backspace \\
\hline & call & CRLF & ; Pint CRLF \\
\hline \multicolumn{4}{|l|}{ SPITBSIZ: } \\
\hline & PRINT & BSIZP1 & ;Print buffer size \\
\hline & $1 d$ & h1, BSZSAV & ; Point to storage \\
\hline & cal1 & $\mathrm{PBCD}$ & ;Print it \\
\hline & $1 d$ & $a,{ }^{\prime} K^{\prime}$ & ; Load a ' $\mathrm{K}^{\prime}$ \\
\hline & cal1 & PBYT & ; Print it \\
\hline & call & CRLF & ; Print CRLF \\
\hline \multirow[t]{8}{*}{ SAMRATS : } & PRINT & SINTV 1 & ;Print sample interval \\
\hline & $1 d$ & h1,SRATE & ;Point to storage \\
\hline & call & PBCD & ;Print it \\
\hline & PRINT & MILSEC & ;Print 'ms' \\
\hline & call & CRLF & ;Print CRLF \\
\hline & ca11 & RTIME & ;Print time \\
\hline & ca11 & CRLF & ;Print CRLF \\
\hline & ret & & store regs. \\
\hline
\end{tabular}


;--- SAVE THE STOP TIME --

SAVTIME :

$\begin{array}{lll}\text { exx } & & \text {; Save regs } \\ \text { ld } & \text { bc, } 10 & \text {; Load count } \\ \text { ld } & \text { de,TIMSAVE } & \text {;Point to time temporary storage } \\ \text { Id } & \text { h1,STOPTB } & \text {; Point to stop time storage } \\ \text { LDIR } & & \text {; Move it } \\ \text { exx } & & \text {; Restore regs. } \\ \text { ret } & & \end{array}$

;--- RESTORE THE STOP TIME ---

RESTIME :

$\begin{array}{ll}\text { exx } & \\ \text { ld } & \text { bc, } 10 \\ \text { ld } & \text { de, STOPTB } \\ \text { ld } & \text { h1, TIMSAVE } \\ \text { LDIR } & \\ \text { exx } & \\ \text { ret } & \end{array}$

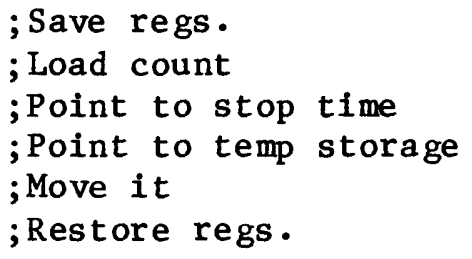

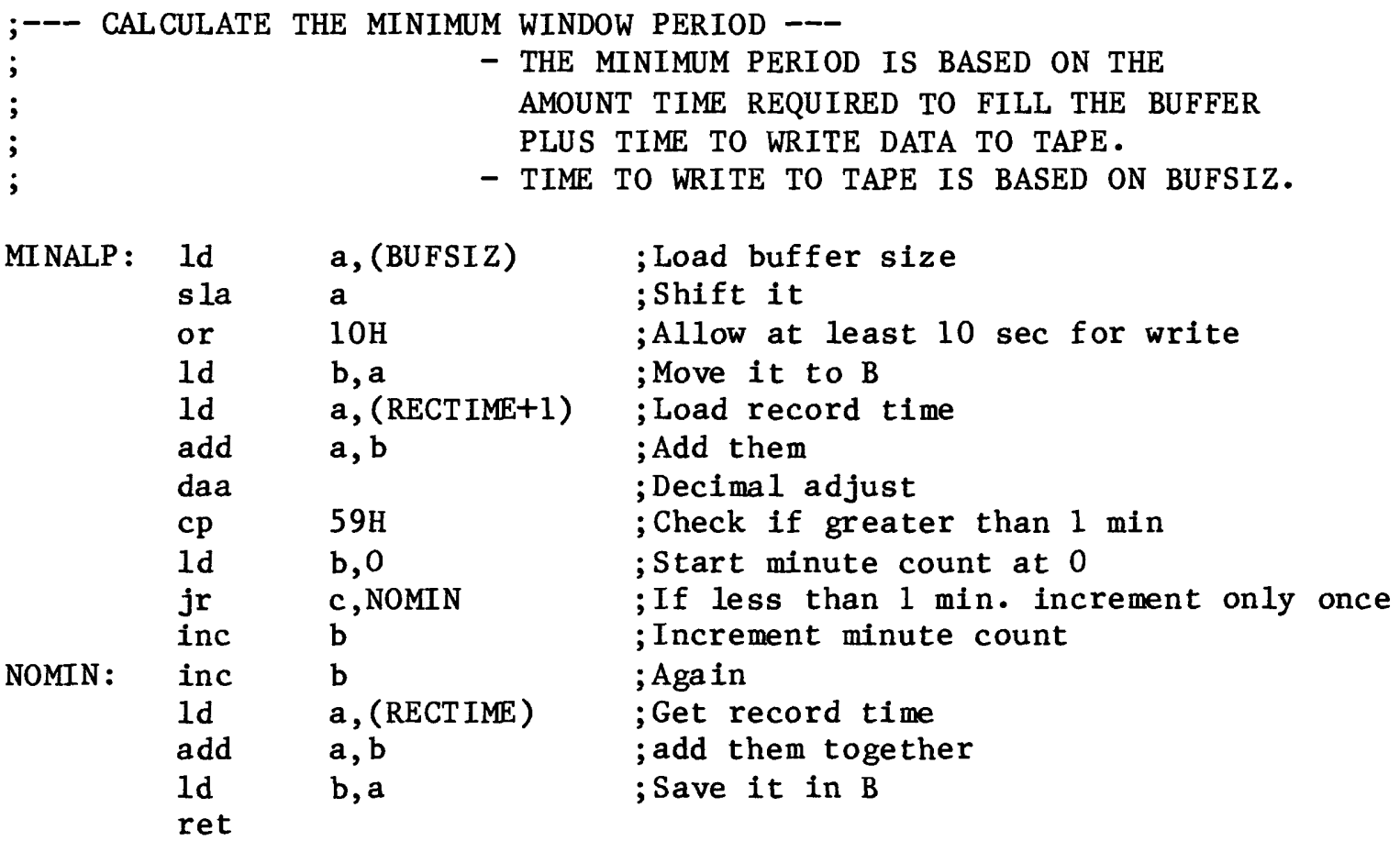


;

CHANNEL :
- GETS 1 OR 2 BCD DIGITS, STORES THEM AT HL, AND CARRY FLAG IS SET IF IMPROPER ENTRY.

;--- COMPUTE AND DISPLAY RECORD TIME ---

\begin{tabular}{|c|c|c|c|}
\hline \multirow[t]{5}{*}{ RTIME : } & $\begin{array}{l}\text { push } \\
\text { exx }\end{array}$ & af & ; Save regs. \\
\hline & PRINT & RTIMEP & ; Print message \\
\hline & $1 d$ & de, (MSAMPS) & ; Get no. samples (max) \\
\hline & $1 d$ & a, (SHIFTER) & ; Get $\mathrm{AD}$ value \\
\hline & $1 d$ & $b, a$ & ; Move it to $\mathrm{B}$ \\
\hline \multirow[t]{19}{*}{ SHLP : } & sra & d & ;Divide by 4 \\
\hline & $\mathrm{rr}$ & e & \\
\hline & djnz & SHLP & ; Until shifter value goes to zero \\
\hline & $1 d$ & a, 60 & ;Divide by 60 to get minutes \\
\hline & cal1 & DIV IDE & \\
\hline & $1 d$ & h1, RECTIME & ; Point to storage \\
\hline & $\begin{array}{l}\text { Id } \\
\text { inc }\end{array}$ & $\begin{array}{l}\mathrm{m}, \mathrm{e} \\
\mathrm{h} 1\end{array}$ & ; Save minutes \\
\hline & $\begin{array}{l}\text { ld } \\
\text { dec }\end{array}$ & $\begin{array}{l}\mathrm{m}, \mathrm{b} \\
\mathrm{h} 1\end{array}$ & ; Save seconds \\
\hline & ca11 & HTBCD & ; Convert it to packed $B C D$ \\
\hline & $\operatorname{cal1}$ & PBCD & ; Print the result minutes \\
\hline & PRINT & MINUTE & \\
\hline & inc & h1 & \\
\hline & cal1 & HTBCD & \\
\hline & cal1 & PBCD & ;Print the resulting seconds \\
\hline & PRINT & SECOND & \\
\hline & cal1 & CRLF & \\
\hline & pop & af & \\
\hline & $\operatorname{exx}$ & & \\
\hline & ret & & \\
\hline \multicolumn{4}{|c|}{;--- PRINT SERIES 非--- } \\
\hline \multirow[t]{4}{*}{ SNPT: } & PRINT & SN & ;Print "SERIES \#" \\
\hline & $1 \mathrm{~d}$ & $\mathrm{~h} 1, \mathrm{CSN}$ & ; Point to the series number \\
\hline & cal1 & $\mathrm{BCDPT}$ & ; Print it \\
\hline & $\begin{array}{l}\text { call } \\
\text { ret }\end{array}$ & CRLF & \\
\hline
\end{tabular}


TABLE LOOKUP ROUTINE ---

- ALL REGISTERS ARE ALTERED.

- ON ENTRY HL MUST POINT TO TABLE AND A MUST HAVE THE ENTRY.

- ROUTINE EXITS WITH TABLE VALUE IN A, TABLE POINTER IN HL, AND THE TABLE OFFSET IN DE.

TBLAD : $1 \mathrm{~d} \quad \mathrm{~d}, \mathrm{Oh}$

ld e,a

add h1, de

ld a, (hI)

; Clear D for 16 bit addition ; Move the entry to $\mathrm{E}$ ; Add the entry to the table

ret ; pointer 
;

$;---$ SET UP SERIES NO. AND BUFFER ---
$;$
;

CONTROL :

\begin{tabular}{|c|c|c|}
\hline $\begin{array}{l}1 \mathrm{~d} \\
1 \mathrm{~d} \\
\mathrm{ld}\end{array}$ & $\begin{array}{l}\mathrm{h} 1, \mathrm{LSN} \\
\mathrm{de}, \mathrm{CSN} \\
\mathrm{a},(\mathrm{de})\end{array}$ & $\begin{array}{l}\text {; Point to the last series number } \\
\text {; Point to the current series no. } \\
\text {; Get LSB of number }\end{array}$ \\
\hline $1 d$ & $\mathrm{~m}, \mathrm{a}$ & ; Save it in LSN \\
\hline inc & h1 & ; Bump pointers \\
\hline inc & de & \\
\hline $1 d$ & $\mathrm{a},(\mathrm{de})$ & ; Get MSB of no. \\
\hline $1 d$ & $\mathrm{~m}, \mathrm{a}$ & ; Save it in LSN \\
\hline $1 d$ & h1, CSN & ; Point to current series no. \\
\hline ca11 & BCDCLR & ; Clear it \\
\hline $1 d$ & $a, 1$ & \\
\hline $1 d$ & $(\mathrm{CSN}), \mathrm{a}$ & ;First series is $\equiv_{1} 1$ \\
\hline $1 d$ & h1, SERBUF & ; Load start of series buffer \\
\hline $1 d$ & (SERPTR), h1 & ; Save it \\
\hline
\end{tabular}

;--- INITIALIZE THE SERIES ---

\begin{tabular}{|c|c|c|c|}
\hline EWSER: & $\begin{array}{l}\text { di } \\
\text { ld } \\
\text { out } \\
1 d \\
\text { ei } \\
1 d \\
\text { cal1 } \\
\text { STA } \\
\text { cal1 } \\
\text { ca11 } \\
\text { ld } \\
\text { cp } \\
\text { jr } \\
\text { cp } \\
\text { jr } \\
\text { jp }\end{array}$ & 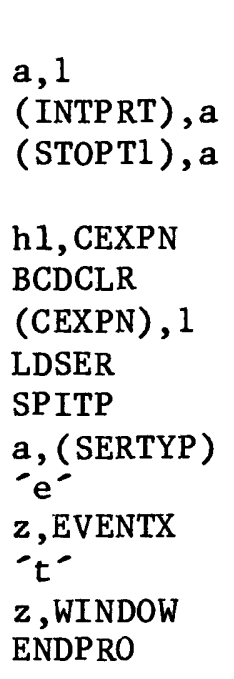 & $\begin{array}{l}\text {; Disable interrupts } \\
\text {; Load } 1 \\
\text {; Send it to interrupt mask } \\
\text {; Stop timer } 1 \\
\text {; Enable interrupts } \\
\text {; Clear the old exp no. } \\
\\
\text {; First experiment is } \# 1 \\
\text {; Load series variables } \\
\text {; Print them } \\
\text {; Load series type } \\
\text {; Is it event mode? } \\
\text {; If it is, setup event } \\
\text {; Is it timer mode? } \\
\text {; If so, setup window } \\
\text {; If neither, then end it }\end{array}$ \\
\hline
\end{tabular}




\begin{tabular}{|c|c|c|c|}
\hline EVENTX : & cal1 & TCHECK & ; Look for start time \\
\hline \multirow[t]{7}{*}{ EVNT2: } & $1 d$ & h1, EVNT1 & ; Save abort vector \\
\hline & $1 d$ & (ABRTV), h1 & \\
\hline & ca11 & INITW & ; Initialize ports and buffers \\
\hline & xor & $\mathbf{a}$ & ; Clear A \\
\hline & out & $($ AVGPRT $), a$ & ; Enable long term average \\
\hline & ca11 & PEM & ;Print exp message \\
\hline & ca11 & EDOIT & ; Get data \\
\hline \multirow[t]{4}{*}{ EVNT1: } & $\begin{array}{l}\operatorname{cal1} \\
\text { jr }\end{array}$ & $\begin{array}{l}\text { NEXTW } \\
\text { nc, EVNT2 }\end{array}$ & $\begin{array}{l}\text {; Increment exp no. } \\
\text {; Continue if not done }\end{array}$ \\
\hline & $\operatorname{ccf}$ & & ; Clear carry flag \\
\hline & ca11 & INCSER & ; Increment series number \\
\hline & & NEWSER & ; Get next series \\
\hline
\end{tabular}

;--- WINDOW SETUP --

$\begin{array}{llll}\text { WINDOW: } & \text { hd } & \text { h1,WIN1 } & \text {; Save abort vector } \\ \text { 1d } & \text { (ABRTV), h1 } & \\ \text { ca11 } & \text { INITW } & \text {; Initialize ports and buffer } \\ \text { ca11 } & \text { PEM } & \text {; Print exp message } \\ \text { ca11 } & \text { TCHECK } & \text {; Check time } \\ \text { ca11 } & \text { DOIT } & \text {; Get data } \\ \text { WIN1: } & \text { ca11 } & \text { NEXTW } & \text {; Increment exp. no. } \\ \text { jr } & \text { nc,WINDOW } & \text {; Continue until done } \\ \text { ccf } & & \text {; Clear the carry flag } \\ \text { ca11 } & \text { INCSER } & \text {; Increment series no. } \\ \text { jp } & \text { NEWSER } & \text {; Start new series }\end{array}$

;-- LOAD SERIES PARAMETERS FROM THE SERIES BUFFER - -

LDSER: exx

$1 d$

$1 \mathrm{~d}$

1d

$1 \mathrm{dir}$

$1 d$

exx

ret
; Save regs.

; Get series pointer

; Load no. of parameters

; Point to NSCRAM

; Move it

; Save pointer

; Restore regs.

;-- PRINT EXPERIMENT MESSAGE - -

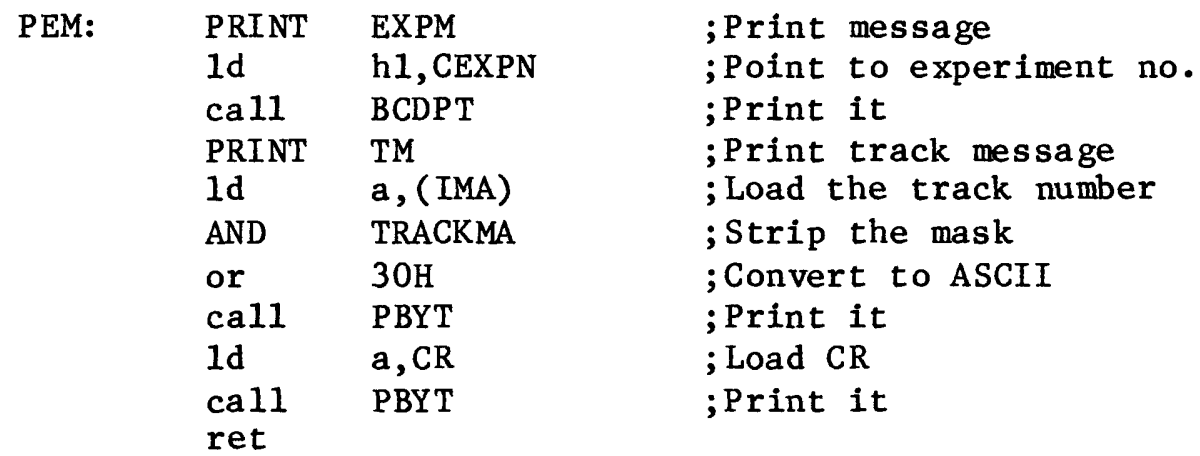




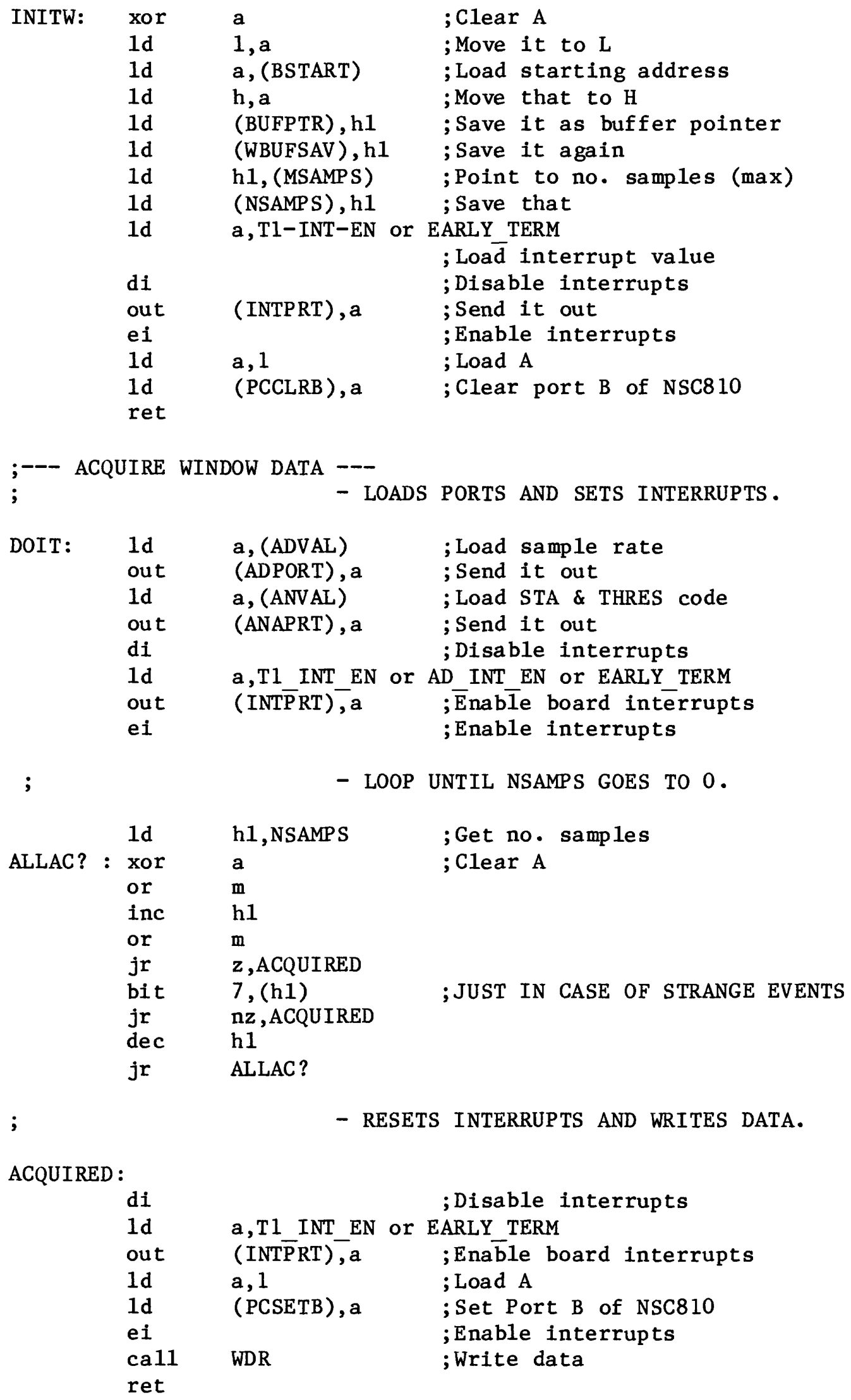

ACQUIRED :

di

$1 d$

out

$1 d$

$1 d$

ei

cal1 WDR

a, T1 INT EN or EARLY TERM

; Disable interrupts

ret

; Ena $\bar{b}$ le board interrupts

; Load A

; Set Port B of NSC 810

; Enable interrupts

; Write data 


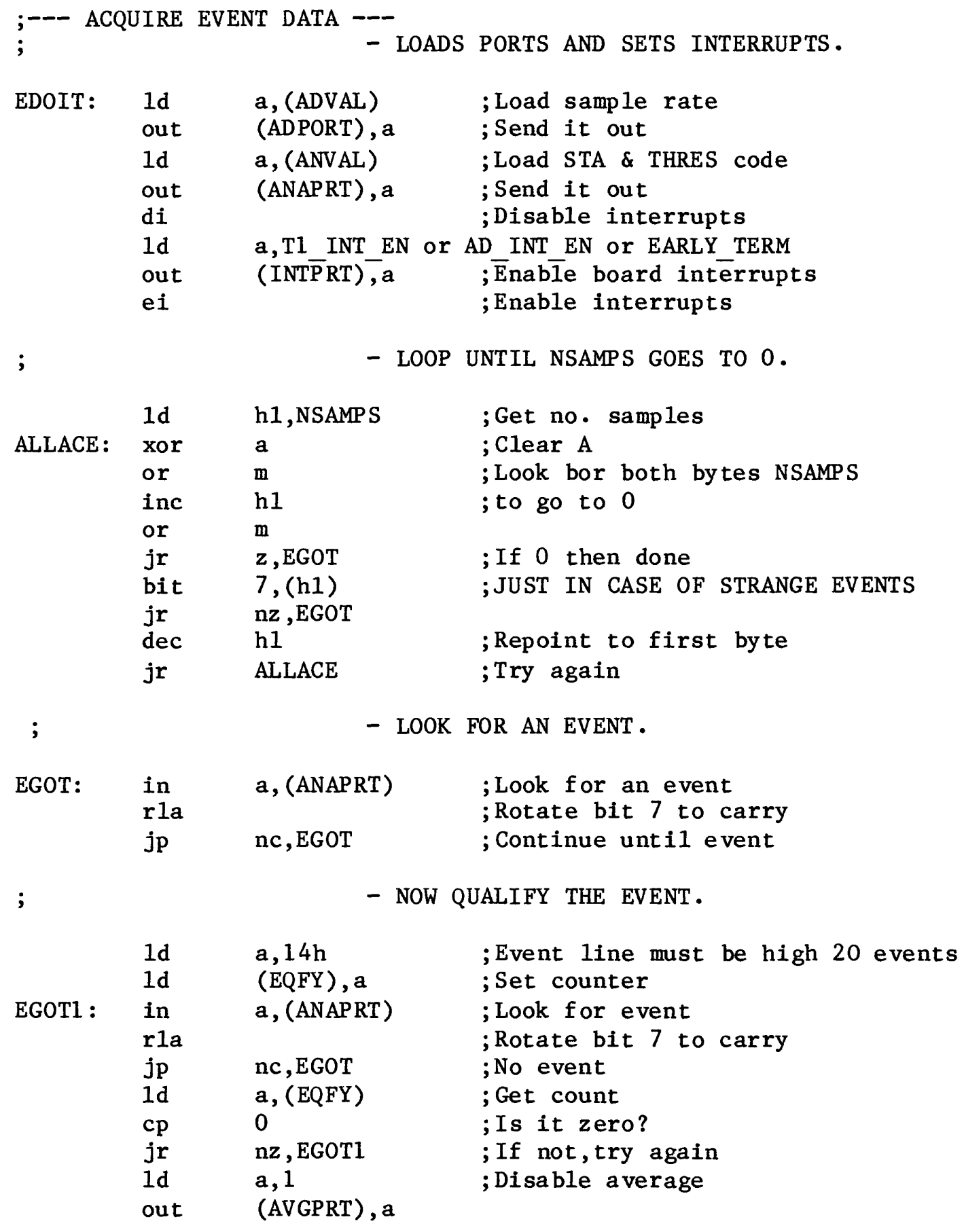




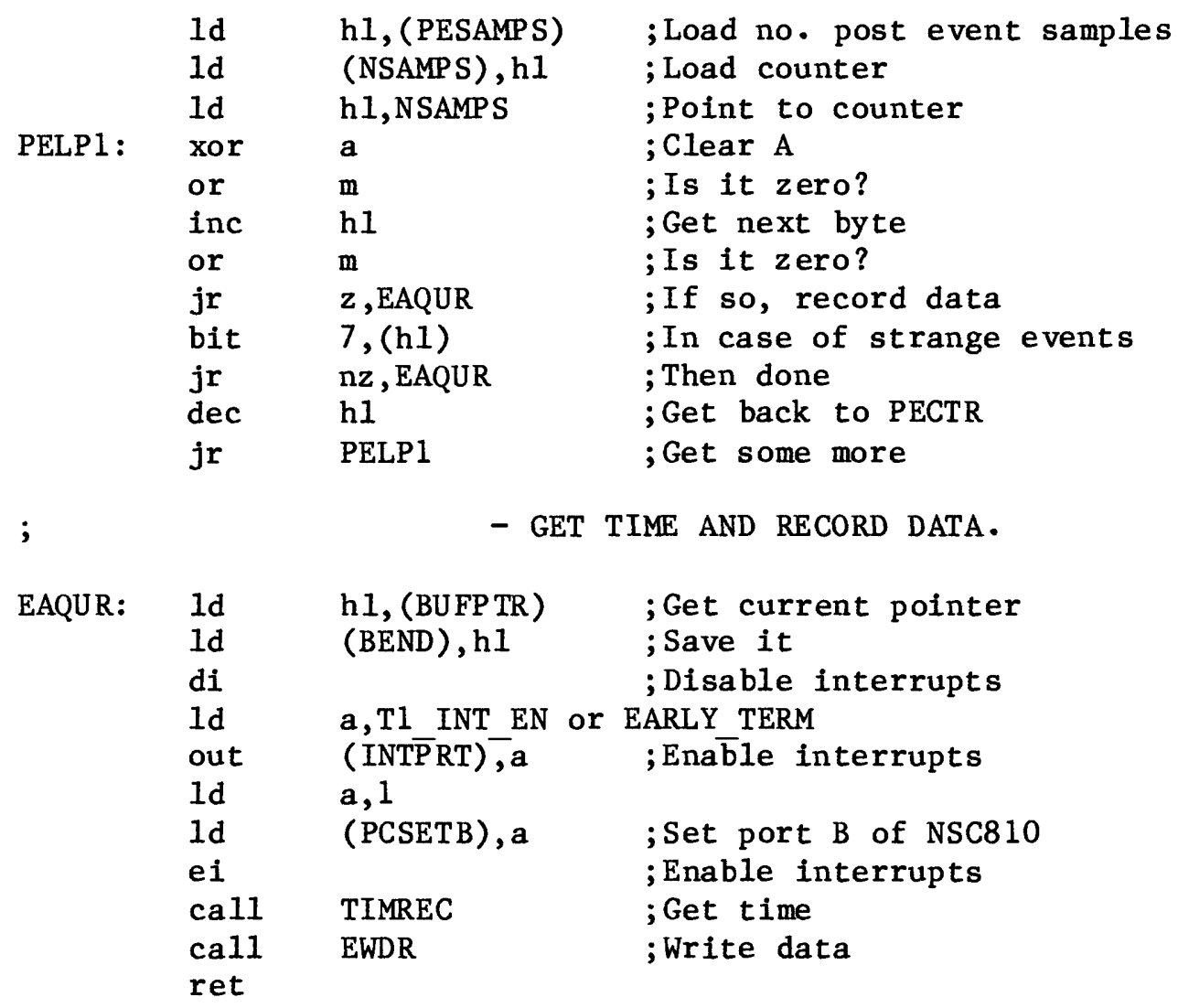




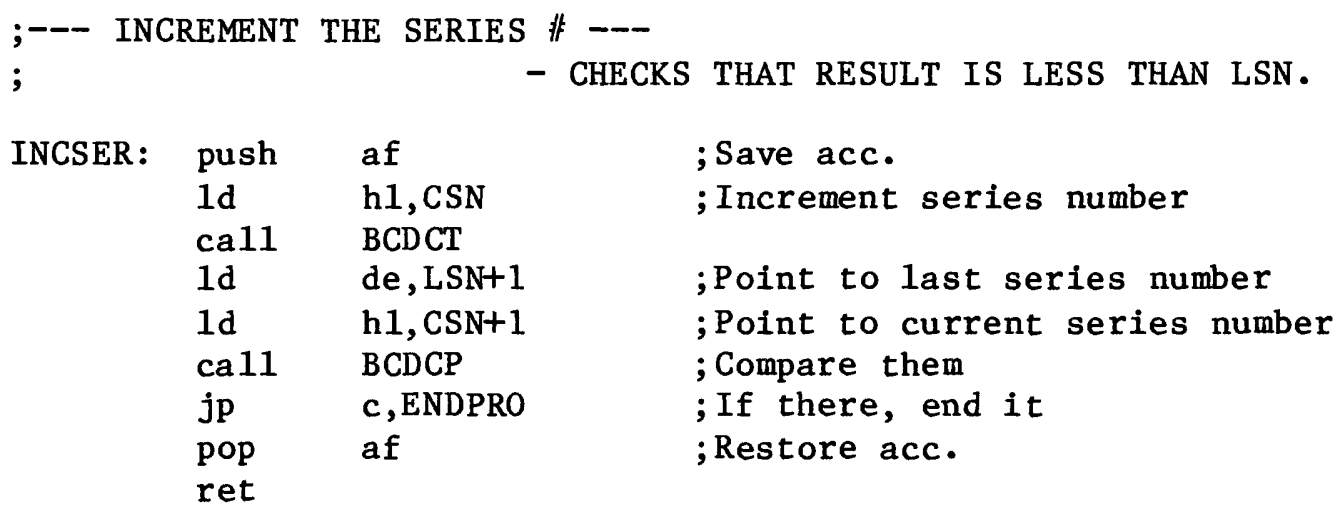




\begin{tabular}{|c|c|c|}
\hline ACHAN : & $d b$ & ${ }^{-}$ACTIVE CHANNEL $(\mathrm{S})=-, 0$ \\
\hline BCHAP : & $d b$ & ${ }^{-}$BASE CHANNEL $(1-4)^{\prime}, 0$ \\
\hline $\begin{array}{l}\text { BSIZP: } \\
\text { BSIZP1 : }\end{array}$ & $\begin{array}{l}d b \\
d b\end{array}$ & $\begin{array}{l}\text {-ENTER } 1,2 \text {, or } 4 \text { blocks of } 8 \mathrm{~K}^{-} \\
\mathrm{CR}, \mathrm{LF},-\mathrm{RECORD} \text { SIZE }=-, 0\end{array}$ \\
\hline CH1 : & $\mathrm{db}$ & ${ }^{-}$CHANNEL $1{ }^{\prime}, 0$ \\
\hline CH2: & $\mathrm{db}$ & ${ }^{-}$CHANNEL $2{ }^{\prime}, 0$ \\
\hline CH3 : & $\mathrm{db}$ & ${ }^{-}$CHANNEL $3{ }^{\circ}, 0$ \\
\hline CH4: & $d b$ & ${ }^{-}$CHANNEL $4^{\prime}, 0$ \\
\hline CHSCI : & $\mathrm{db}$ & ${ }^{-}$CHIEF SCIENTIST ${ }^{\prime}, 0$ \\
\hline CRUISE : & $\mathrm{db}$ & 'CRUISE \# \\
\hline DEPL : & $\mathrm{db}$ & 'DEPLOYMENT $\# \quad-, 0$ \\
\hline DBP : & $\mathrm{db}$ & $-\mathrm{db}^{-}, 0$ \\
\hline EEXPM: & $\mathrm{db}$ & ${ }^{-}$(Enter 0 for maximum number) ${ }^{-}, 0$ \\
\hline EQUALS : & $\mathrm{db}$ & $-\quad=-, 0$ \\
\hline EVENTP : & $\mathrm{db}$ & ${ }^{-E V E N T}$ MODE`, CR, LF, 0 \\
\hline EXPM: & $\mathrm{db}$ & 'EXPERIMENT 非, 0 \\
\hline FED : & $d b$ & 'FRONT END DAMPING', CR, LF, 0 \\
\hline FEG : & $\mathrm{db}$ & 'FRONT END GAIN', CR,LF, 0 \\
\hline INSTR: & $\mathrm{db}$ & 'INSTRUMENT 非 $\quad, 0$ \\
\hline IST: & $\mathrm{db}$ & 'IMPROPER START TIME', CR,LF,O \\
\hline IST1 : & $\mathrm{db}$ & 'IMPROPER STOP TIME',CR,LF,O \\
\hline LAT : & $d b$ & 'LATITUDE \\
\hline LONG : & $\mathrm{db}$ & `LONGITUDE \\
\hline MAX : & $\mathrm{db}$ & 'MAXIMUM `, 0 \\
\hline MINUTE: & $\mathrm{db}$ & ${ }^{-} \min \cdot{ }^{-}, 0$ \\
\hline MILSEC : & $d b$ & ${ }^{-} \mathrm{ms} \cdot{ }^{-}, 0$ \\
\hline
\end{tabular}




\begin{tabular}{|c|c|c|}
\hline NCAP : & $\mathrm{db}$ & $\mathrm{CR}, \mathrm{LF},{ }^{-} \equiv$ 非 OF CHANNELS $(1-4)^{-}, 0$ \\
\hline NEXPP : & $\mathrm{db}$ & ${ }^{-} \equiv$ OF RECORDS $=-, 0$ \\
\hline SN : & $\mathrm{db}$ & `SERIES 非 $`, 0$ \\
\hline NEXTSER: & $d b$ & CR,LF, `DO YOU WISH ANOTHER SERIES',0 \\
\hline PESP : & $\begin{array}{l}d b \\
d b\end{array}$ & $\begin{array}{l}C R, L F,-\operatorname{ENTER} 87(.5), 75,50 \text {, or } 25 \% \\
C R, L F\end{array}$ \\
\hline PESPP : & $\mathrm{db}$ & ${ }^{-P O S T-E V E N T ~ S A M P L E ~}(\%)^{-}, 0$ \\
\hline RTIMEP : & $\mathrm{db}$ & ${ }^{-} \mathrm{RECORD}$ TIME $=-, 0$ \\
\hline SECOND : & $\mathrm{db}$ & $-\sec \cdot{ }^{-}, 0$ \\
\hline $\begin{array}{l}\text { SINTV : } \\
\text { SINTV1: }\end{array}$ & $\begin{array}{l}\mathrm{db} \\
\mathrm{db}\end{array}$ & $\begin{array}{l}\text { 'ENTER 1ms, } 2 \mathrm{~ms}, 4 \mathrm{~ms}, \text { or } 8 \mathrm{msec}- \\
\text { CR,LF, - SAMPLE RATE }=-0\end{array}$ \\
\hline SPHERE : & $\mathrm{db}$ & -SPHERE \# $\quad \quad, 0$ \\
\hline STA: & $\begin{array}{l}\mathrm{db} \\
\mathrm{db}\end{array}$ & $\begin{array}{l}\text { CR,LF, 'ENTER .05, .10, .25, or .50 SEC. - } \\
C R, L F\end{array}$ \\
\hline STAl : & $d b$ & -STA TIME CONST $=-, 0$ \\
\hline STFS : & $\mathrm{db}$ & CR,LF, 'START - \\
\hline TFS : & $d b$ & ${ }^{-T I M E} \quad-, 0$ \\
\hline STOP : & $\mathrm{db}$ & -STOP $\quad, 0$ \\
\hline TIMI M: & $\mathrm{db}$ & 'STOP TIME OF LAST SERIES `,0 \\
\hline TIMNOW: & $\mathrm{db}$ & -TIME NOW: $\quad-, 0$ \\
\hline $\begin{array}{l}\text { THRSH : } \\
\text { THRSH1 : }\end{array}$ & $\begin{array}{l}d b \\
d b\end{array}$ & $\begin{array}{l}\text { CR,LF, 'ENTER 6, } 12,18 \text {, or } 24 \mathrm{db} .^{-}, \mathrm{CR}, \mathrm{LF} \\
\text {-THRESHOLD } \\
=\end{array}$ \\
\hline TM: & $\mathrm{db}$ & $-\quad$ TRACK 非, 0 \\
\hline WARN8 : & $\mathrm{db}$ & ${ }^{-} 164^{\prime}$ \\
\hline WARN1 : & $\begin{array}{l}d b \\
d b\end{array}$ & $\begin{array}{l}\text { 'K RESISTOR HEADERS ON FILTER BOARD FOR' } \\
\text {-THIS SAMPLE RATE' }\end{array}$ \\
\hline WARNO : & $\mathrm{db}$ & $\mathrm{CR}, \mathrm{LF},-\star \star \star \star$ WARNING $* * *-, \mathrm{CR}, \mathrm{LF}, 0$ \\
\hline WE : & $d b$ & ${ }^{-T I M E R}$ or EVENT MODE(T/E) ${ }^{-}, 0$ \\
\hline WOFF1 : & $d b$ & ${ }^{-} \operatorname{ENTER}(0-59 \text { sec. })^{-}$ \\
\hline WOFF : & $\mathrm{db}$ & $C R, L F, `$ WINDOW OFFSET $=-, 0$ \\
\hline WPER1 : & $\mathrm{db}$ & 'ENTER $\left({ }^{\prime}, 0\right.$ \\
\hline $\begin{array}{l}\text { WPER2 : } \\
\text { WPER : }\end{array}$ & $\begin{array}{l}d b \\
d b\end{array}$ & $\begin{array}{l}-99 \min .)^{-} \\
C R, L F,- \text { PERIOD of RECORDS }=-, 0\end{array}$ \\
\hline WPRMT : & $d b$ & 'TIMER MODE',CR,LF, 0 \\
\hline
\end{tabular}




\section{; TABLES}

;

- BUFFER SIZE TABLES

BBTBL: db $\quad 00 \mathrm{~h}, 0 \mathrm{e} 0 \mathrm{~h}, 0 \mathrm{c} 0 \mathrm{~h}, 00 \mathrm{~h}, 80 \mathrm{~h}$

BSTBL : db $00 \mathrm{~h}, 20 \mathrm{~h}, 40 \mathrm{~h}, 00 \mathrm{~h}, 80 \mathrm{~h}$

;

- SAMPLE RATE TABLES

ADTBL: $\quad \mathrm{db} \quad 0,2,6,0,1,0,0,0,5$

SHTBL: db $00 \mathrm{~h}, 0 \mathrm{ah}, 09 \mathrm{~h}, 0,08 \mathrm{~h}, 0,0,0,07 \mathrm{~h}$

;

- WARNING TABLE

WNTBL :

db $\quad 021 h, 041 h, 00 h, 082 h$

END 